\title{
Product Characterization for Entrained Flow Coal/Biomass Co-Gasification
}

\author{
Final Technical Report \\ Reporting Period:
}

Oct 1, 2008 - Sep 30, 2011

\author{
Shawn Maghzi \\ Ramanathan Subramanian \\ George Rizeq \\ Surinder Singh \\ John McDermott \\ Boris Eiteneer \\ David Ladd \\ Arturo Vazquez \\ Denise Anderson \\ Noel Bates
}

December 11, 2011

DOE Award No. DE-NT0006305

GE Global Research

1 Research Circle

Niskayuna, NY 12309 


\section{DISCLAIMER}

"This report was prepared as an account of work sponsored by an agency of the United States Government. Neither the United States Government nor any agency thereof, nor any of their employees, makes any warranty, express or implied, or assumes any legal liability or responsibility for the accuracy, completeness, or usefulness of any information, apparatus, product, or process disclosed, or represents that its use would not infringe privately owned rights. Reference herein to any specific commercial product, process, or service by trade name, trademark, manufacturer, or otherwise does not necessarily constitute or imply its endorsement, recommendation, or favoring by the United States Government or any agency thereof. The views and opinions of authors expressed herein do not necessarily state or reflect those of the United States Government or any agency thereof." 


\section{ABSTRACT}

The U.S. Department of Energy's National Energy Technology Laboratory (DOE NETL) is exploring affordable technologies and processes to convert domestic coal and biomass resources to high-quality liquid hydrocarbon fuels. This interest is primarily motivated by the need to increase energy security and reduce greenhouse gas emissions in the United States. Gasification technologies represent clean, flexible and efficient conversion pathways to utilize coal and biomass resources. Substantial experience and knowledge had been developed worldwide on gasification of either coal or biomass. However, reliable data on effects of blending various biomass fuels with coal during gasification process and resulting syngas composition are lacking.

In this project, GE Global Research performed a complete characterization of the gas, liquid and solid products that result from the co-gasification of coal/biomass mixtures. This work was performed using a bench-scale gasifier (BSG) and a pilot-scale entrained flow gasifier (EFG). This project focused on comprehensive characterization of the products from gasifying coal/biomass mixtures in a high-temperature, high-pressure entrained flow gasifier. Results from this project provide guidance on appropriate gas clean-up systems and optimization of operating parameters needed to develop and commercialize gasification technologies.

GE's bench-scale test facility provided the bulk of high-fidelity quantitative data under temperature, heating rate, and residence time conditions closely matching those of commercial oxygen-blown entrained flow gasifiers. Energy and Environmental Research Center (EERC) pilot-scale test facility provided focused high temperature and pressure tests at entrained flow gasifier conditions. Accurate matching of syngas time-temperature history during cooling ensured that complex species interactions including homogeneous and heterogeneous processes such as particle nucleation, coagulation, surface condensation, and gas-phase reactions were properly reproduced and lead to representative syngas composition at the syngas cooler outlet. The experimental work leveraged other ongoing GE R\&D efforts such as biomass gasification and dry feeding systems projects. Experimental data obtained under this project were used to provide guidance on the appropriate clean-up system(s) and operating parameters to coal and biomass combinations beyond those evaluated under this project. 


\section{TABLE OF CONTENTS}

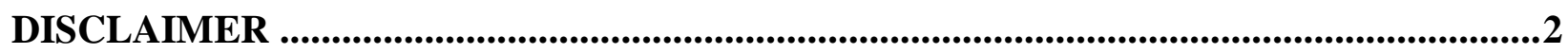

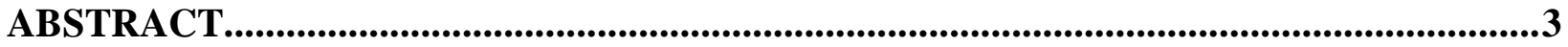

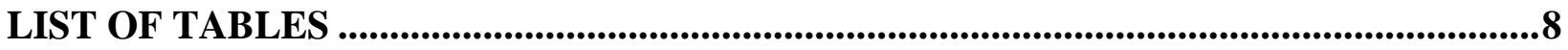

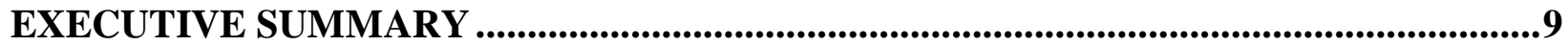

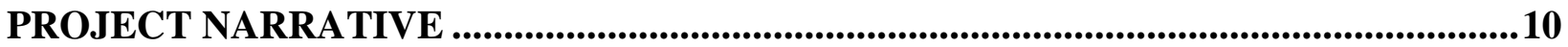

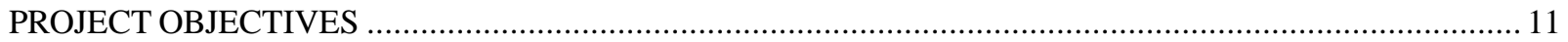

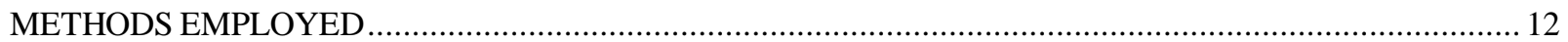

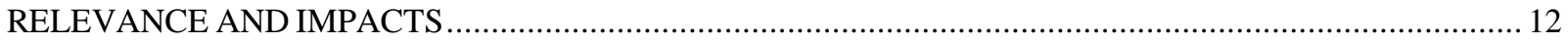

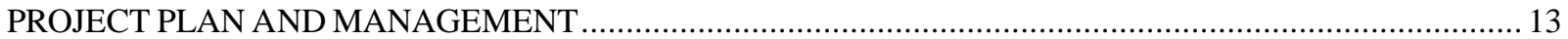

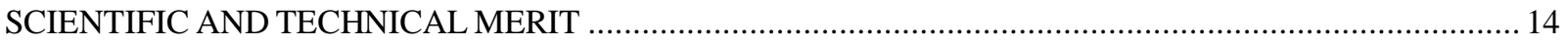

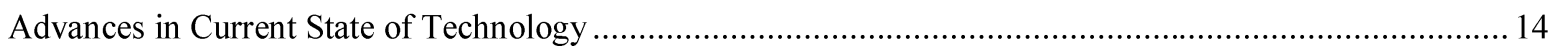

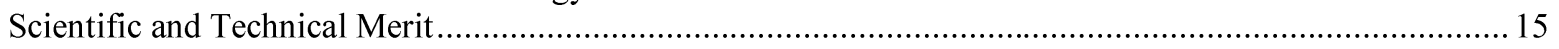

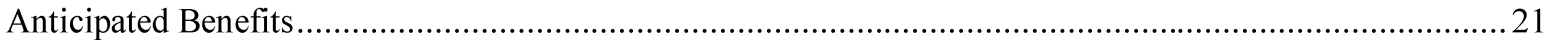

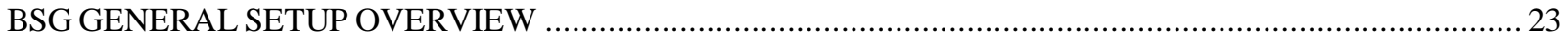

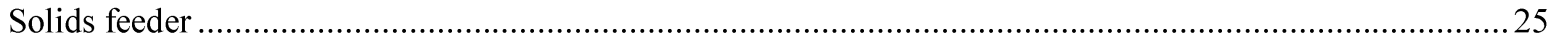

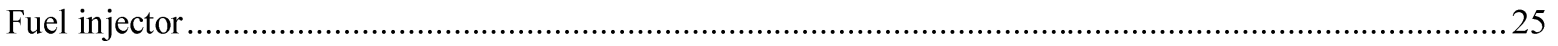

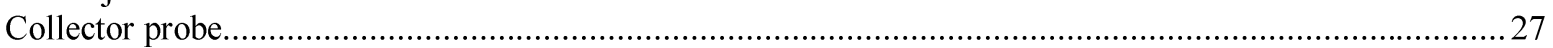

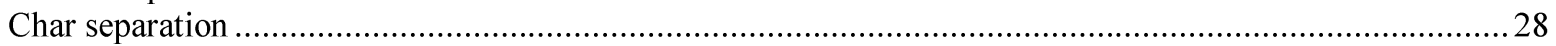

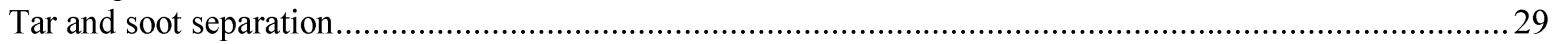

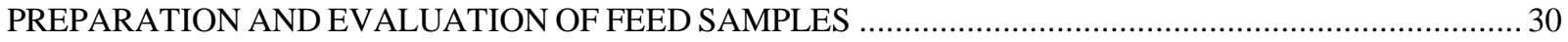

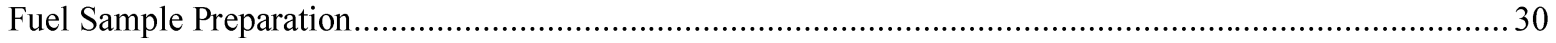

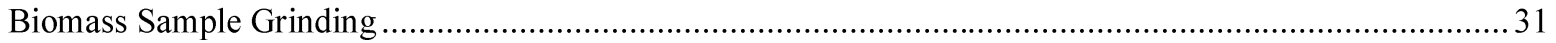

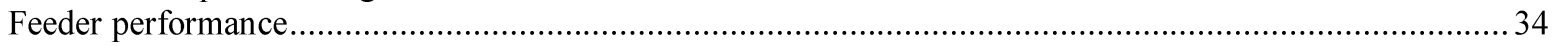

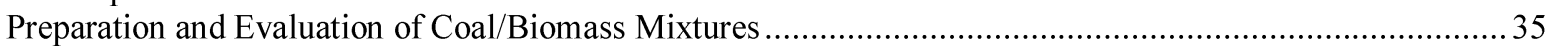

BENCH SCALE GASIFICATION TEST EQUIPMENT AND SAMPLE ANALYSIS ................................... 38

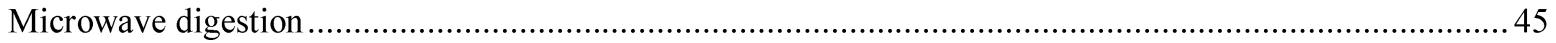

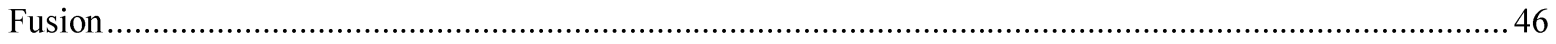

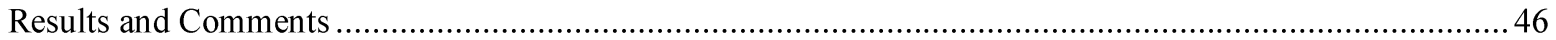

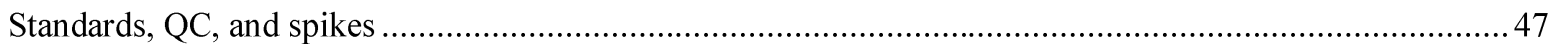

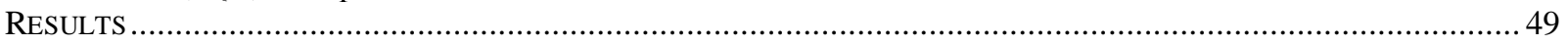

Gas concentration results for three mixtures of coal and biomass..........................................................50

Gas concentration results for PRB coal with two biomass types.................................................................5 54

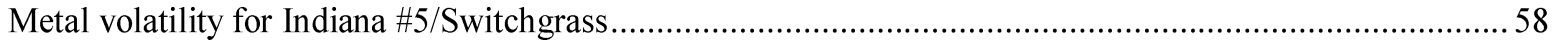

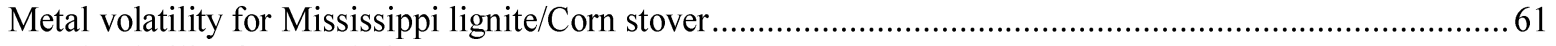

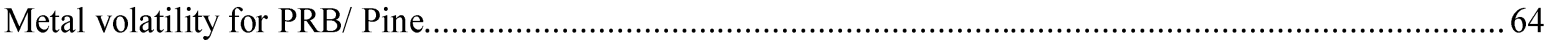

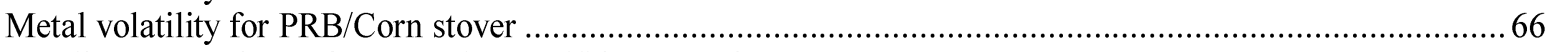

Baseline comparison of pure coal to coal/biomass mixture ........................................................................69

EERC EFG REPORT: GASIFICATION OF INDIANA NO. 5 COAL BLENDED WITH SWITCHGRASS IN

THE EERC'S SMALL PILOT-SCALE ENTRAINED-FLOW GASIFIER …................................................. 71

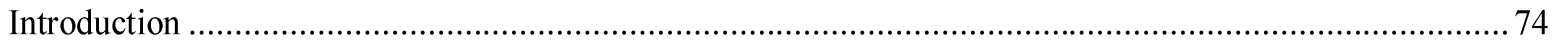

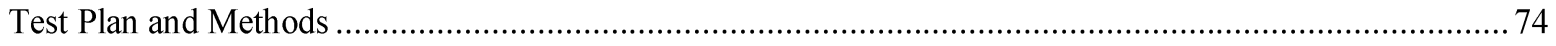

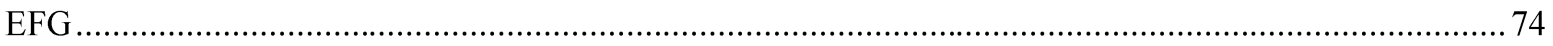

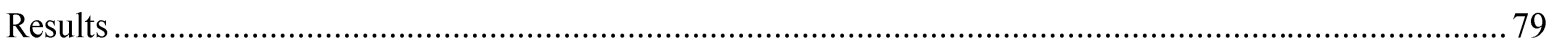

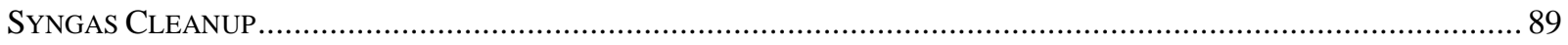




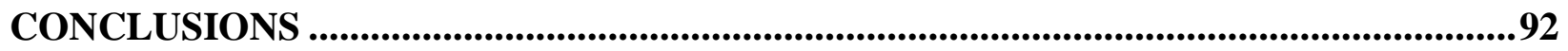

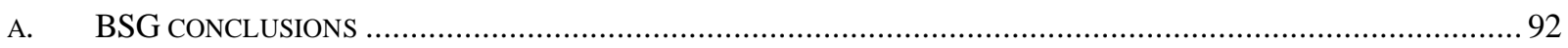

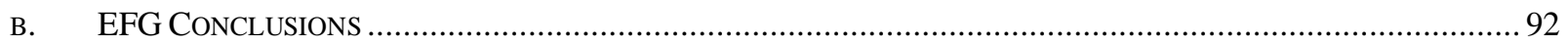

LIST OF ACRONYMS AND ABBREVIATIONS .......................................................93

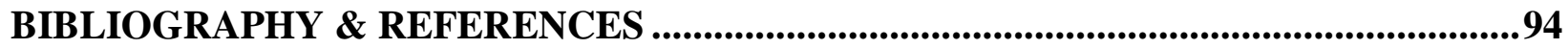




\section{LIST OF FIGURES}

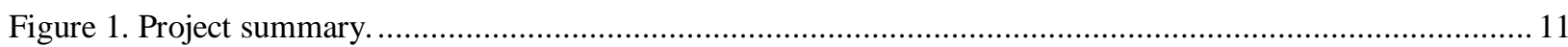

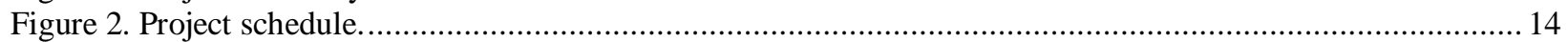

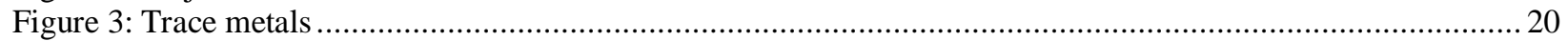

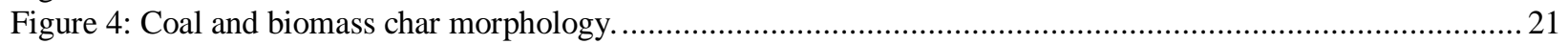

Figure 5: Diagram showing flow of gas and particles and position of collection system for BSG .........................224

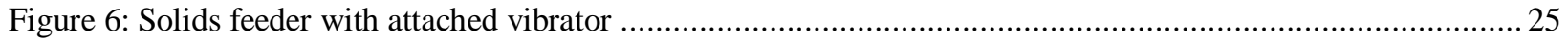

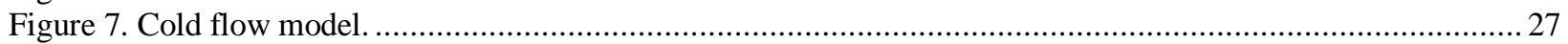

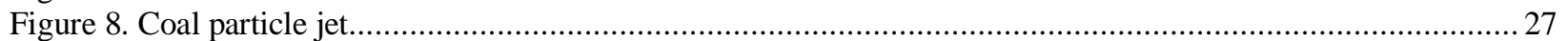

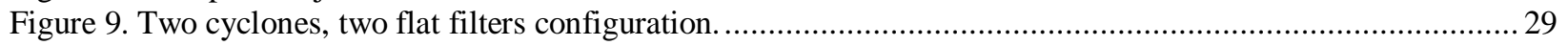

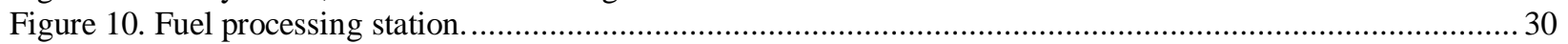

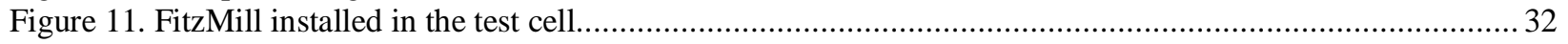

Figure 12. Switchgrass particle size distribution after grinding in jet mill and FitzMill........................................ 33

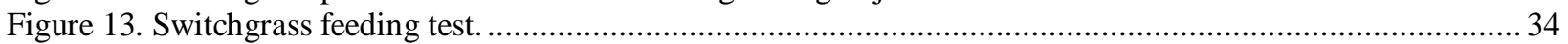

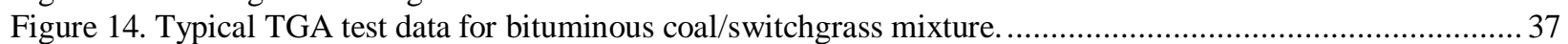

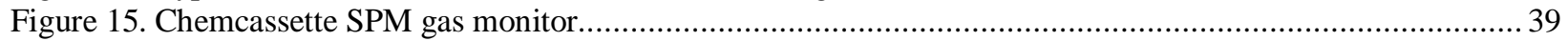

Figure 16. Schematic of the humidifier system used with Chemcassette ${ }^{\mathrm{TM}}$ SPM gas monitor. .............................. 40

Figure 17. SEM photograph of bituminous char particle (uncoated) ................................................................ 41

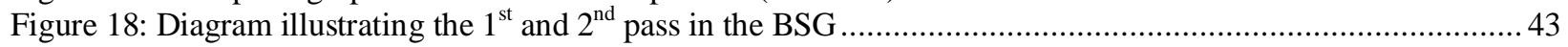

Figure 19. SEM photograph of char particles formed in the first pass through the BSG ..................................... 45

Figure 20. SEM photograph of char particles formed in the second pass through the BSG................................... 45

Figure 21: Hydrogen concentration for three different coal/biomass mixtures ................................................50

Figure 22: Carbon Monoxide concentration for three different coal/biomass mixtures.......................................... 51

Figure 23: Ammonia concentration for three different coal/biomass mixtures ................................................ 52

Figure 24: Hydrogen cyanide concentration for three different coal/biomass mixtures ....................................... 52

Figure 25: Hydrogen Sulfide concentration for three different coal/biomass mixtures ..........................................5 53

Figure 26: Sulfur dioxide concentration for three different coal/biomass mixtures.............................................. 53

Figure 27: Hydrogen concentration for two different PRB/biomass mixtures ................................................... 54

Figure 28: Carbon Monoxide concentration for two different PRB/biomass mixtures...........................................55

Figure 29: Ammonia concentration for two different PRB/biomass mixtures .................................................. 55

Figure 30: Hydrogen Cyanide concentration for two different PRB/biomass mixtures...........................................56

Figure 31: Hydrogen Sulfide concentration for two different PRB/biomass mixtures .......................................... 57

Figure 32: Sulfur Dioxide concentration for two different PRB/biomass mixtures........................................... 57

Figure 33: Metal volatility of Arsenic and Selenium for Indiana \#5/Switchgrass mixture ................................... 58

Figure 34: Potassium and Sodium volatility for Indiana \#5/Switchgrass mixture ................................................ 59

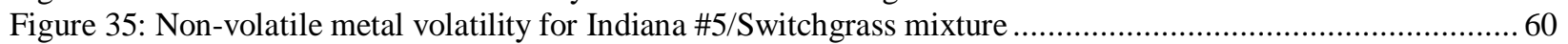

Figure 36: Volatile metal volatility for Indiana \#5/Switchgrass mixture ............................................................. 61

Figure 37: Potassium and Sodium volatility for Mississippi Lignite/Corn stover mixture .....................................62 62

Figure 38: Arsenic and Selenium volatility for Mississippi Lignite/Corn stover mixture....................................... 62

Figure 39: Non-volatile metal volatility for Mississippi Lignite/Corn stover mixture............................................ 63

Figure 40: Volatile metal volatility for Mississippi Lignite/Corn stover mixture ............................................... 63

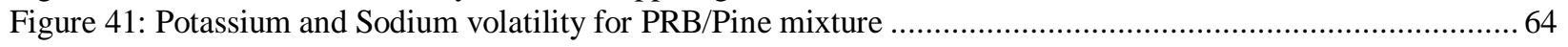

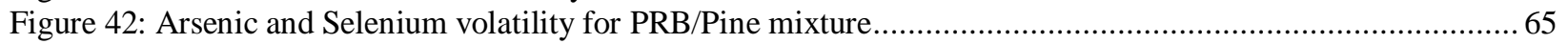

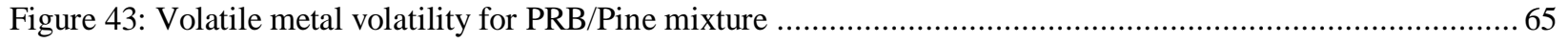

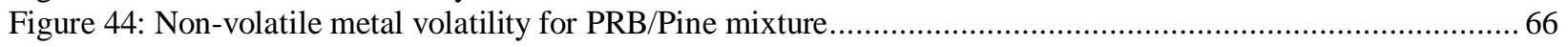

Figure 45: Potassium and Sodium volatility for PRB/Corn stover mixture .................................................... 67

Figure 46: Arsenic and Selenium volatility for PRB/Corn Stover mixture ........................................................... 67

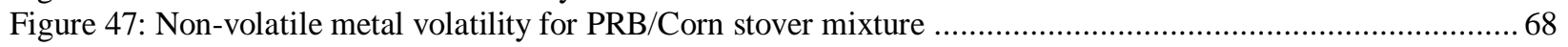

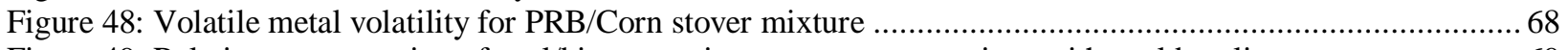

Figure 49: Relative concentration of coal/biomass mixture gas concentrations with coal baseline .........................69

DOE Contract: DE-NT0006305 $6 \quad$ Final Technical Report, October 11 '2011 
Figure 50: Relative minor metal volatility of coal/biomass mixture with coal baseline ....................................... 70

Figure 51: Relative minor metal volatility of coal/biomass mixture with coal baseline ...................................... 71

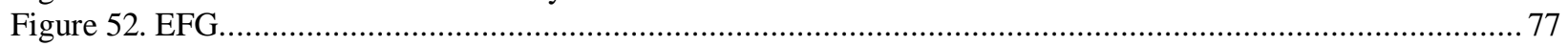

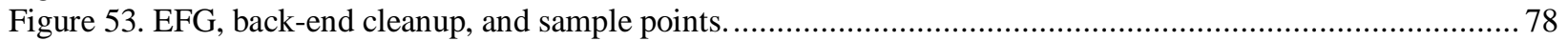

Figure 54. Syngas composition as measured by the LGA-35 for Test 1 (September 19, 2011)............................ 84

Figure 55. Syngas composition as measured by the LGA-35 for Test 2 (September 20, 2011) ........................... 85

Figure 56. Syngas composition as measured by the LGA-39 for Test 3 (October 17 and 18, 2011)..................... 86

Figure 57. Effect of syngas temperature on partition of metals a) As, b) $\mathrm{Ba}$, c) Cd, d) $\mathrm{K}$, e) $\mathrm{Na}$, f) $\mathrm{Pb}, \mathrm{g}$ ) $\mathrm{Se}, \mathrm{h}$ ) $\mathrm{Si}$, i)

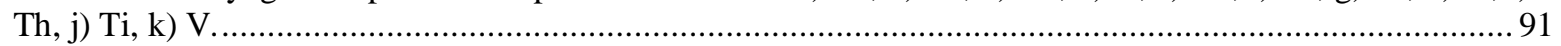




\section{LIST OF TABLES}

Table 1. Project milestones.

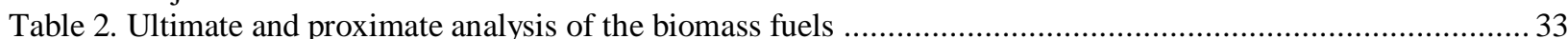

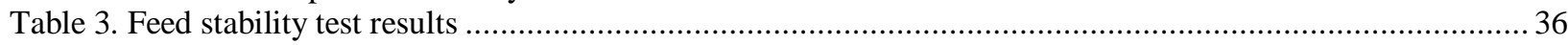

Table 4. Yields of volatiles, ash-free char, and ash, measured in the TGA........................................................ 37

Table 5. Measurement ranges of various Chemcassette ${ }^{\mathrm{TM}}$ sensing tapes........................................................... 40

Table 6. SRM and sample spike recoveries using microwave based sample preparation method. All values in wt\%. Non-certified SRM elements in italics.

Table 7. SRM and sample spike recoveries using fusion based sample preparation method. All values in wt $\%$. Non-

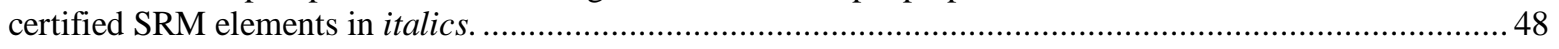

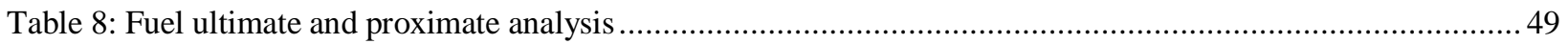

Table 8: Minor and trace metal concentration of coal and biomass feedstocks ..................................................69

Table 10. Test Plan for Coal-Biomass Blend Testing at the EERC …............................................................. 76

Table 11. Proximate-Ultimate and Heating Value Analysis of Indiana No. 5 Coal ............................................. 79

Table 12.Proximate-Ultimate and Heating Value Analysis of Switchgrass .......................................................... 79

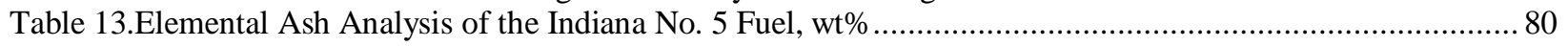

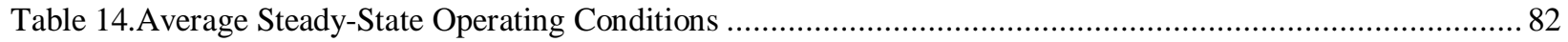

Table 15.Average Syngas Compositions Attained During Two Test Periods Using the LGA-35........................... 86

Table 16.Average Syngas Composition Attained During Two Test Periods Using the Varian Analyzer..................87

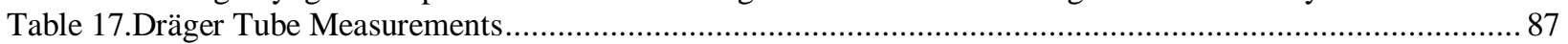

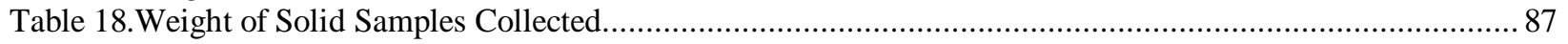

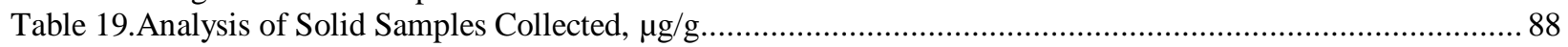

Table 20: Syngas composition from a coal gasification plant........................................................................ 89 


\section{EXECUTIVE SUMMARY}

This is the final technical report for this U.S. DOE NETL (Contract No. DE-NT0006305) and GE supported project summarizing project accomplishments for the period starting Oct 1, 2008 and ending Sep 30, 2011. This report provides a project narrative and a summary of project activities and accomplishments during this reporting period.

The primary project goal was to perform a complete characterization of the gas, liquid, and solid products that result from the co-gasification of various coal/biomass mixtures (three coal types with three biomass types) with focus on biomass concentrations between $30 \mathrm{wt} . \%$ and $50 \mathrm{wt} \%$ (dry coal and dry biomass basis) to provide guidance on the appropriate gas clean-up systems and optimization of operating parameters for development of future gasification systems.

Under this project, GE Global Research carried out a comprehensive characterization of the coal/biomass co-gasification products using bench-scale gasifier (BSG) at GE and a pilot-scale entrained flow gasifier (EFG) at Energy \& Environmental Research Center (EERC), an agency of the University of North Dakota. To minimize expensive experimentation with the EFG, the BSG was used to map the composition of the gaseous, liquid, and solid products, define their concentration ranges, and optimize product analysis methods and procedures. The EFG was used in the latter part of the project to perform a focused set of experiments based upon the initial results obtained from the BSG. Experiments were performed on mixtures of the three major types of coal (bituminous, sub-bituminous, and lignite) with three types of biomass (cornstover, wood, and grass). Feedstocks included pine wood sawdust as a representative wood biomass and milled switchgrass as a representative herbaceous biomass. Wood sawdust and milled switchgrass were well suited for experimental testing in the small-scale entrained flow gasification facilities. The main focus of the experiments was on biomass concentrations between 30 wt. \% and $50 \mathrm{wt}$ \% (dry coal and dry biomass basis).

The main work conducted during the project focused on conducting gasification experiments with coal and biomass mixtures for 3 different coals and 3 different biomass types and benchmarking it against pure coal gasification. The experiments were conducted mainly in BSG at the Fuel Conversion Lab (FCL) in Irvine, California and high pressure experiments for selected conditions were conducted at EFG at EERC. It was found that while many of the inorganic elements are volatile at the high temperature gasification conditions, subsequent cleanup and cooling processes in a full-scale gasification system would condense and substantially capture most of these components. 


\section{PROJECT NARRATIVE}

The U.S. Department of Energy's National Energy Technology Laboratory (DOE NETL) is exploring affordable technologies and processes to convert domestic coal and biomass resources to high-quality liquid hydrocarbon fuels. This interest is primarily motivated by the need to increase energy security and reduce greenhouse gas emissions in the United States. Gasification technologies represent clean, flexible and efficient conversion pathways to utilize coal and biomass resources. Substantial experience and knowledge had been developed worldwide on gasification of either coal or biomass. However, reliable data on effects of blending various biomass fuels with coal during gasification process and resulting syngas composition are lacking.

In this project, GE Global Research performed a complete characterization of the gas, liquid and solid products that result from the co-gasification of coal/biomass mixtures (Figure 1). This work was performed using a bench-scale gasifier (BSG) and a pilot-scale entrained flow gasifier (EFG). This project focused on comprehensive characterization of the products from gasifying coal/biomass mixtures in a high-temperature, high-pressure entrained flow gasifier. Results from this project provide guidance on appropriate gas clean-up systems and optimization of operating parameters needed to develop and commercialize gasification technologies. 


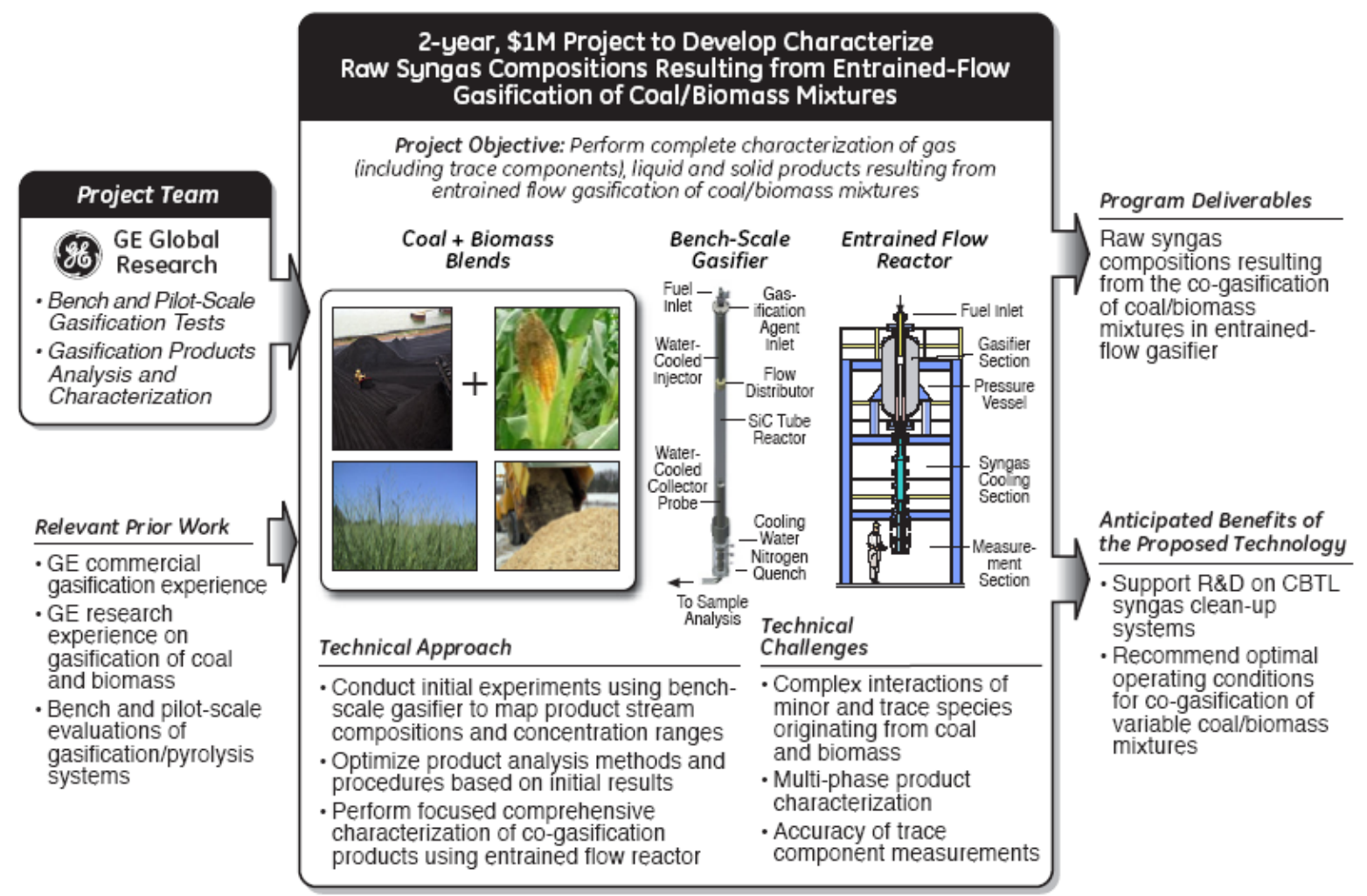

Figure 1. Project summary.

GE's bench-scale test facility provided the bulk of high-fidelity quantitative data under temperature, heating rate, and residence time conditions closely matching those of commercial oxygen-blown entrained flow gasifiers. Energy and Environmental Research Center (EERC) pilot-scale test facility provided focused high temperature and pressure tests at entrained flow gasifier conditions. Accurate matching of syngas time-temperature history during cooling ensured that complex species interactions including homogeneous and heterogeneous processes such as particle nucleation, coagulation, surface condensation, and gas-phase reactions were properly reproduced and lead to representative syngas composition at the syngas cooler outlet. The experimental work leveraged other ongoing GE R\&D efforts such as biomass gasification and dry feeding systems projects. Experimental data obtained under this project were used to provide guidance on the appropriate clean-up system(s) and operating parameters to coal and biomass combinations beyond those evaluated under this project.

\section{PROJECT OBJECTIVES}

The following technical objectives were achieved during this project: 
- Conducted comprehensive set of experiments using bench-scale gasifier to characterize the product stream

- Optimized product analysis methods and procedures based on bench-scale gasifier results

- Characterized co-gasification products in pilot-scale entrained flow gasifier using focused test matrix

- Explored clean-up requirements for mixtures containing three types of coal (bituminous, sub-bituminous, and lignite) and three types of biomass (cornstover, wood, and grass)

- Evaluated the applicability of the observed trends to a wider range of coal/biomass fuels and operating conditions

\section{METHODS EMPLOYED}

The raw syngas compositions that resulted from the gasification of various coal/biomass combinations were characterized experimentally for mixtures of three major coal types (bituminous, sub-bituminous, and lignite) with three biomass types [cornstover, wood (sawdust), and grass (switchgrass)]. The main focus was on biomass concentrations between $30 \mathrm{wt} \%$ and $50 \mathrm{wt} \%$ (dry coal and dry biomass basis). Initial experiments were performed in an atmospheric pressure entrained-flow bench-scale gasifier (BSG) at temperatures up to $1,400{ }^{\circ} \mathrm{C}$ and particle residence times up to $5 \mathrm{~s}$. At the outlet of the gasifier, the product stream was rapidly quenched by inert gas. The solid (char, soot, ash, aerosols), liquid (tar, if any), and gaseous products were analyzed separately by on-line and off-line methods. The concentrations of syngas components and their variation ranges as functions of coal/biomass mixture composition and operating conditions were established. Sampling and analysis methods were optimized and validated, and data confidence intervals were determined. Based on the results of the bench-scale experiments, a focused measurement campaign was performed using EERC's entrained flow gasifier (EFG). The EFG is comprised of a gasifier section and a syngas cooling section. The test section is equipped with an array of access ports and analytical equipment. The EFG was operated at temperatures up to $1500^{\circ} \mathrm{C}$ and pressures up to $275 \mathrm{psi}$, closely reproducing conditions of some commercial entrained flow gasifiers. Raw syngas compositions, including solid, liquid, and gaseous products, were characterized at the outlet of syngas cooler for major syngas components, nitrogen $\left(\mathrm{NH}_{3}\right.$ and $\left.\mathrm{HCN}\right)$, sulfur $\left(\mathrm{H}_{2} \mathrm{~S}\right.$ and $\left.\mathrm{COS}\right)$, chlorine, alkali, and trace metal concentrations. Based on the bench-scale and EFG experimental results, recommendations for appropriate cleanup systems and operating parameters for the commercial entrained flow gasifier were developed.

\section{RELEVANCE AND IMPACTS}

To provide an accurate description of the raw syngas composition as a function of operating parameters and fuel mixture characteristics, experimental measurements were performed using the BSG and EFG test facilities, which are uniquely suited to the objectives of this project providing high-fidelity quantitative experimental data. The experimental approach offers the following advantages:

- Both the BSG and the EFG are high-temperature (up to $1,600^{\circ} \mathrm{C}$ ) entrained flow facilities capable of achieving fast particle heating rates exceeding $10^{4}{ }^{\circ} \mathrm{C} / \mathrm{s}$ that are close to those 
employed by commercial entrained flow gasifiers. The devolatilization process, the first step of fuel conversion, is significantly affected by the heating rate of the fuel particles, and in turn, to a large extent determines the composition, structure, and behavior of volatilized species and solid residues during subsequent gasification steps.

- Both the BSG and the EFG are designed to operate under plug-flow conditions and provide precisely controlled testing environments that allow accurate monitoring of time and temperature histories of gases and particles during the gasification process. The experimental data obtained in BSG and EFG can be directly used to develop and validate predictive gasification models describing commercial gasifiers. In contrast, the direct or slipstream measurements performed in large-scale gasifiers can be affected by flow recirculation and other factors that cannot be accurately determined and controlled. As a result, the data obtained by such measurements are more difficult to interpret and generalize to other types of gasifiers or different operating conditions.

- A combination of atmospheric pressure data obtained in the BSG with high-pressure (up to $275 \mathrm{psi}$ ) data obtained in the EFG provides guidance for appropriate gas cleanup systems over a wide range of operating pressures.

The combination of GE's vast experience in research, development, and commercialization of gasification technologies, the design and operation of the bench-scale gasifier, and EERC's experience in operating the EFG experimental facility achieves the greatest impact on advancing environmentally-sound conversion technologies to produce liquid hydrocarbon fuels from coal/biomass mixtures.

\section{PROJECT PLAN AND MANAGEMENT}

This project was organized into four interrelated tasks including:

- Project management and planning

- Characterization of solid, liquid, and gaseous products of coal/biomass gasification at bench scale

- Validation and optimization of sampling and analysis methods and procedures

- Complete characterization of coal/biomass gasification products in the EFG

Responsibilities for each task were clearly assigned to task leaders with the required technical expertise to carry out the approach. The principal investigator coordinated all project activities, ensured that technical deliverables were met and risks retired, and was the primary point of contact for DOE. The original project schedule is shown in Figure 2. The project was later modified to complete the project in 3 years. 


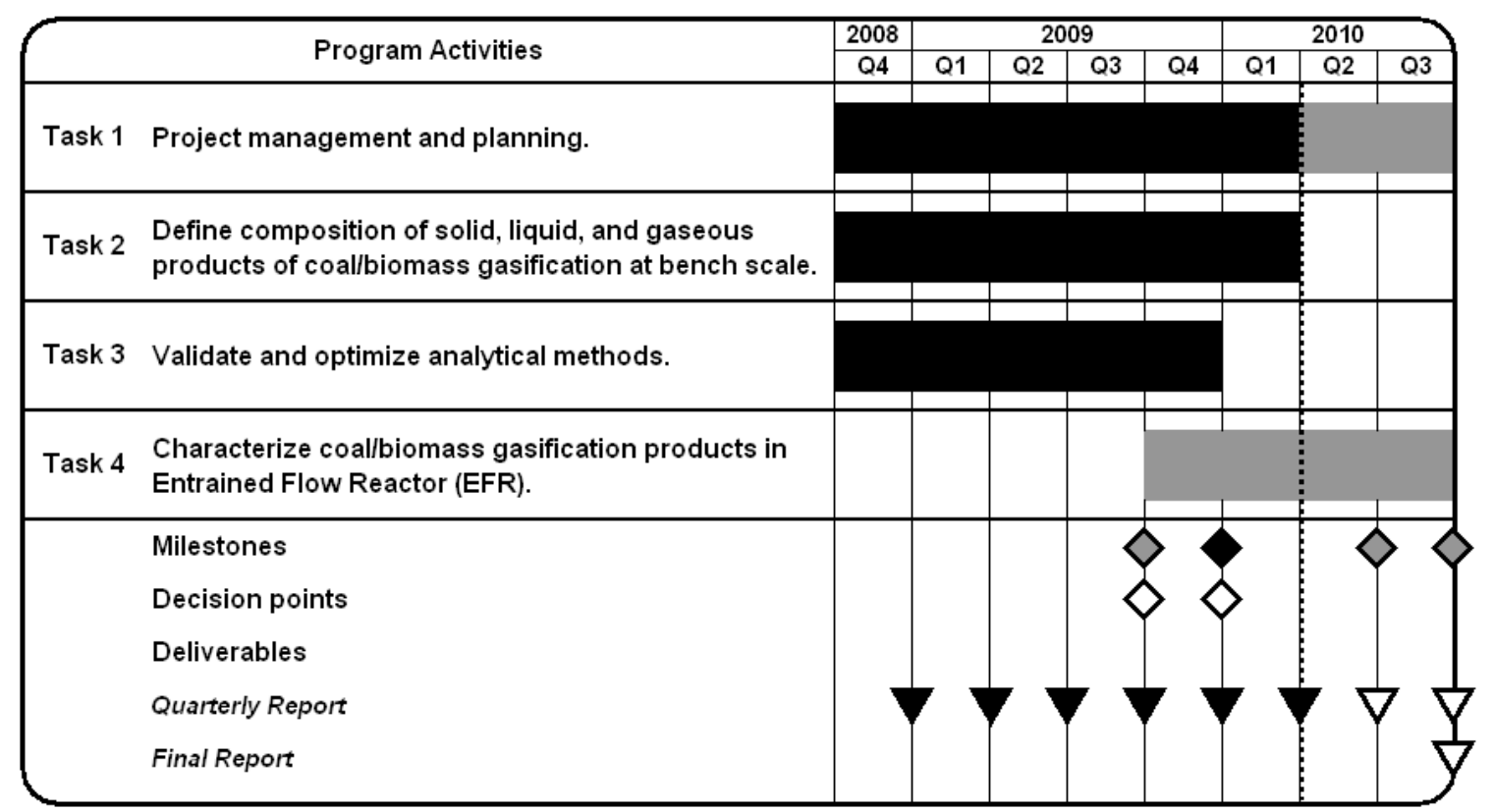

Figure 2. Project schedule.

\section{SCIENTIFIC AND TECHNICAL MERIT}

\section{Advances in Current State of Technology}

Biomass is considered a renewable energy source since carbon dioxide emissions caused by its use are absorbed during biomass growth. Only biomass offers the possibility of producing nearly carbon-neutral liquid transportation fuels that provide feasible alternatives for the transportation sector in the foreseeable future. This issue is particularly relevant today as transportation is responsible for a large part of global $\mathrm{CO}_{2}$ emissions. The portion of transportation in the total energy consumption is increasing, especially in developing countries.

Common barriers to biomass utilization at scales large enough to make a noticeable contribution to global energy production include biomass variability, availability, seasonality, and low energy density. The influence of these factors can be substantially mitigated if biomass is used synergistically with the most abundant fossil fuel resource-coal. The worldwide efforts to develop and commercialize coal/biomass co-combustion and co-gasification technologies have intensified over the last several years. The feasibility of co-combusting or co-gasifying small quantities of biomass (typically less than $10 \%$ by weight) had been demonstrated in many projects. For example, the Tampa Electric Company Integrated Gasification Combined Cycle (TECO IGCC), located at Mulberry, Polk County, FL, demonstrated that a fuel blend of coal, petroleum coke, and eucalyptus grove (1.2\% biomass by weight) could be successfully gasified to produce electricity using the IGCC system, without an adverse impact on the biomass 
availability and plant performance. However, successful long-term utilization of larger biomass quantities, in the order of $30 \%$ by weight or higher, must still be achieved.

Air-blown circulating fluidized bed (CFB) gasifiers are widely considered to be well-suited for small-scale biomass gasification. However, nitrogen dilution, high costs, high tar concentrations in the product gas, and the need for subsequent gas clean-up suggest that CFB gasifiers are not the most cost-effective option for large-scale gasification. High-temperature, high-pressure entrained flow (EF) oxygen-blown gasification, with its high efficiency and ability to provide the syngas at pressures required for downstream Fischer-Tropsch (FT) synthesis without additional compression steps, offers the best commercial potential for large-scale conversion of coal/biomass mixtures to liquid fuels.

Co-gasification of coal and biomass in EF gasifiers presents several technical challenges including:

- Reliable feeding into the pressurized gasifier.

- Unknown effects of coal and biomass compositions on the solid, liquid (if any), and gaseous products of co-gasification.

- Effects of syngas impurities on downstream equipment such as water-gas shift (WSG) and FT catalysts.

The first and last issues are addressed separately under other DOE-funded projects awarded in the same Funding Opportunity Announcement DE-PS26-08NT00258 as in this project. The other research areas respectively are: Area of Interest 1 (Feeding Coal/Biomass Mixtures Across a Pressure Gradient) and Area of Interest 3 (Optimization of the FT and WGS Processes).

The work presented in this report addresses the second bulleted issue above focusing on complete characterization of the raw syngas that result from the gasification of coal and biomass mixtures, including trace components, and the assessment of requirements for the gasifier operating parameters and the downstream gas cleanup systems.

\section{Scientific and Technical Merit}

While coal gasification products have been studied in the past, data on characterization of the products resulting from biomass and coal/biomass mixtures gasification in an EF gasifier is scarce. The product distribution, which results from co-gasification of coal and biomass blends, will depend on the interaction between various components of coal and biomass and cannot be predicted a priori based on the knowledge of product distributions from pure coal and pure biomass gasification. Non-linear effects due to the possible interaction of inorganic constituents present in biomass with coal char must be verified and experimentally characterized to provide guidance on the development of appropriate clean-up systems. In particular, the amount of volatilization and retention of trace elements during co-gasification will depend on the complex interplay between various components of coal and biomass fuels and must be carefully described for each coal/biomass blend. Moreover, different slag behavior resulting from coal/biomass cogasification can pose operational problems and affect the refractory-lined walls of the gasifier 
and the syngas cooler. With uncertainties in gasifier operation and costs associated with gas clean-up systems, complete characterization of coal/biomass co-gasification represents a critical step toward the commercialization of this technology.

Entrained flow oxygen-blown coal gasification typically yields a product gas that contains $\mathrm{H}_{2}$, $\mathrm{CO}, \mathrm{CO}_{2}, \mathrm{H}_{2} \mathrm{O}$, small quantities of $\mathrm{CH}_{4}$, sulfur compounds (such as $\mathrm{H}_{2} \mathrm{~S}, \mathrm{COS}$ and $\mathrm{CS}_{2}$ ), nitrogen compounds (such as $\mathrm{NH}_{3}$ and $\mathrm{HCN}$ ), halides, alkali and trace metals, small particles of soot and ash, and trace concentrations of organic and hetero-organic components (including $\mathrm{S}, \mathrm{N}$ and $\mathrm{O}$ ). Ash-forming components, including the inorganic mineral matter present in the feedstock, melt inside the gasifier and are typically removed as a liquid slag. The quality of the raw product gas is insufficient to meet the feed specifications for downstream processes, such as FT synthesis. The typical catalysts used in these processes are extremely sensitive to small amounts of impurities in the raw product gas. As a result, these catalysts are regenerated or replaced on a regular basis in an attempt to maintain the reactor's productivity and optimal catalyst performance in FT synthesis. Feed gas specifications for these processes are determined based on an economic trade-off between increased capital and operating expenditures for gas clean up and decreased reactor yields due to catalyst poisoning.

Due to differences in fuel properties, co-gasification of biomass with coal in an entrained flow reactor is expected to affect the product gas composition. While the main gasification products for both fuel types comprise $\mathrm{H}_{2}, \mathrm{CO}, \mathrm{CO}_{2}$, and $\mathrm{H}_{2} \mathrm{O}$, albeit in varying concentrations, the makeup of minor components of the syngas can change dramatically depending on chemical compositions of both coal and biomass as well as process conditions. Figure 3 presents the typical elemental composition of several biomasses that were the focus of the program [1].

In addition to the major elements $(\mathrm{C}, \mathrm{H}, \mathrm{O}, \mathrm{N}, \mathrm{S})$, minor elements $(\mathrm{Al}, \mathrm{Ca}, \mathrm{Fe}, \mathrm{K}, \mathrm{Mg}, \mathrm{Na}, \mathrm{P}, \mathrm{Si}$, Ti) and trace elements (As, $\mathrm{Ba}, \mathrm{Cd}, \mathrm{Co}, \mathrm{Cr}, \mathrm{Cu}, \mathrm{Hg}, \mathrm{Mn}, \mathrm{Mo}, \mathrm{Ni}, \mathrm{Pb}, \mathrm{Sb}, \mathrm{Tl}, \mathrm{V}, \mathrm{Zn}$ ) are also present in biomass fuels. These inorganic constituents can significantly affect the behavior of biomass during thermal processing, directly influencing the quality and conversion during pyrolysis, combustion, and gasification (e.g. [2]). Many of the inorganic components are retained in the char and can influence the combustion or gasification of the solid residue [3-4].

In particular, the higher alkali metal content of biomass, relative to coal, poses a serious operational problem since these metals can easily vaporize at the high temperatures encountered in commercial EF gasifiers. The condensation of volatile metals and their compounds can form sticky deposits on heat exchangers and downstream gas clean-up equipment. The problems associated with deposit formation during combustion of biomass and co-combustion of biomass with coal have been investigated by many researchers in bench-scale and full-scale facilities (see for example [5-8]). Substantially less is known about the mechanistic and chemical aspects of deposit formation during gasification of coal and biomass mixtures, especially following the exposures to high temperatures and pressures characteristic of EF gasifiers.

In contrast to combustion under oxidizing conditions, thermodynamic modeling predicts a much higher proportion of alkali in the gas phase under reducing conditions during gasification [9]. Alkali species in coal are mostly associated with mineral matter and are not easily volatilized 
during gasification. For example, in bituminous coals, they are present mainly in the mineral components, such as in the mineral matrix itself (e.g. Feldspat and Muscovit) or as $\mathrm{NaCl}$ or $\mathrm{KCl}$ inclusions. For lignite coals, they are mainly found bound to phenolic hydroxyl and carbonate groups in the organic structure. In contrast, biomass materials contain sodium and potassium largely in water-soluble forms in vacuoles but also as constituents of organic structures. These forms are readily accessible for release during combustion or gasification, resulting in subsequent chemical reactions to form gas-phase and condensed metal species. The gas-phase alkali species formed in gasification process are predominantly chlorides and hydroxides, whereas the condensed phase metal species consist mainly of silicates. The critical control variables that affect the formation of the gas-phase alkali species include the concentrations of sulfur, silicon, and particularly chlorine, and gasification conditions such as pressure, temperature and the oxygen/fuel ratio. Alkali gas-phase species may exacerbate the problems associated with deposit formation on cooled walls or heat exchanger tubes. The deposition of sub-micron alkali-rich particles or condensation of alkali vapors on the heat-exchanger surface may create a sticky layer that promotes particle retention and the growth of the deposit layer, leading to increased thermal resistance, reduced efficiencies, and high maintenance costs.

While debarked wood is a relatively clean fuel with low ash content, herbaceous biomass feedstocks typically have a higher content of ash and heteroatoms, especially potassium and chlorine, which are needed as catalysts for the faster metabolism. Chlorine concentrations in certain types of biomass residues, such as straws, cereals and grasses, can be substantial and can lead to the formation of $\mathrm{HCl}$, which can cause high temperature corrosion in the gasifier. Chlorides can also contribute to the production of low $\mathrm{pH}$ conditions in the syngas quenching and scrubbing operations. In the presence of chlorine, alkali chlorides become the most thermodynamically stable gas-phase alkali species at the high temperatures that are typical in EF gasifiers. Additionally, experiments and thermodynamic modeling show that under both combustion and gasification conditions the alkali volatilization can be significantly enhanced by chlorine $[9,10]$.

For the biomass feedstocks of interest in this program, the concentrations of sulfur and nitrogen species in the product gas from biomass gasification are expected to be lower, compared to those from coal gasification. The complex interaction of sulfur, chlorine, and alkali species is primarily driven by temperature and species concentrations and can lead to the formation of corrosive alkali salts downstream of the gasifier. Additional cleaning steps, such as control of chloride concentration in the process water, may be required to mitigate these issues.

In addition to posing operational difficulties, nitrogen, sulfur, alkali and chlorine species (including $\mathrm{H}_{2} \mathrm{~S}, \mathrm{COS}, \mathrm{NH}_{3}, \mathrm{HCN}$, chlorides, and particulates) act as severe poisons to commercial FT catalysts. Sulfur is an irreversible poison for the typical FT catalysts. The tolerance for sulfur contaminants in the FT feed gas is low, requiring 'deep cleaning' of the feed. The typical feed specifications for $\mathrm{N}$, alkali, $\mathrm{S}$, and $\mathrm{Cl}$ compounds for FT synthesis are on the order of $10 \mathrm{ppb}$, requiring cleaning efficiencies exceeding 99.9\% [11].

The configuration and operating requirements of the clean-up system will be to a large extent dictated by the syngas cooling method (direct quench or dry cooler). While the direct quench may provide some benefits (such as additional scrubbing of undesirable species) making it attractive in the short term, the dry syngas cooling in combination with hot or warm syngas 
clean-up will be more attractive in the long term, driven by efficiency requirements and consistent trends toward zero plant discharge and minimization of water requirements. The study of syngas cleaning requirements resulting from the dry syngas cooling suggested in this program is aligned with the long-term trends of gasification technology development. Additionally, since impurity concentrations resulting from dry syngas cooling might be higher than those resulting from a direct quench, this program will provide relevant data for the downstream cleaning equipment under a more challenging scenario of dry syngas cooling.

The trace metal composition of biomass fuels differs significantly from that of coals. While the metal constituents of coal fuels have been studied in detail, data on the trace element composition of biomass is limited. Figure 3 illustrates the typical concentrations of some trace elements for biomass and coal fuels, similar to those that will be studied in this program [12,13]. It can be seen that the differences in the concentrations of some trace species, between coal and biomass, can often exceed several orders of magnitude. In addition, the modes of occurrence of these elements in coal and biomass are substantially different. The possible forms of occurrence of heavy metals in coals include pyrite, sulphides, carbonates, clays, or organic matter. In biomass, most metals play some role in enzymes, but predominantly they appear to be bound to organic or organic acid groups or associated with inorganic ions such as carbonates, oxalates and phosphates in aqueous solution. In coal, many trace elements are mostly associated with mineral matter, are not easily volatilized, and tend to be relativelyinert during gasification. However, in biomass many trace elements are associated with the organic matrix and are readily released during gasification $[14,21,22]$. If the formation of solid phase is thermodynamically favorable, the released trace elements may re-condense immediately on existing solid particles. Since recondensation may be kinetically constrained at typical gas residence times observed in EF gasifiers, some portion of the volatilized trace elements will exit the reactor with the syngas. The behavior of the individual trace elements during gasification depends not only on their concentrations and on their modes of occurrence in the fuel, but also on other factors such as the concentrations of minor elements $(\mathrm{Na}, \mathrm{K}, \mathrm{Ca}, \mathrm{S}, \mathrm{Cl}$, and $\mathrm{P}$ ). Predicting the trace element partitioning in the gasification products using thermodynamic equilibrium models is very complex due to the large number of species involved and incomplete thermodynamic data available for some of them. Modeling results often contradict experimental observations, in part due to kinetic limitations (see e.g. [14]). Careful analysis of model assumptions and predictions is required to obtain meaningful results.

The trace metals that are of primary concern due to their volatility and toxicity (As, $\mathrm{Cd}, \mathrm{Hg}$, and Se) are present in plant residue biomass at significantly lower concentrations than in coal, while $\mathrm{Pb}$ concentrations are comparable between the two fuel types (Figure 3). The trace toxic metal emissions have upper specification limits that are regulated by the U.S. Environmental Protection Agency under the Clean Air Act. While it is expected that these toxic metals emissions may be mitigated in some cases due to the reduction of the overall concentration resulting from utilization of biomass, such assumptions must be verified experimentally since the relative partitioning of heavy metals in gasification products might differ from the coal-only case.

The elements of intermediate concern include $\mathrm{Cr}, \mathrm{Cu}, \mathrm{Ni}, \mathrm{V}$, and $\mathrm{Zn}$. The vanadium content of biomass fuels (Figure 3) is significantly lower than that of coal. The concentrations of $\mathrm{Ni}$ and $\mathrm{Cr}$ 
are comparable between the two fuel types, while the concentrations of $\mathrm{Cu}$ and $\mathrm{Zn}$ present in biomass exceed those of coal by as much as an order of magnitude. The measurements of $\mathrm{Ni}, \mathrm{Cr}$, and $\mathrm{Mn}$ can be complicated by possible contamination resulting from abrasion and erosion of the stainless steel components of the gasifier and sampling system. The elements $\mathrm{Ba}, \mathrm{Be}, \mathrm{Co}, \mathrm{Mn}$, $\mathrm{Mo}$, and $\mathrm{Sb}$ are of somewhat lesser concern due to their lower volatility.

During gasification, some of the minor and trace components of the fuel will be volatilized (K, $\mathrm{Na}, \mathrm{S}, \mathrm{Cl}, \mathrm{Zn}, \mathrm{Pb}, \mathrm{Cd}, \mathrm{Ca}, \mathrm{Mg}$ and $\mathrm{Si}$ ) and released to the gas phase. Reducing conditions characteristic to gasification can substantially increase the volatility of some trace elements compared to oxidizing conditions typical to combustion [15]. Subsequent syngas cooling will lead to nucleation and condensation of these volatiles to form fine aerosol particles with sizes between $1 \mathrm{~nm}$ and $1 \mu \mathrm{m}$. The non-volatile compounds will form, by coalescence or melting, ash particles with a wide range of compositions, shapes, and sizes. These ash particles consist mainly of refractory species, such as $\mathrm{Ca}, \mathrm{Mg}$ and $\mathrm{Si}$, as well as of smaller amounts of bound volatile compounds, such as $\mathrm{K}$ and $\mathrm{Na}$. During syngas cooling, the vapors of volatilized compounds can also condense or react on the surface of existing solid particles (char, soot, and ash). Due to the much larger specific surface area of the fine particles in comparison to the coarse particles, surface-dependent mechanisms, such as heterogeneous condensation or surface reaction of metal vapor, lead to increased (enriched) concentrations of condensing or reacting trace elements with decreasing particle size. Under assumptions of a purely physical condensation mechanism, spherical particles with diameters much larger than the gas mean free path and negligible particle size increase due to condensation, the concentration of condensed species in particles is proportional to $1 / \mathrm{d}^{2}$, where $\mathrm{d}$ is the particle diameter. If the gas-to-particle conversion is controlled by surface chemical reactions and/or pore diffusion in the porous particles, the concentration of condensed species is proportional to 1/d. Both types of behavior were observed in experiments $[16,17]$. The smallest particles, substantially enriched in trace elements, due to their size will tend to preferentially penetrate commercial gas-cleaning devices. In fact, most of the particulate control devices exhibit size dependent collection efficiencies with minimum efficiencies typically seen for submicron particles in the range of 0.1-1.0 $\mu \mathrm{m}$ diameter. These particles contain neither the mass (momentum) to be removed by impaction nor the high diffusional velocities necessary to migrate to collection surfaces [18]. Since these particles are also more likely to be inhaled, their analysis must be included into the human health risk assessment [19].

The morphology of solid char and ash samples will be characterized using a scanning electron microscope (SEM). Figure 4 illustrates a comparison between the chars resulting from fixed bed pyrolysis of coal and biomass (soy hulls). The data shown in Figure 4 was obtained under a separate GE program on biomass gasification.

The minor elements that are present in coal and biomass fuels ( $\mathrm{Al}, \mathrm{Ca}, \mathrm{Fe}, \mathrm{K}, \mathrm{Mg}, \mathrm{Na}, \mathrm{P}, \mathrm{Si}, \mathrm{Ti}$ ) are of key relevance regarding ash melting, deposit and slag formation, corrosion, and catalyst deactivation effects. The trace elements (As, $\mathrm{Ba}, \mathrm{Cd}, \mathrm{Co}, \mathrm{Cr}, \mathrm{Cu}, \mathrm{Hg}, \mathrm{Mn}, \mathrm{Mo}, \mathrm{Ni}, \mathrm{Pb}, \mathrm{Sb}, \mathrm{Tl}, \mathrm{V}$, $\mathrm{Zn}$ ) are of special importance for particulate emissions and environmental assessment for most coal and biomass thermochemical conversion technologies. Procedures for determining these elements in biofuels are not well-standardized. Most laboratories determine minor and trace elements in biofuels using "in house" methods or standards originally developed for fossil fuels. 
This often leads to considerable deviations between the results of different laboratories as discussed by Baernthaler in a recent report on the comparative studies of ash-forming elements in solid biofuels [20]. The results of that report, as well as others [21-23] demonstrate that acid digestion methods in combination with inductively coupled plasma-atomic emission spectroscopy (ICP-AES) and inductively coupled plasma-mass spectrometry (ICP-MS) are suitable for analyses of the above mentioned elements.
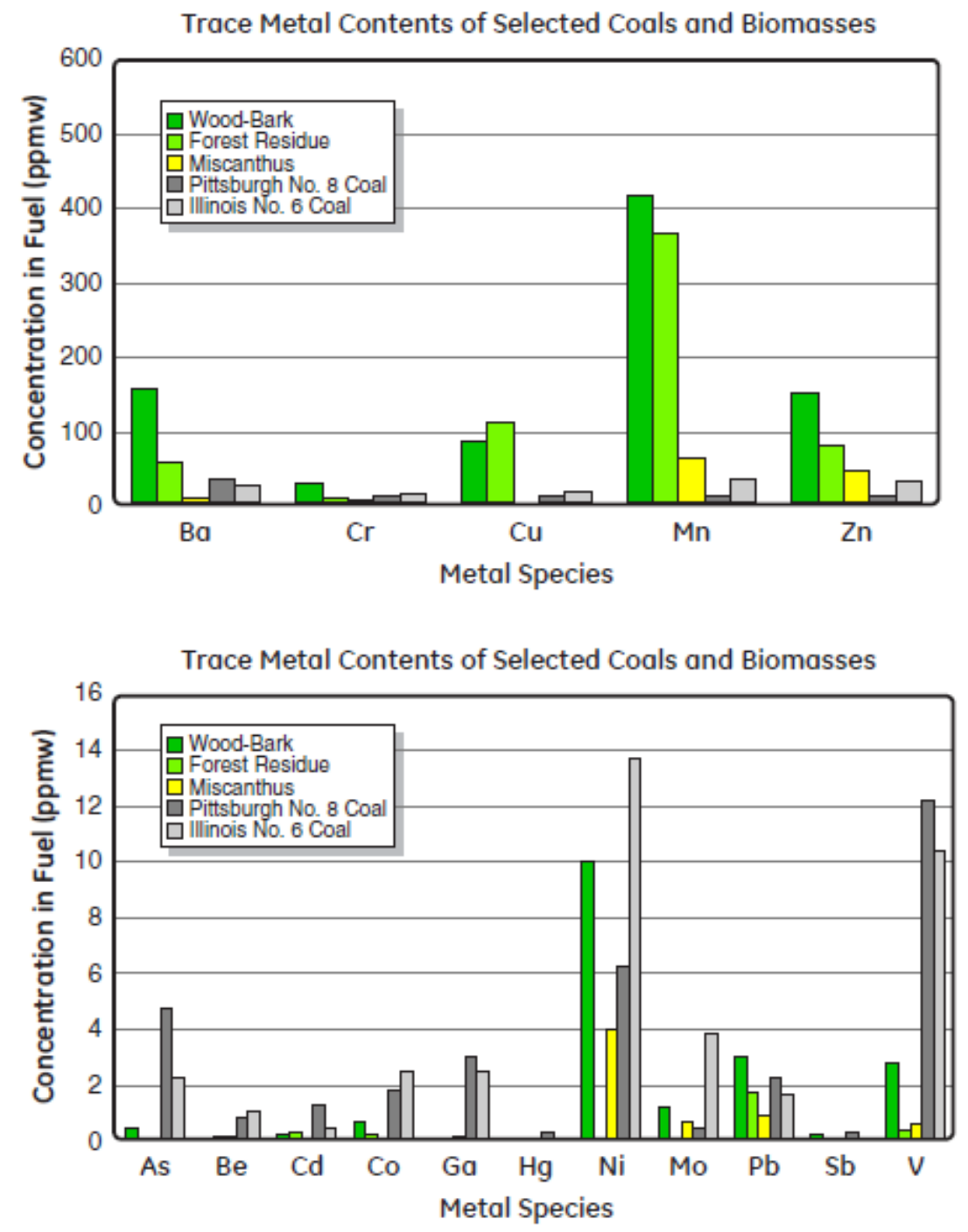

Figure 3: Trace metals 


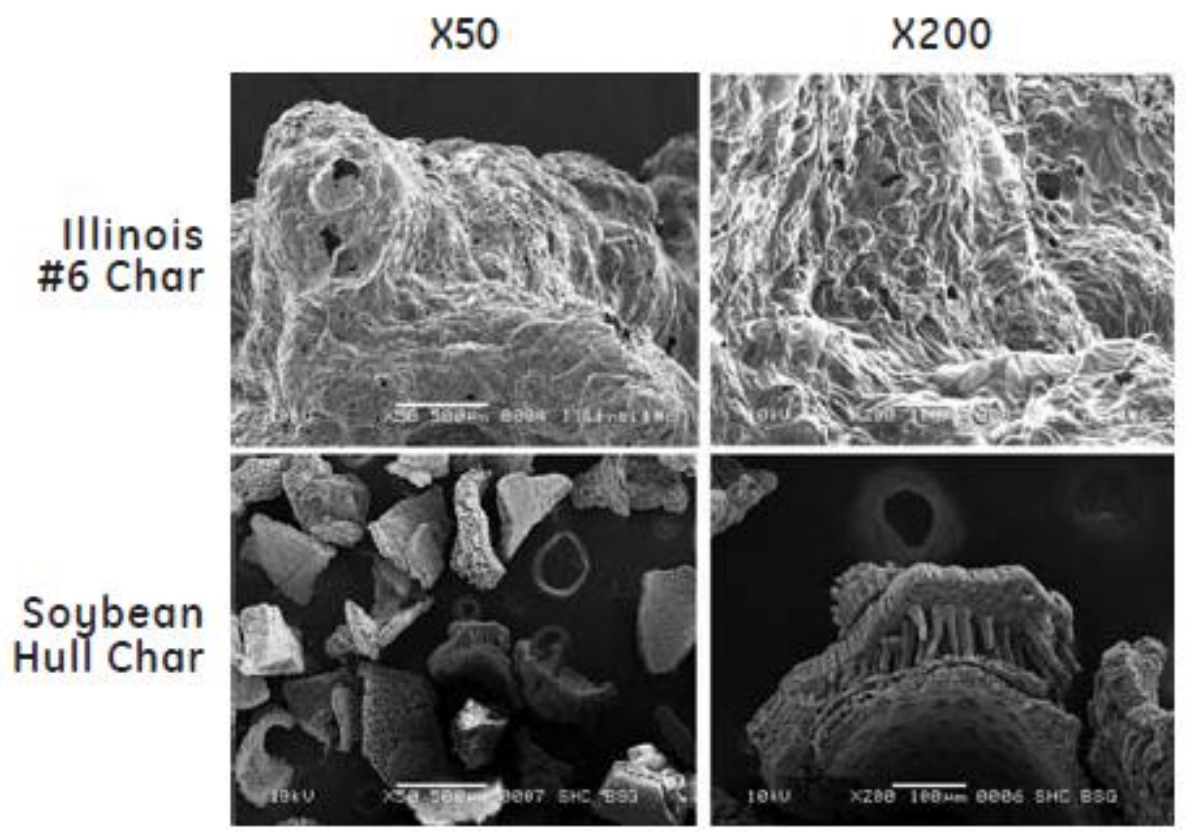

Figure 4: Coal and biomass char morphology.

Based on the results of the literature studies, as well as the significant expertise in chemical and elemental analysis developed by GE Global Research, the ICP-AES and ICP-MS methods with appropriate sample digestion methods were applied in the program to determine the minor and trace metal concentrations in the fuel samples and gasification products. Several ICP-AES and ICP-MS instruments are available at GE Global Research's facility in Niskayuna, NY. The samples collected during BSG and EFG testing were properly packaged, sealed, and shipped to GE Global Research, Niskayuna for trace metal analysis. The time between sample collection and analysis was minimized to the extent possible.

\section{Anticipated Benefits}

The program delivers a comprehensive description of raw syngas compositions, resulting from the co-gasification of coal/biomass mixtures. This effort supports R\&D on CBTL syngas cleanup systems and helps determine the optimal operating conditions for the co-gasification process. In conjunction with an optimal feeding strategy for biomass and optimized FT processes, this represents a critical step towards the commercialization of co-gasification technology. Oxy-cogasification of coal and biomass mixtures with steam presents several advantages over conventional coal gasification technologies, including increased efficiency and reduced greenhouse gas footprint. In addition, this approach mitigates several risks associated with biomass-only gasifiers, including feedstock availability and variability, high specific costs, low efficiency, high tar concentrations in the raw syngas, and potential for shut down due to biomass shortage. 
This program provides crucial information required to expand the entrained flow gasification technology to coal/biomass mixtures with biomass inputs exceeding $30 \%$ by dry weight. At these high biomass utilization levels, the EF coal/biomass co-gasification has the potential to provide a noticeable contribution to reducing the carbon footprint of the global energy production, especially if $\mathrm{CO}_{2}$ sequestration option is employed. 
The original project milestones are listed in Table 1.

Table 1. Project milestones.

\begin{tabular}{c|l}
\multicolumn{1}{c}{ Timing } & \multicolumn{1}{c}{ Milestones } \\
\hline 0 months & Project kickoff meeting in Pittsburgh, PA \\
\hline 12 months & Completion of bench-scale coal/biomass mixture gasification testing \\
\hline 12 months & Review of bench-scale test results; decision to proceed to pilot-scale testing \\
\hline 15 months & $\begin{array}{l}\text { Verification, validation, and documentation of methods and procedures for complete } \\
\text { characterization of solid, liquid, and gaseous gasification products }\end{array}$ \\
\hline 21 months & Completion of pilot-scale coal/biomass mixture gasification testing \\
\hline 24 months & Compiled database of bench- and pilot-scale gasification product compositions \\
\hline
\end{tabular}

\section{BSG GENERAL SETUP OVERVIEW}

GE Global Research's high-temperature atmospheric pressure Bench-Scale Gasifier (BSG) operates with fuel feeding rates up to $30 \mathrm{~g} / \mathrm{h}$, allowing generation of substantial amounts of char in a semi-continuous regime. The sampling system includes cyclones for separation and collection of solid products (char and ash), filters for soot and tar aerosol capture, and a gas analysis system. The online gas measurement system includes a continuous emissions monitor (CEM) rack, a Fourier-Transform Infrared (FTIR) spectrometer, and a gas chromatograph (GC) analyzer. The BSG is configured with a movable feed injector to allow residence times (up to $\sim 5$ seconds) for gasification experiments. The BSG was used to perform experiments with particle heating rates ranging from about $10^{3}$ to $10^{4} \mathrm{C} / \mathrm{sec}$. 


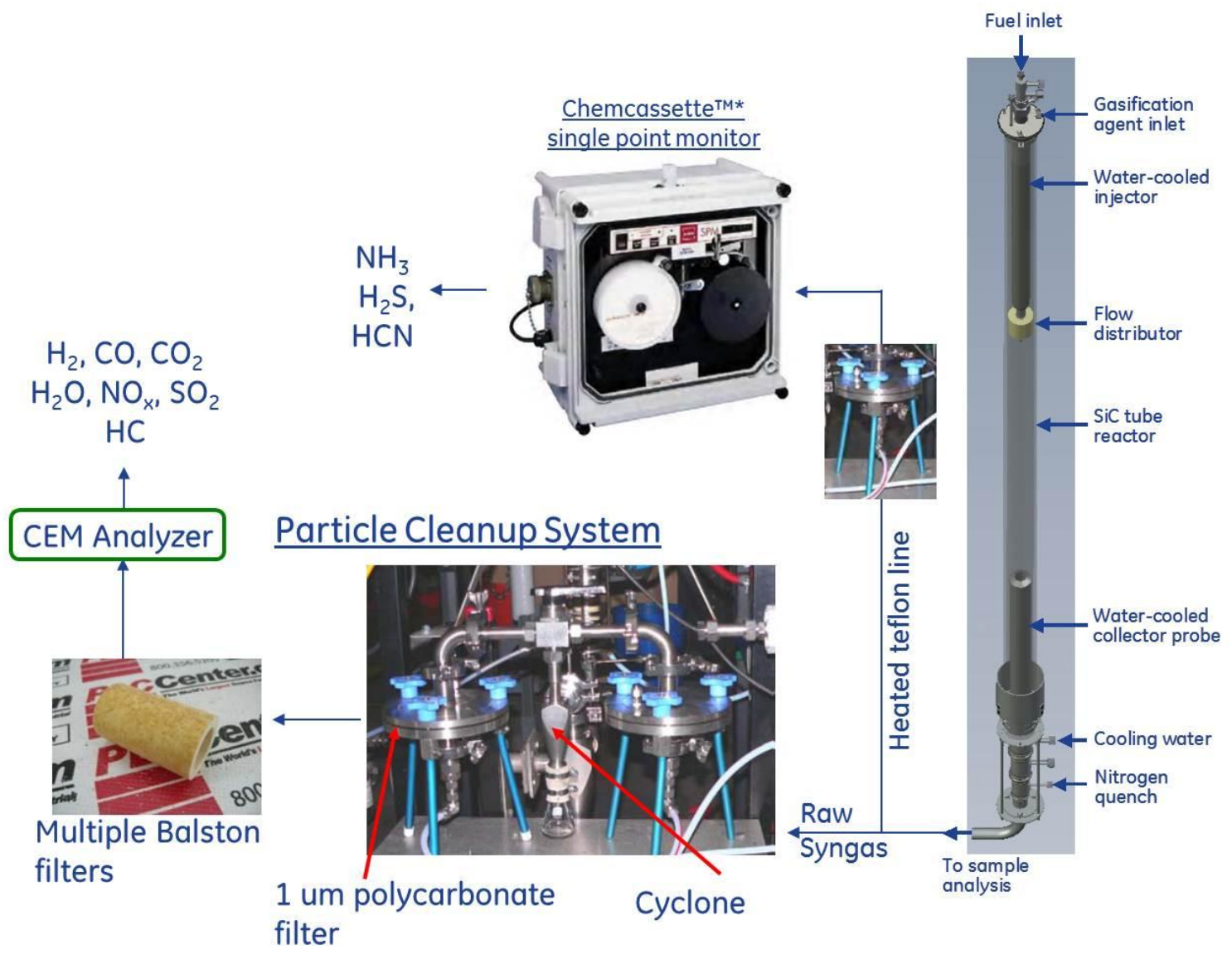

Figure 5: Diagram showing flow of gas and particles and position of collection system for BSG 


\section{Solids feeder}

The BSG solids feeder system shown in Figure 6 is made of a linear table, fixed feed tube, reservoir and vibrator. The linear table moves the reservoir-vibrator assembly upward and once the fuel in the reservoir meets the end of the fixed tube feeding begins. The feed rate is determined by the diameter of the fuel reservoir and liner table velocity. The vibrator helps to fluidize the bed of particles for steady feeding.

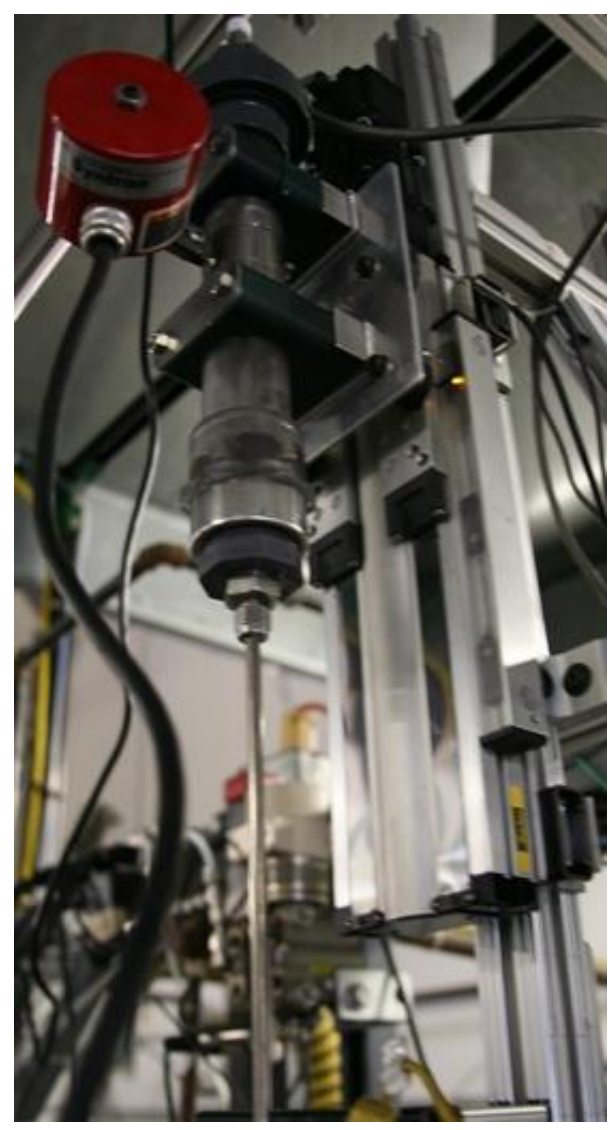

Figure 6: Solids feeder with attached vibrator

\section{Fuel injector}

In order to achieve high fuel particle heating rates, a long water-cooled injector is used. The tip of the injector reaches into the heated zone of the furnace, such that after exiting the injector, the solid fuel particles immediately enter the high-temperature region of the reaction zone. This 
design achieves particle heating rates exceeding $10^{4} \mathrm{C} / \mathrm{s}$. In a baseline configuration, the injector is installed into the reactor tube such that the tip of the injector is positioned at the top of the heated zone, attaining the maximum reaction zone length of 36 ".

The desired distribution of the gas flow inside the reaction zone is that characteristic of the idealized plug flow, with uniform velocity profile independent of axial or radial position. To minimize fuel particle impingement on the reactor tube wall and to maximize the particle collection efficiency by the collector probe, the jet of the fuel particles must remain narrow and centered along the reactor tube centerline. While the initial diameter of the particle jet at the exit of the injector tip is equal to the injector tube ID (0.18"), the jet width increases as particles travel down the reaction zone due to diffusion, turbulent mixing, and reacting flow effects.

In order to visualize the flow inside the reactor tube, a 1:1 scale model of the reactor constructed from a transparent acrylic tube was used as shown in Figure 7. The actual injector assembly was utilized to inject the fuel particles into the acrylic flow tube. A 1" OD stainless steel tube connected to the inlet of the vacuum pump was employed at the bottom of the acrylic flow tube to simulate the collector probe. A vacuum pump and a high-resolution needle choke valve were used to maintain desired flow through the acrylic tube. Inlet primary and secondary gas flows were controlled by mass flow controllers (MFCs). Visual observation confirmed that the fuel particle jet remained narrow over the whole length of the acrylic tube (36"), as illustrated in Figure 8. Particle collection efficiency in the cold flow model using a stainless steel cyclone was measured to be approximately $93 \%$. While it is expected that the turbulence and diffusional effects will play a larger role under the high temperature, the cold flow visualization study qualitatively confirmed steady behavior and low dispersion of the particle jet. 


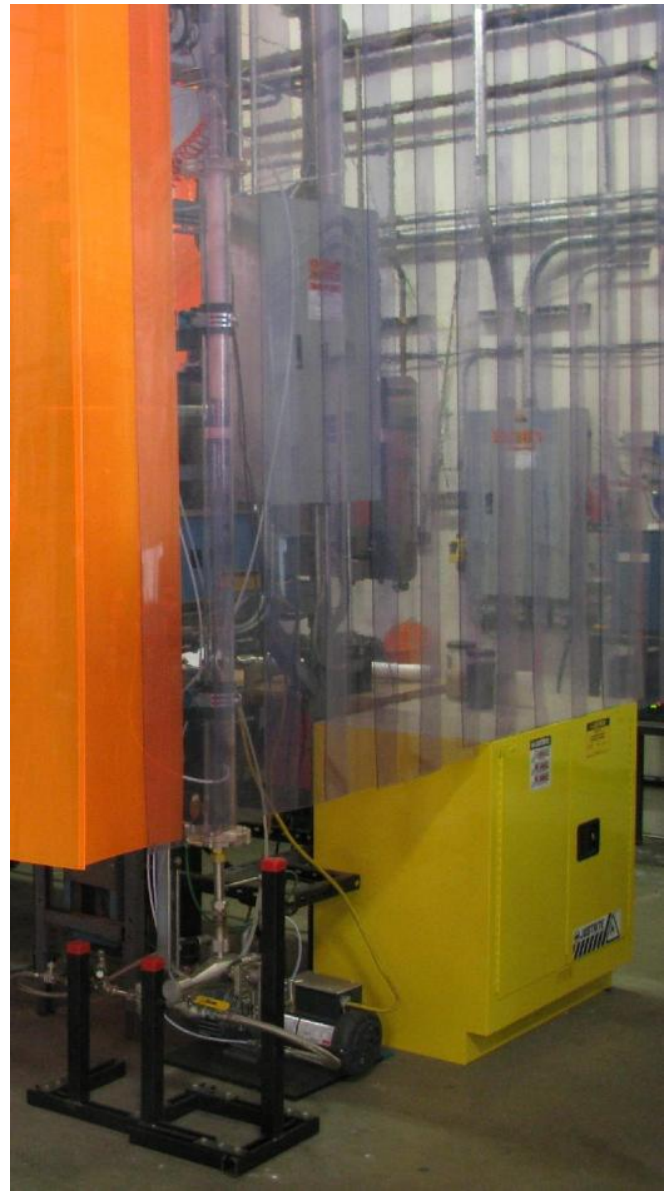

Figure 7. Cold flow model.

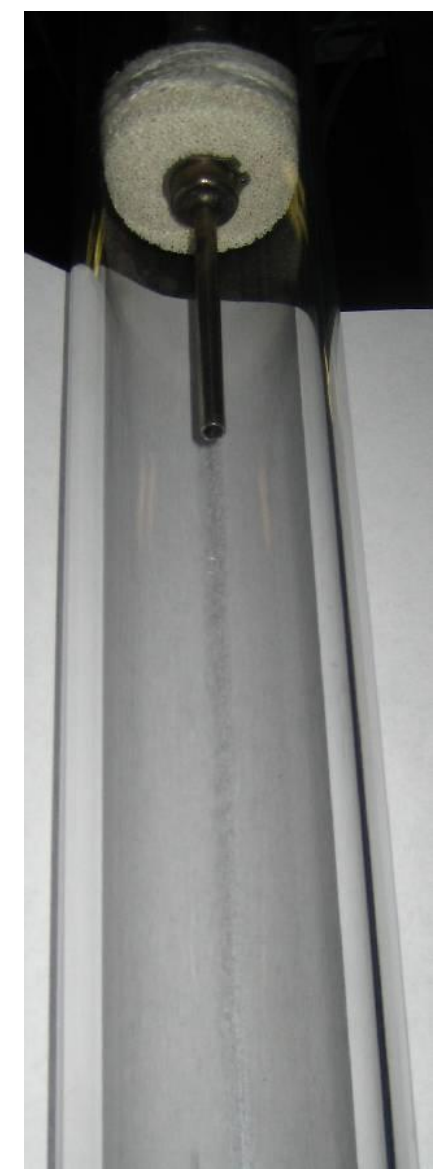

Figure 8. Coal particle jet.

\section{Collector probe}

The BSG water-cooled collector probe is designed after probes used previously at Sandia National Labs (e.g. Fletcher [24]) and in several Brigham Young University (BYU) studies (e.g. $\mathrm{Ma}$ [25]). The collector probe is used to collect the whole sample stream flowing out of the reactor, promptly quench the sample flow to "freeze" its chemical composition, and transport the sample to the downstream separation devices. An inert gas (typically nitrogen) is used to rapidly quench the hot sample gas via high-velocity jets issuing through 16 small diameter holes located immediately downstream of the collector probe tip. The second fraction of the inert gas seeps through the innermost tube made of sintered stainless steel, creating an inert gas blanket between 
the sample flow and the tube surface, substantially reducing deposition on the probe wall. The quench gas is cooled by the contact with a water-cooled jacket.

The collector probe tip has a tapered conical shape with the outer surface sloped at 30 degrees angle. This design prevents the char particles that deposit on the outer tip surface from reaching the sampling system if they later become dislodged.

\section{Char separation}

The sample stream quenched with the inert gas comes out of the collector probe. In general, this stream can contain solid particles (char, ash and soot), liquid droplets (tar), and various gaseous compounds. Upon quenching, some of the high boiling point compounds can condense on the surface of the existing particles or form aerosols.

A stainless steel cyclone manufactured by URG Corporation is used directly downstream of the collector probe to separate larger solid particles, primarily consisting of partially converted char. Designed for diesel emissions applications, this cyclone has a nominal particle cutoff point (particle size captured with $50 \%$ efficiency) of $10 \mu \mathrm{m}$ at a flow rate of 16.7 SLPM. It should be kept in mind that the cyclone cutoff point will change if the particle density changes. Initial tests were performed with the cyclone installed in a horizontal orientation, since this configuration minimizes the length of the sampling lines. However, it was found during the cold flow tests that substantial fraction of the coal particles was collected in the conical section of the cyclone, and did not reach the collection cup as intended. Since particles collected outside of the collection cup can become re-entrained into the sample flow, reducing the separation efficiency, it was decided to use the cyclone in a standard vertical orientation. To increase the cyclone's holding capacity, the standard stainless steel collection cup can be replaced by a large capacity $(500 \mathrm{~mL}$ or more) glass jar connected to the bottom of the cyclone via a section of a large diameter vacuum rubber hose and two stainless steel ring clamps.

A second, smaller stainless steel cyclone can be used as standalone or in series with the larger cyclone. Also designed for diesel emissions applications, the smaller cyclone has a nominal particle cutoff point of $2.5 \mu \mathrm{m}$ at a flow rate of 16.7 SLPM.

As the sample stream passes the cyclone, solid particles larger than the cyclone cutoff diameter are efficiently separated from the gas stream and captured in the cyclone's collector. Particles with sizes below the cyclone cutoff point have low collection efficiency in the cyclone and mostly remain suspended in the gas stream after passing through the cyclone. Calculations show that at baseline conditions (5 SLPM secondary gas flow plus 30 SLPM quench gas flow), the large cyclone has the cutoff point of approximately $6.6 \mu \mathrm{m}$, while the small cyclone at the same gas flow rate has the cutoff point of $2.2 \mu \mathrm{m}$ for particles with density of $500 \mathrm{~kg} / \mathrm{m}^{3}$. When feeding $100-\mu \mathrm{m}$ coal particles, both cyclones will be able to capture most of the char formed 
under pyrolysis or gasification conditions under residence time and temperature conditions of the BSG.

\section{Tar and soot separation}

The small particles that pass through the cyclones are comprised of char fragments, soot particles, and condensed tars and aerosols. Many of the tar compounds formed during devolatilization of coal have boiling points exceeding $300^{\circ} \mathrm{C}$. Most of these tar compounds are solid at room temperatures.

Based on previous sample collection experience acquired mostly at BYU, tar and soot were collected on flat polycarbonate filters. Initially, a $90-\mathrm{mm}$ diameter filter $(1.0 \mu \mathrm{m}$ openings $)$ was used to collect the tar and soot sample. However, at coal feeding rate of approximately $30 \mathrm{~g} / \mathrm{hr}$, the filter got plugged only few minutes after coal feed started. Subsequent sample system configurations use $142-\mathrm{mm}$ diameter flat polycarbonate filters, with $1.0 \mu \mathrm{m}$ openings.

Figure 9 shows one of the tested sample system configurations, with large and small cyclones connected in series, and two 142-mm filters in parallel configuration. Two three-way valves allowed alternate operation of the filters. When the first filter became loaded with sample material, the flow was switched to the second filter. While the second filter was collecting sample, the first filter was disconnected, the loaded filter media replaced with a clean media, and the first filter line was assembled again. Subsequently, the flow was switched again and the

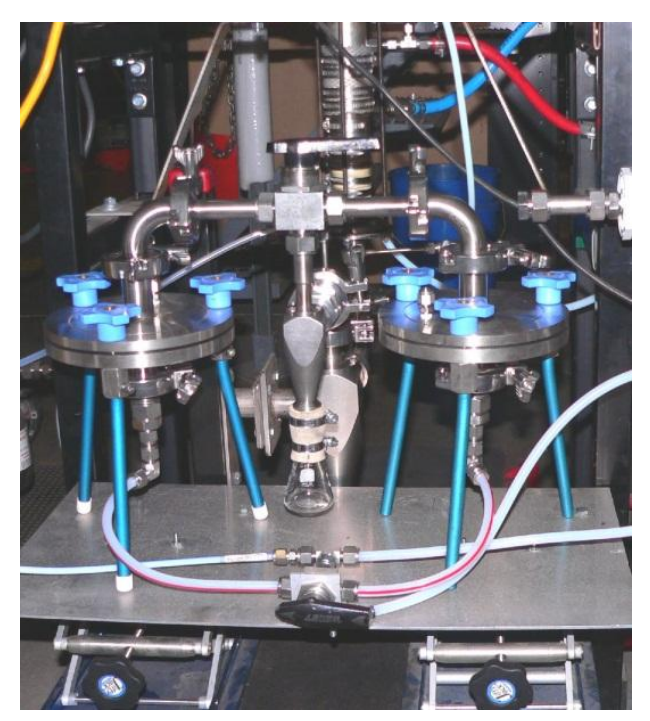

Figure 9. Two cyclones, two flat filters configuration.

operation repeated. Unfortunately, the quick plugging of the filters made this method of 
operation impractical at coal feed rates of $20-30 \mathrm{~g} / \mathrm{hr}$, since it required full attention of two test operators.

Based on the results of the shakedown tests, it was decided to use a somewhat different filter configuration that includes a 142-mm flat filter in parallel with a high-capacity pleated filter. The tar samples for subsequent analyses were collected periodically on 142-mm polycarbonate filter media. While collecting a representative filter sample from a pleated filter element might be difficult or even impossible, this design allowed a stable long-term operation of the facility and adequate sample collection times for accurate analysis of gaseous species, cyclone catch, and polycarbonate filter catch.

\section{PREPARATION AND EVALUATION OF FEED SAMPLES}

\section{Fuel Sample Preparation}

Care in sample preparation is essential for the BSG experiments to achieve stable and reliable fuel feed into the reactor. The vibratory feeder of the BSG facility works best with fuel samples having a narrow particle size distribution (PSD). Coal and biomass samples will be sieved to obtain desired PSD. The target coal particle size range is $90-106 \mu \mathrm{m}(-140+170 \mathrm{mesh})$. Target biomass particle sizes will be established for each biomass based on requirements of stable and reliable feed. Additionally, sieve analysis of solid fuels will be performed to establish or verify particle size distribution of external samples.

Sample preparation for this project will be performed utilizing the fuel processing station shown in Figure 10. This fuel processing station includes a jet mill with interchangeable screens, a rapping sieve shaker, a laboratory balance, and a complete set of sieves. The fuel processing station is capable of operating under inert gas purge if desired.

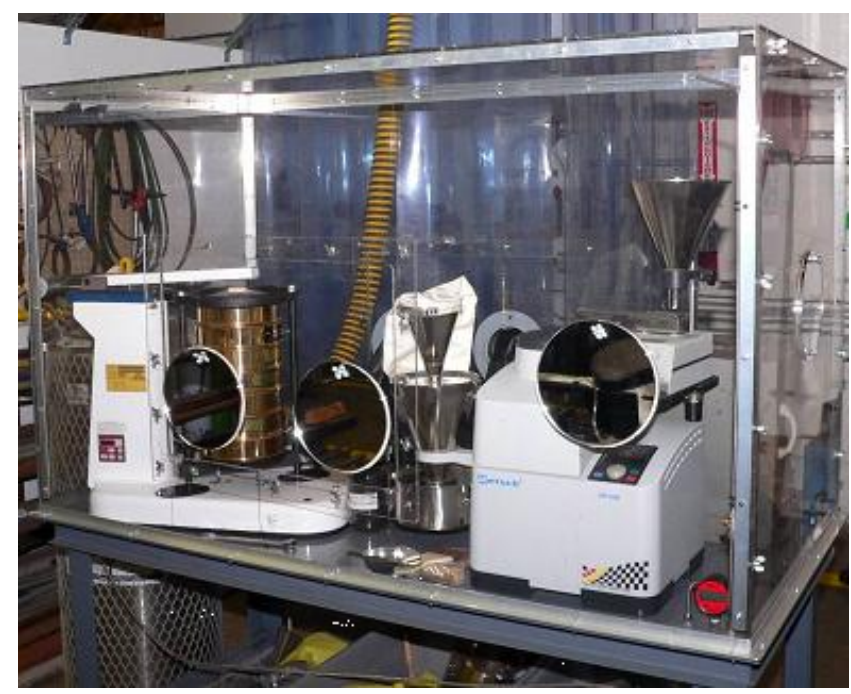

Figure 10. Fuel processing station. 


\section{Biomass Sample Grinding}

Operation of the bench scale gasifier (BSG) includes feeding of the solid fuel particles at a specified mass flow rate into an externally heated reactor vessel. The fuel particles are entrained by the gas flow and undergo devolatilization and gasification reactions as they move downwards through the reactor. Particle residence times in the heated zone of the reactor primarily depend upon the gas velocity of gasifying agent and the particle settling velocity. The settling velocity, in turn, is a function of particle size, shape, mass, and the gas characteristics such as density and viscosity. The size of the solid fuel particles must be properly selected to provide desired residence time in the reactor. The heating rate of the particle is also affected by the particle size and shape. Additionally, feedstock particle size and morphology affect the fuel feeding characteristics. The latter aspect is of particular importance for the very low feed rates used in the BSG (approximately from 2 to 30 grams per hour). The fuel feeding into the reactor must be stable and smooth in order to minimize variability of the gasification process and to achieve high measurement accuracy required in the current program.

The original project plan anticipated use of the Retsch ZM200 centrifugal mill (also called jet mill) for grinding biomass samples to achieve desired particle sizes (typically below $250 \mu \mathrm{m}$ ). Some of the sized particle samples generated by jet mill presented feeding problems (uneven flow and plugging), most notably the pine sawdust sample with the particle sizes in the 75-106 $\mu \mathrm{m}$ range. Due to the batch operation of the jet mill and low yields of the biomass particles in the desired individual size ranges of 150 to $250 \mu \mathrm{m}(-60+100$ US mesh); 106 to $150 \mu \mathrm{m}(-100+140$ US mesh); and 75 to106 $\mu \mathrm{m}(-140+200$ US mesh), significant amount of manual labor was required to prepare these biomass samples using the jet mill.

A hammer mill (FitzMill Model "D” Comminuting Machine, hereinafter, FitzMill) was installed and commissioned for preparation of ground biomass samples. Figure 11 illustrates the FitzMill installed in one of the test cells at the Fuel Conversion Laboratory in Irvine. This hammer mill allows much higher throughput than the jet mill, substantially reducing labor requirements for sample preparation. In addition, the FitzMill is optimized for grinding and particle size control of hard-to-grind materials, such as fibrous biomass. The optimized mill configuration results in production of clean-cut particles with well-defined sizes, as well as improved particle flowability and sieving characteristics. The yields of the biomass particles in the desired size ranges (75 to $250 \mu \mathrm{m})$ are substantially improved over those of the jet mill, as illustrated by Figure 12. 


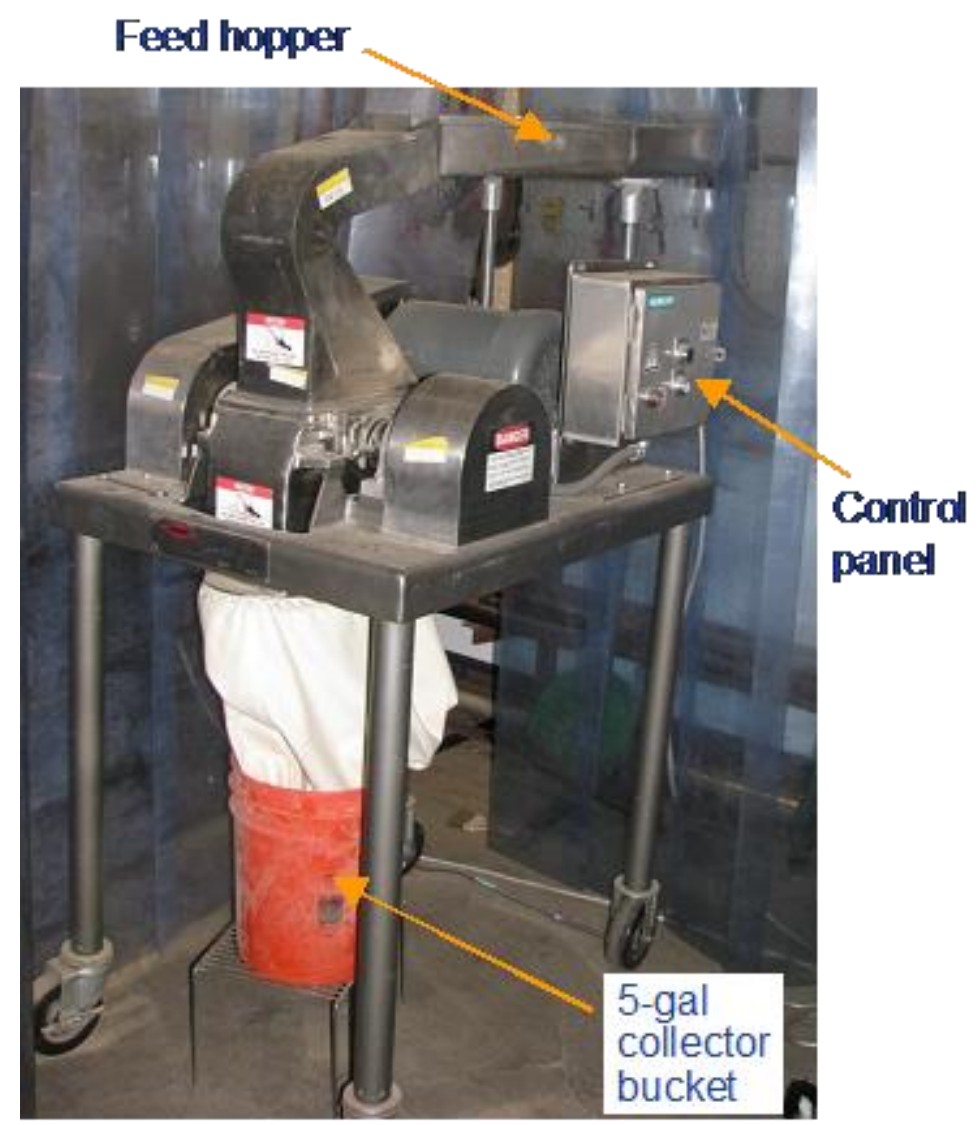

Figure 11. FitzMill installed in the test cell.

A detailed Safety Review of the FitzMill operation has been performed in accordance with the GE Global Research Management of Change Policy and Environmental, Health and Safety policies. The Safety Review included assessment of various risks associated with personnel safety and potential equipment damage. As a result of the Safety Review, a standard operating procedure (SOP) for the FitzMill operation has been created. The SOP addresses specific health and safety hazards, emergency shutdown procedures, normal system startup, operation, and shutdown procedures, maintenance and cleaning, and operator training. While the Safety Review and the standard operating procedure are crucial to ensure the safe and reliable mill operation, these procedures pertain to the facilities owned by GE Global Research. Therefore, all activities on preparing and conducting the Safety Review and creating the SOP have been funded by the internal GE GR programs, and not by the current program sponsored by DOE.

Substantial amounts of ground and sieved samples of switchgrass, pine sawdust and corn stover were prepared using the FitzMill. Standard Laboratories, Inc. (Casper, WY) performed the 
ultimate and proximate analyses of these samples. The results of these analyses are listed in Table 2.

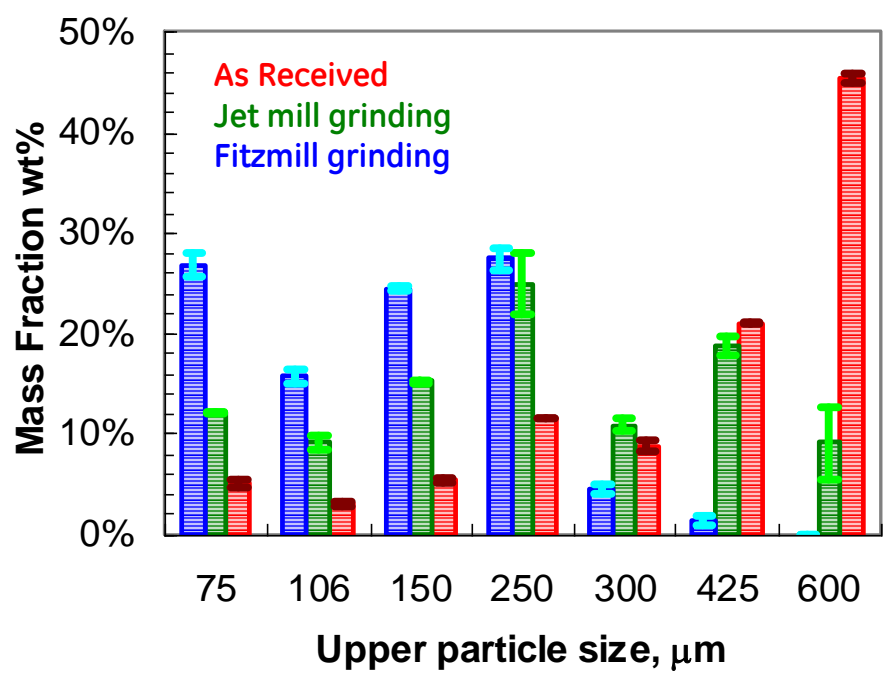

Figure 12. Switchgrass particle size distribution after grinding in jet mill and FitzMill.

Table 2. Ultimate and proximate analysis of the biomass fuels

\begin{tabular}{|c|c|c|c|c|c|c|}
\hline Biomass & \multicolumn{2}{|c|}{ Switchgrass } & \multicolumn{2}{|c|}{ Pine Sawdust } & \multicolumn{2}{|c|}{ Corn Stover } \\
\hline \multicolumn{7}{|l|}{ PROXIMATE } \\
\hline & as rec'd & dry & as rec'd & dry & as rec'd & dry \\
\hline$\%$ Moisture & 9.65 & & 7.46 & & 7.62 & \\
\hline$\%$ Ash & 6.91 & 7.65 & 0.34 & 0.37 & 4.32 & 4.68 \\
\hline$\%$ Vol. Matter & 67.40 & 74.60 & 74.82 & 80.85 & 72.98 & 79.00 \\
\hline \% Fixed Carbon & 16.04 & 17.75 & 17.38 & 18.78 & 15.08 & 16.32 \\
\hline \multicolumn{7}{|l|}{ ULTIMATE } \\
\hline & as rec'd & dry & as rec'd & $d r y$ & as rec'd & dry \\
\hline \% Moisture & 9.65 & & 7.46 & & 7.62 & \\
\hline$\%$ Ash & 6.91 & 7.65 & 0.34 & 0.37 & 4.32 & 4.68 \\
\hline$\%$ Carbon & 41.98 & 46.46 & 47.34 & 51.16 & 43.44 & 47.02 \\
\hline$\%$ Hydrogen & 4.44 & 4.91 & 5.41 & 5.85 & 4.87 & 5.27 \\
\hline$\%$ Nitrogen & 0.43 & 0.48 & 0.05 & 0.05 & 0.78 & 0.84 \\
\hline$\%$ Total Sulfur & 0.12 & 0.13 & 0.00 & 0.00 & 0.07 & 0.08 \\
\hline$\%$ Oxygen (diff.) & 36.47 & 40.37 & 39.40 & 42.57 & 38.90 & 42.11 \\
\hline
\end{tabular}




\section{Feeder performance}

Inadequate feeder performance was observed for the biomass samples obtained by grinding in the jet mill. Large feed rate variations (up to $35 \%$ relative deviation) were observed for the switchgrass sample with particle sizes in the range of 150 to $250 \mu \mathrm{m}(-60+100$ US mesh), as shown in Table 3 of the Quarterly Technical Progress Report No. 2, Reporting Period: January 1, 2009 - March 31, 2009.

Several improvements to the solid fuel feeding system were made. These improvements included reducing internal diameter of the feeder reservoir while simultaneously increasing the translational speed of the linear table, as well as increasing the intensity of the feeder reservoir vibration. The feeder vibrator was adjusted to medium amplitude for coal-only feeding and to maximum amplitude for biomass and coal/biomass mixture feeding. Coal/biomass mixtures were prepared using selected biomass particle sizes that displayed best feeding performance. A continuous feed rate measurement method was employed to accurately quantify the feeder performance. The feeder was disconnected from the reactor, and the feeder output was directed to a collector placed on a scale. The weight of the collector with the collected sample was recorded with a time interval of 5 seconds. Figure 13 shows the results of the feeding test for switchgrass sample with the particle size 75 to $106 \mu \mathrm{m}(-140+200$ US mesh).

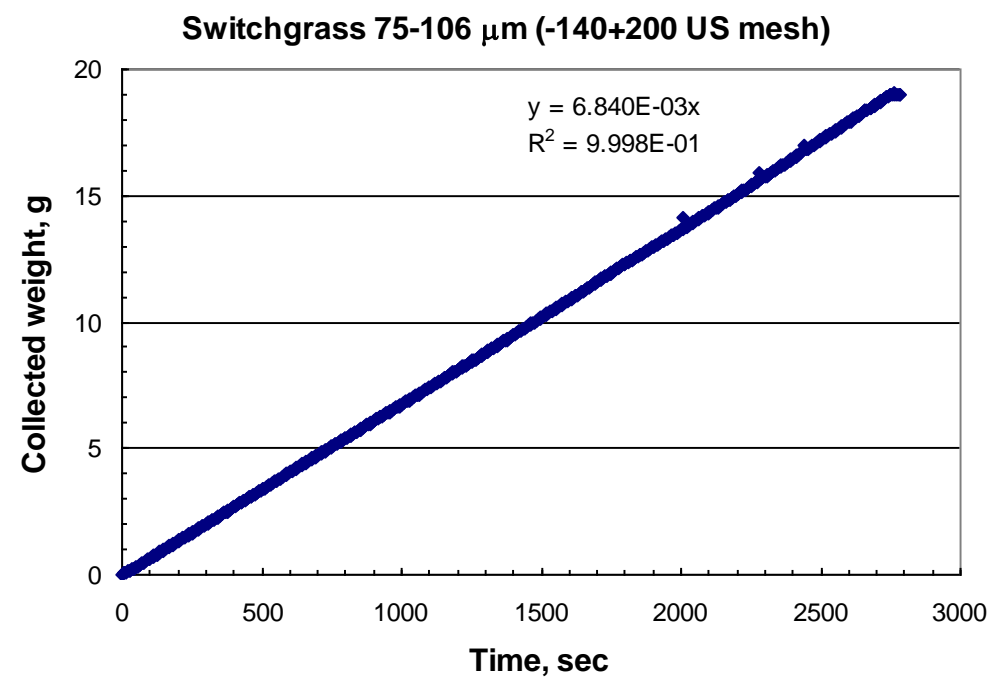

Figure 13. Switchgrass feeding test. 
Table 3 illustrates the variation of the observed feed rate calculated as the amount of sample collected over 3-minute intervals. As can be seen from Table 3, the feed rate remains stable over about 1-hour feeding test duration, with coefficients of variation (COV) in the range of about 3 to $7 \%$.

\section{Preparation and Evaluation of Coal/Biomass Mixtures}

Several mixtures of ground bituminous coal and biomass samples were prepared by mixing the feedstocks overnight in a rotary mixer (US Stoneware Model 755). The following particle sizes were used for mixture preparation: bituminous coal 90 to $106 \mu \mathrm{m}(-140+170$ US mesh); switchgrass 75 to $106 \mu \mathrm{m}(-140+200$ US mesh); pine sawdust 150 to $250 \mu \mathrm{m}(-60+100$ US mesh). Mixtures of $70 \%$ bituminous coal and 30\% biomass (dry coal and dry biomass weight) were prepared. The feeding characteristics of these samples were assessed as described in the previous section.

The initial homogeneity of prepared coal/biomass mixture was evaluated by taking samples from three spatially separate locations in the mixing jar and analyzing them in the thermogravimetric analyzer (TGA). The segregation of the coal/biomass mixtures in the vibrating fuel feed reservoir during the feeding tests was evaluated by collecting at least three separate samples: at the beginning, in the middle, and close to the end of the feeding test. These samples were also analyzed using TGA. 
Table 3. Feed stability test results

\begin{tabular}{|c|c|c|c|}
\hline \multirow{2}{*}{$\begin{array}{c}\text { Collection } \\
\text { stop time, } \\
\text { minutes }\end{array}$} & \multicolumn{3}{|c|}{ Collected weight, grams } \\
\cline { 2 - 4 } & $\begin{array}{c}\text { Coal } \\
906 \mu \mathrm{m}\end{array}$ & $\begin{array}{c}\text { Switchgrass } \\
75-106 \mu \mathrm{m}\end{array}$ & $\begin{array}{c}\text { Coal/Switchgrass } \\
90-106 / 75-106 \mu \mathrm{m}\end{array}$ \\
\hline 3 & 1.46 & 1.19 & 1.30 \\
6 & 1.48 & 1.21 & 1.34 \\
9 & 1.46 & 1.24 & 1.39 \\
12 & 1.48 & 1.23 & 1.40 \\
15 & 1.46 & 1.21 & 1.35 \\
18 & 1.41 & 1.19 & 1.40 \\
21 & 1.17 & 1.23 & 1.44 \\
24 & 1.33 & 1.25 & 1.43 \\
27 & 1.49 & 1.27 & 1.13 \\
30 & 1.45 & 1.29 & 1.33 \\
33 & 1.50 & 1.19 & 1.43 \\
36 & 1.49 & 1.26 & 1.51 \\
39 & 1.40 & 1.28 & 1.49 \\
42 & 1.34 & 1.31 & 1.49 \\
45 & 1.49 & 1.28 & 1.48 \\
48 & 1.42 & & 1.53 \\
51 & 1.39 & & 1.47 \\
54 & 1.59 & & 1.46 \\
57 & 1.63 & & \\
\hline Average & 1.44 & 1.24 & 0.10 \\
Std. Dev. & 0.10 & 0.04 & \\
COV & $6.8 \%$ & $3.2 \%$ & \\
\hline
\end{tabular}

Figure 14 illustrates the typical TGA test data for a mixture of bituminous coal and switchgrass. Initially, the sample is heated in the stream of inert gas (typically, nitrogen). As can be seen from Figure 14 , the moisture evaporation starts around $100^{\circ} \mathrm{C}$, while rapid volatiles release starts at approximately $260-290^{\circ} \mathrm{C}$. Once the pyrolysis is finished, as can be witnessed by stabilization of the sample weight in the time interval from about 3500 to about 5200 seconds, a flow of preheated air is started through the TGA cell. The residual weight after approximately 5600 seconds in Figure 14 corresponds to residual ash. The amounts of released volatiles (including moisture), char, and ash can are evaluated from the TGA data as shown in Figure 14.

Table 4 lists the yields of volatiles, ash-free char, and ash obtained using TGA and averaged for two replicate samples of the bituminous coal and two replicate samples of the switchgrass. Based 
on the average data for coal and switchgrass, the expected values for a mixture of coal and switchgrass (70\% coal and 30\% switchgrass on dry coal and dry biomass basis) were calculated as shown in Table 5. Measurement ranges of various Chemcassette ${ }^{\mathrm{TM}}$ sensing tapes. The average measured values for the three samples collected from spatially separate locations in the mixing jar (called "Spatial Variation") and the three samples collected during the feeding test as described above (called "Segregation") are also listed. As can be seen from Table 5. Measurement ranges of various Chemcassette ${ }^{\mathrm{TM}}$ sensing tapes. The coefficients of variation between both spatial variation samples and segregation samples are small. Both these sets of data are close to the expected values calculated as a linear combination of coal and switchgrass values at 70/30 mixing ratio. The largest variation is observed in the ash content of the samples. It appears that this variation is caused by the sample-to-sample variation and the relatively small sample size (approximately $50 \mathrm{mg}$ ).

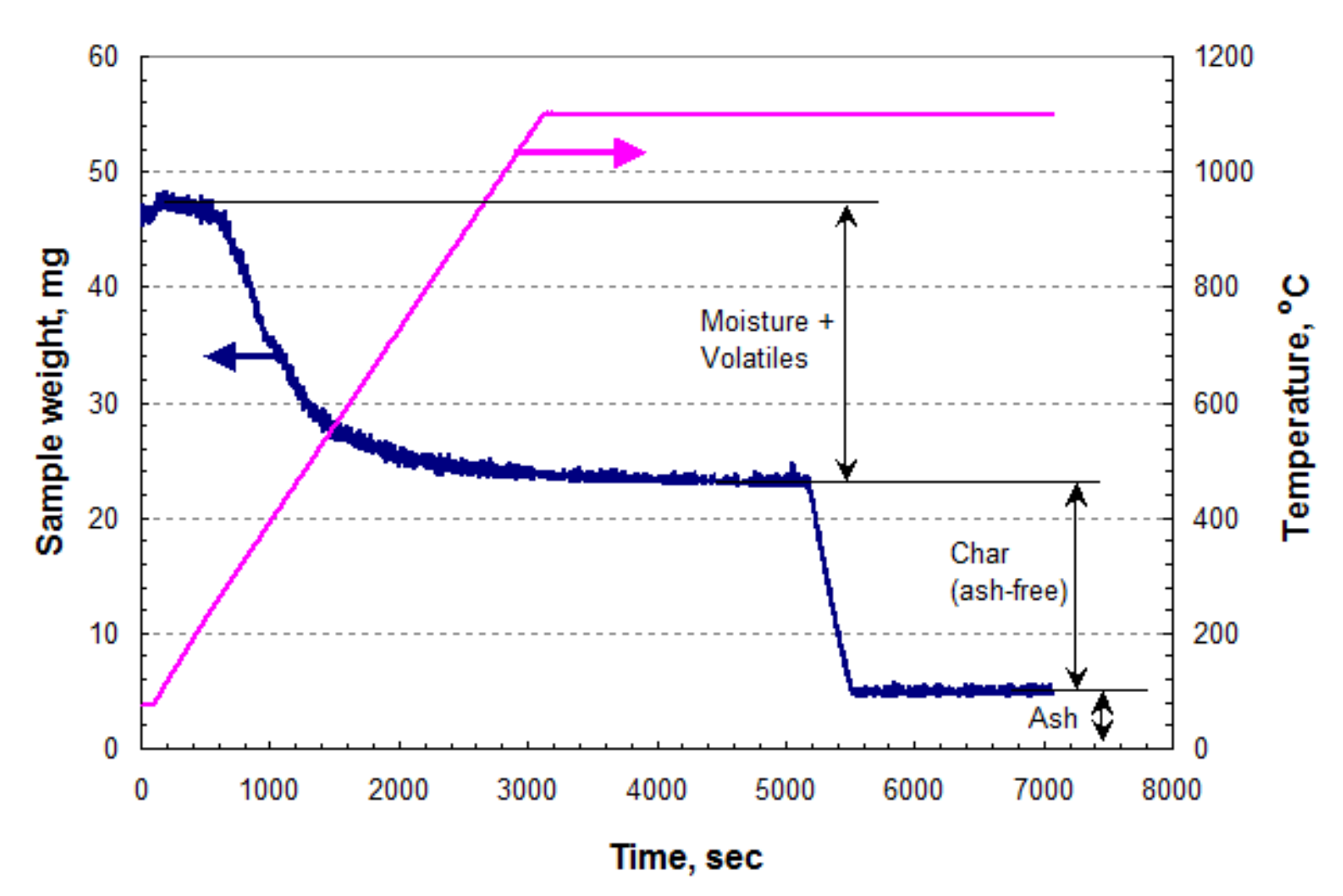

Figure 14. Typical TGA test data for bituminous coal/switchgrass mixture.

Table 4. Yields of volatiles, ash-free char, and ash, measured in the TGA.

\begin{tabular}{|c|c|c|c|c|c|c|c|c|c|c|c|c|c|}
\hline & \multirow{2}{*}{\multicolumn{3}{|c|}{ Bituminous coal }} & \multirow{2}{*}{\multicolumn{3}{|c|}{ Switchgrass }} & \multicolumn{7}{|c|}{ Bituminous coal / Switchgrass mixture $(70 / 30)$} \\
\hline & & & & & & & \multirow{2}{*}{ Expected } & \multicolumn{3}{|c|}{ Spatial Variation } & \multicolumn{3}{|c|}{ Segregation } \\
\hline & Average & St. Dev. & $\mathrm{COV}$ & Average & St. Dev. & $\mathrm{COV}$ & & Average & St. Dev. & $\mathrm{cov}$ & Average & \begin{tabular}{|l|} 
St. Dev. \\
\end{tabular} & $\mathrm{cov}$ \\
\hline Moisture+Volatiles (\%) & 40.86 & 2.69 & $6.59 \%$ & 78.16 & 0.31 & $0.40 \%$ & 51.96 & 50.93 & 0.64 & $1.26 \%$ & 48.99 & 0.65 & $1.33 \%$ \\
\hline Char $(\%)$ & 51.51 & 0.07 & $0.14 \%$ & 14.36 & 1.10 & $7.68 \%$ & 40.62 & 39.64 & 0.69 & $1.73 \%$ & 40.54 & 0.65 & $1.59 \%$ \\
\hline Ash (\%) & 7.63 & 2.76 & $36.14 \%$ & 7.48 & 0.78 & $10.50 \%$ & 7.42 & 9.43 & 0.81 & $8.63 \%$ & 10.46 & 1.30 & $12.45 \%$ \\
\hline
\end{tabular}




\section{BENCH SCALE GASIFICATION TEST EQUIPMENT AND SAMPLE ANALYSIS}

\section{Gas species measurements}

\section{Continuous emission monitors CEMs}

Several emission monitors are used for continuous gas concentration readings during a BSG test run. Before entering the CEMs rack the sample gas is conditioned. A sample pump pressurizes to 3 psi a split stream of reactor gas. The pressurized gas then enters a gas chiller at $5^{\circ} \mathrm{C}$ to ensure no condensation in the analyzers. A Balston filter removes any remaining fine particles and aerosols from the sample gas before the analyzer manifold. A Servomex analyzer with single beam single wavelength photometric gas modules is used for carbon monoxide and carbon dioxide. A third Servomex module with a paramagnetic cell analyzer is used for oxygen measurement. A Siemens Calomat thermal conductivity gas analyzer is used for measuring Hydrogen. A California analytical model 400 HCLD Analyzer with a heated chemiluminescent detector is used for oxides of nitrogen. A California analytical model ZRH gas analyzer with an infrared gas detection cell is used for sulfur oxides. The emission monitors are calibrated before each test run with calibration standard gases. After each run the zero and span level is checked to allow for any drift correction. There is measurable interference on several of the analyzers from species present in the reactor gases. Effort was made to compensate for these interferences by introducing a matrix of known gas mixtures to the CEMs rack. Strong interferences of $\mathrm{CO}_{2}$ were measured on the $\mathrm{CO}, \mathrm{H}_{2}$ and $\mathrm{SO}_{2}$ analyzer. The interference of $\mathrm{CO}_{2}$ on the $\mathrm{SO}_{2}$ analyzer made the readings unreliable.

\section{ChemCassette Analyzer}

An analytical gas detector based on Chemcassette ${ }^{\mathrm{TM}}$ technology was chosen for detection of minor gaseous species under the current program. The Chemcassette ${ }^{\text {TM}}$-based gas detectors manufactured by Honeywell Analytics have been used for toxic gas monitoring for over 25 years. These detectors, highly resistant to corrosive species and particulate matter, utilize an optical scanning system to detect the presence of gas by a color change on the chemically impregnated paper tape. Chemcassette ${ }^{\mathrm{TM}}$ technology is highly specific and reacts extremely fast to the presence of parts per billion ( $\mathrm{ppb}$ ) levels of many hazardous gases. Various gas monitors are available for analyzing gas species using gas-specific tapes in different measurement ranges.

During the current reporting period, a Chemcassette ${ }^{\mathrm{TM}}$ single point monitor (SPM) gas monitor was procured from Honeywell Analytics and installed in the BSG test cell. The overall appearance of the Chemcassette ${ }^{\mathrm{TM}}$ SPM monitor and a schematic representation of tapes exposed to different gaseous compounds are shown in Figure 15. A typical sampling time is about 15 seconds, with samples taken approximately every minute. Different types of sensing tapes are used for different compounds. Typically, a tape can be exchanged in about 2 minutes. 


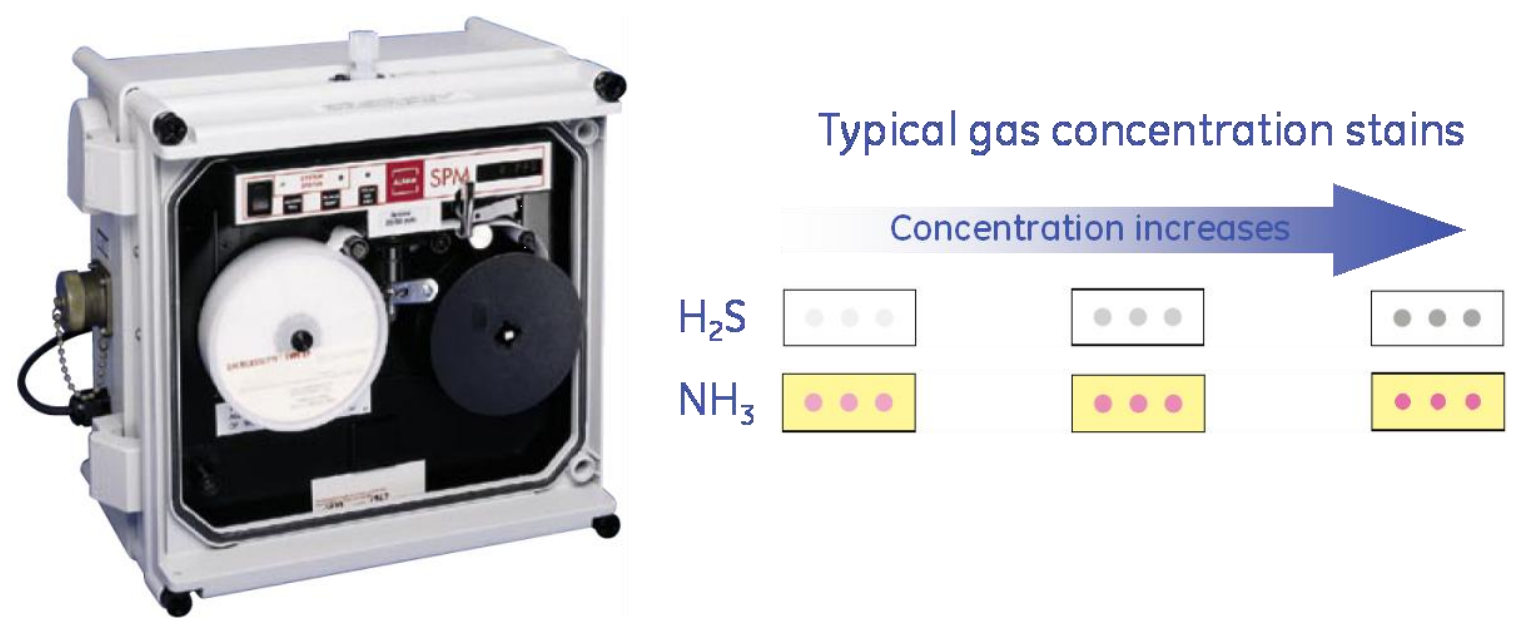

Figure 15. Chemcassette SPM gas monitor.

After extensive calibration, the Chemcassette ${ }^{\mathrm{TM}}$ SPM monitor has been used for the quantification of $\mathrm{HCN}, \mathrm{NH}_{3}$, and $\mathrm{H}_{2} \mathrm{~S}$ resulting from the gasification of coal, biomass, and coalbiomass mixtures in the BSG. Certified calibration gases were diluted using an Environics Series 4000 multi component gas mixer to generate a wide range of known gas concentrations for SPM monitor calibration. The chemical sensing tapes are designed for optimum performance at a relative humidity $(\mathrm{RH})$ between $30 \%$ and $60 \%$, a typical relative humidity range for room air.

BSG product gas is quenched with nitrogen in the collector probe, leading to substantial sample dilution with nitrogen. Typical relative humidity of quenched BSG gas is below 15-20\%. During initial SPM monitor testing, it was noticed that the SPM monitor response to each measured species could vary substantially, depending on the relative humidity of the sample gas. To ensure accurate and reproducible data, a sample gas humidifier system was assembled following SPM manufacturer's recommendations and installed. Figure 16 shows a schematic of humidifier system used with Chemcassette ${ }^{\mathrm{TM}}$ SPM gas monitor.

Another feature of the Chemcassette ${ }^{\mathrm{TM}}$ technology is a limited measurement range for each compound. Measurement ranges of various Chemcassette ${ }^{\mathrm{TM}}$ sensing tapes used in the current program are shown in Table 5. At concentrations above the measurement range, tape saturation occurs, while at concentrations below the measurement range, the tape sensitivity is insufficient. When the gas concentrations of interest in the BSG product gas stream exceeded the measurement limit of the SPM detector, humid air was used to dilute the sample gas such that the resulting concentration would fall into the tape applicability range. A tracer method was developed to accurately measure the dilution ratio. Carbon dioxide is measured upstream and downstream of the dilution point using two IR-based continuous emissions monitors. This $\mathrm{CO}_{2}$ tracer method provides a continuous and accurate measure of the dilution ratio. 


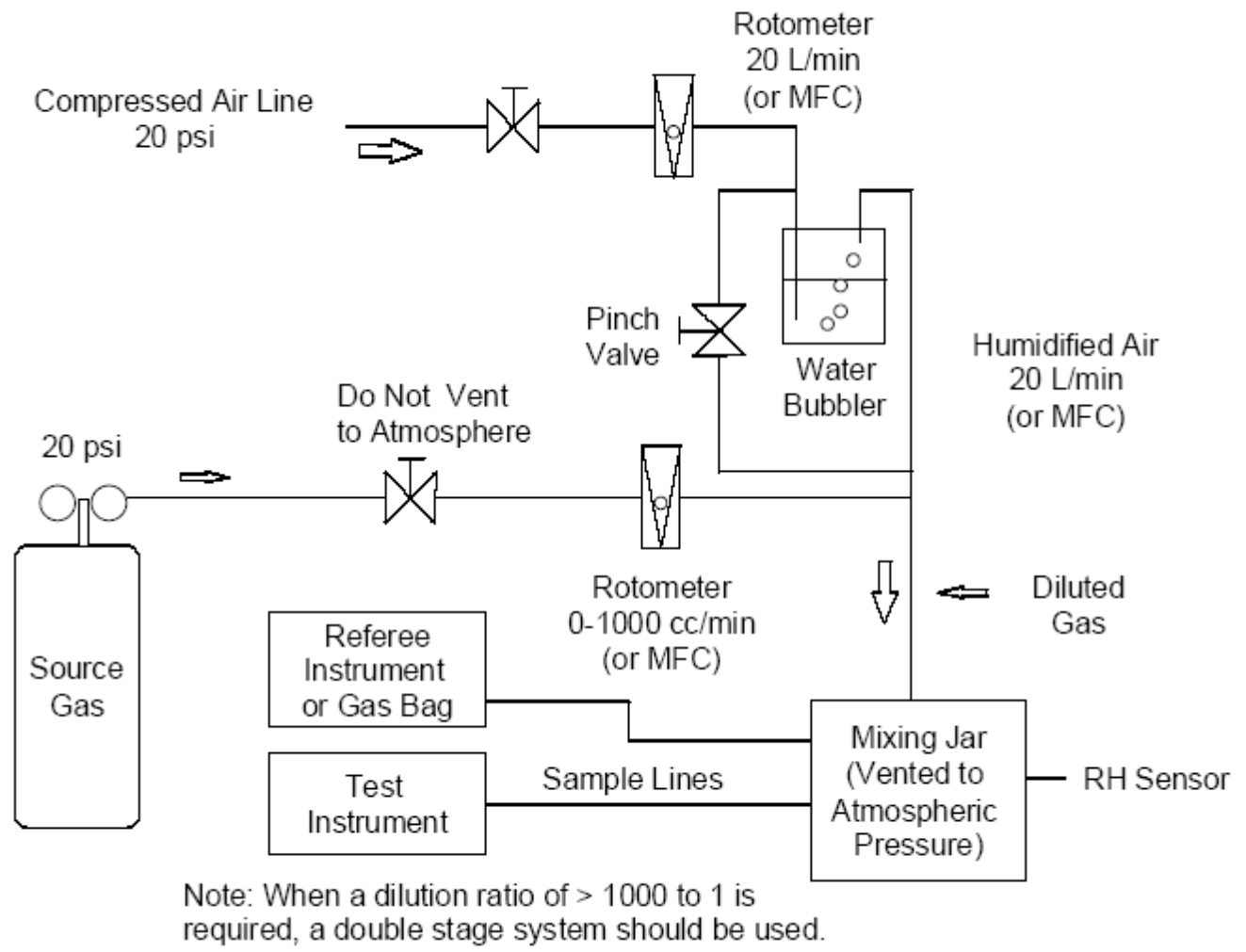

Figure 16. Schematic of the humidifier system used with Chemcassette ${ }^{\mathrm{TM}}$ SPM gas monitor.

Table 5. Measurement ranges of various Chemcassette ${ }^{\mathrm{TM}}$ sensing tapes.

\begin{tabular}{|c|c|}
\hline Compound & Measurement Range, ppmv \\
\hline $\mathrm{NH}_{3}$ & $2.6-75$ \\
\hline $\mathrm{HCN}$ & $1.1-30$ \\
\hline $\mathrm{H}_{2} \mathrm{~S}$ & $1.1-30$ \\
\hline
\end{tabular}

\section{Microscopic analysis of coal char}

Analyses of the char produced during baseline coal gasification tests was completed. Figure 17 shows a SEM photograph of the uncoated sample of char produced from a high-volatile (hvB) bituminous coal. The parent coal sample was dry sieved to obtain particles sized between 106 and $150 \mu \mathrm{m}(-100+140$ US mesh). The majority of the char particles formed under the baseline coal gasification conditions in the BSG appear to be cenospheric (Group I, according to Bailey et 
al. [26]), as described in the previous quarterly progress report (Quarterly Technical Progress Report No. 2, Reporting Period: January 1, 2009 - March 31, 2009). These particles have relatively thin walls (typically $5-10 \mathrm{~nm}$ thick) and large central voids. During gasification, the thin shell is rapidly consumed, leaving behind a carbonaceous skeleton that can fragment during later stages of the gasification. These observations are in agreement with literature data on bituminous coal gasification at fast heating rates (see, for example, Wall et al. [27]).

The small bright speckles clearly seen in Figure 17 have been identified as separate mineral particles using the electron microprobe analysis (EPMA). These mineral particles mostly consist of the $\mathrm{K}, \mathrm{Al}, \mathrm{Mg}$, and $\mathrm{Na}$ silicates, consistent with the mineralogical analysis of the coal ash. During gasification of the carbonaceous shell of the cenospheric particles such as those shown in Figure 17, these mineral inclusions can be liberated as individual small particles and get entrained in the syngas stream. Due to their small size (from sub-micron to several $\mu \mathrm{m}$ in diameter), these particles may remain suspended in the gas stream and penetrate through the syngas cleaning equipment, with subsequent deposition on the Fisher-Tropsch catalysts used for syngas conversion to liquid fuels. Therefore, understanding of the char morphology and composition as well as the nature and modes of occurrence of the inorganic materials is important for predicting the behavior of the residual inorganic particles suspended in the product gas stream and their effects on the downstream gas cleaning equipment and Fisher-Tropsch catalysts.

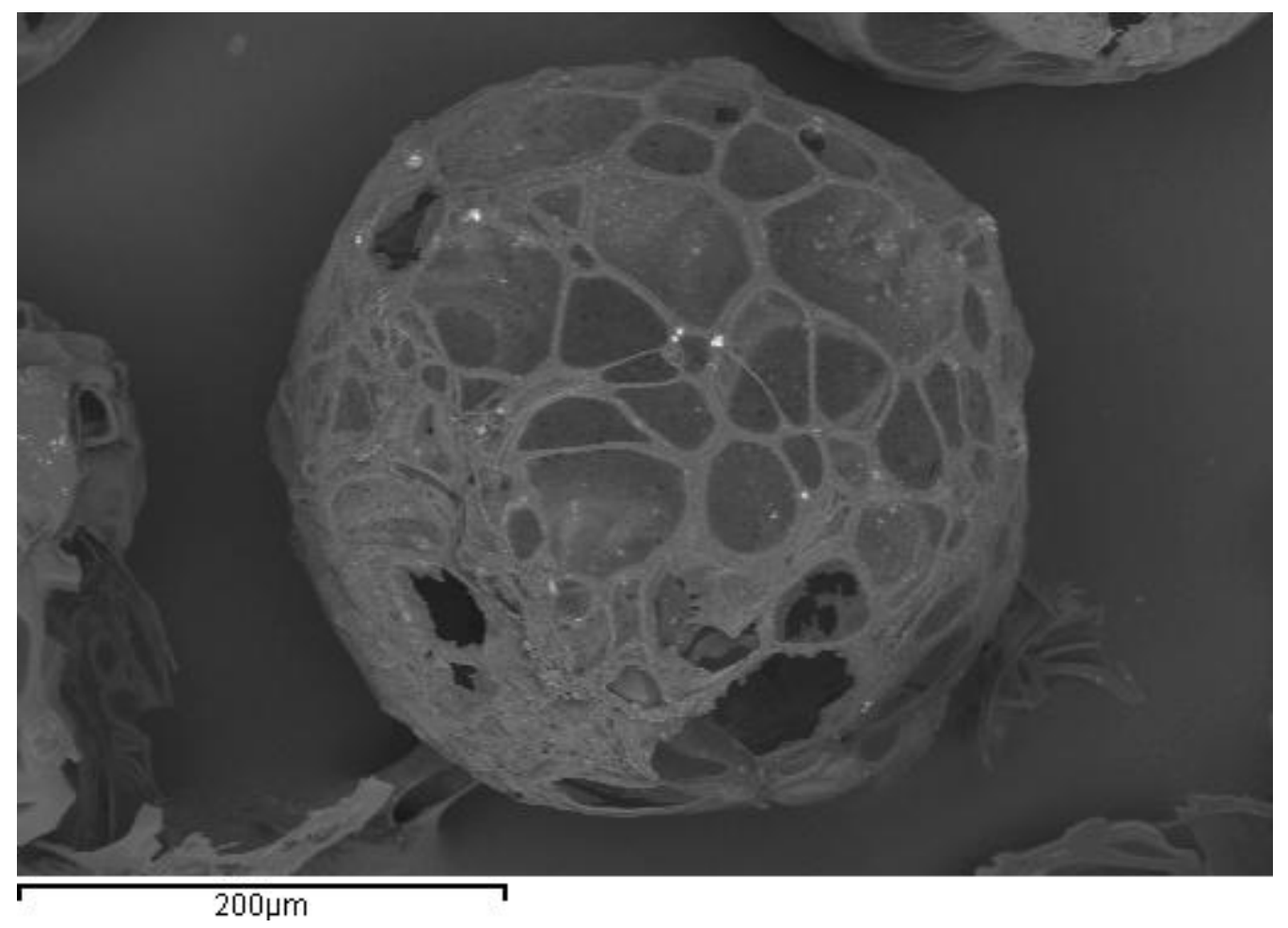

Figure 17. SEM photograph of bituminous char particle (uncoated). 


\section{Minor and Trace Element Speciation}

Analysis of relative amounts of each element in cyclone catch vs. filter catch enables element speciation between volatilized and non-volatilized fractions. During the project, minor and trace element concentrations measured in the cyclone catch and the filter catch samples obtained during both passes through the BSG were corroborated by assuming that the volatile elements formed during the first pass do not interact with species in the second pass through the BSG. In calculating volatilities, the minor and trace element concentrations measured during the second pass were scaled to the same char feeding rate in the second pass as the char generation rate in the first pass. The uncertainty in volatility calculations were calculated from the gas concentrations measurement uncertainties during both passes using the Design for Six Sigma (DFSS) statistical tools. The ICP analyses were repeated twice for each cyclone catch sample to access analytical method reproducibility. However, the analytical method reproducibility for filter catch samples formed in the second pass through the BSG could not be established due to the small quantities of material in these samples.

Volatility of elements formed during the first pass in the BSG has been defined as

$$
\text { Volatility }=\frac{W_{(\text {filtercatch }) 1}}{W_{(\text {filtercatch }) 1}+W_{(\text {cyclonecat }) 1}}
$$

Volatility of each element under the 'two-pass' approach has been calculated as

$$
\text { Volatility } y_{2}=\frac{W_{(\text {filtercatch }) 1}+W_{(\text {filtercatch }) 2}}{W_{(\text {filtercatch }) 1}+W_{(\text {filtercatch }) 2}+W_{(\text {cyclonecat }) 2}}
$$

where $W_{\text {filter catch }}$ and $W_{\text {cyclone catch }}$ are the weight fractions of the element in filter catch and cyclone catch, and subscripts 1 and 2 refer to the first pass and the second pass, respectively. As described in the previous progress reports, minor and trace elements can be divided into two groups: those that displayed very low volatility (non-volatile elements, including $\mathrm{Al}, \mathrm{Ca}, \mathrm{Fe}, \mathrm{Ti}$, $\mathrm{Si}, \mathrm{V}, \mathrm{Ba}, \mathrm{Th}, \mathrm{U}$ ) and those that showed substantial volatility (volatile elements, including $\mathrm{K}, \mathrm{Na}$, $\mathrm{Co}, \mathrm{Cu}, \mathrm{As}, \mathrm{Se}, \mathrm{Rb}, \mathrm{Mo}, \mathrm{Sb}, \mathrm{Pb}$ ).

Enhanced volatilization of $\mathrm{Na}$ and $\mathrm{K}$ can lead to increased deposit formation on heat transfer surfaces and downstream gas clean-up equipment in a full-scale gasifier. As observed earlier and described in the previous progress reports, the volatility of $\mathrm{Na}$ and $\mathrm{K}$ calculated using the "twopass' approach increases with increasing temperature, while being essentially independent of the $\mathrm{O} / \mathrm{C}$ ratio.

The most volatile analyzed elements are $\mathrm{Pb}, \mathrm{Sb}, \mathrm{As}$, and $\mathrm{Se}$, while $\mathrm{Cu}, \mathrm{Rb}, \mathrm{Mo}$, and $\mathrm{Mn}$ show intermediate volatility. As, $\mathrm{Cd}, \mathrm{Hg}$ and $\mathrm{Se}$ are of primary concern due to their toxicity, as these 
metal emissions have upper specification limits that are regulated by the U.S. Environmental Protection Agency under the Clean Air Act.

\section{CHAR REINJECTION TESTS}

The gasification tests performed using a single pass through the bench-scale gasifier typically result in low to moderate char conversions. The char conversion at atmospheric pressure is limited by the BSG residence times (typically about 2-3 seconds for $100 \mu \mathrm{m}$ particles). Additionally, the gasification agent (secondary gas) is diluted with nitrogen in order to limit the temperature increase caused by the oxidation of the released volatiles. This nitrogen dilution reduces the heterogeneous rates of char gasification.

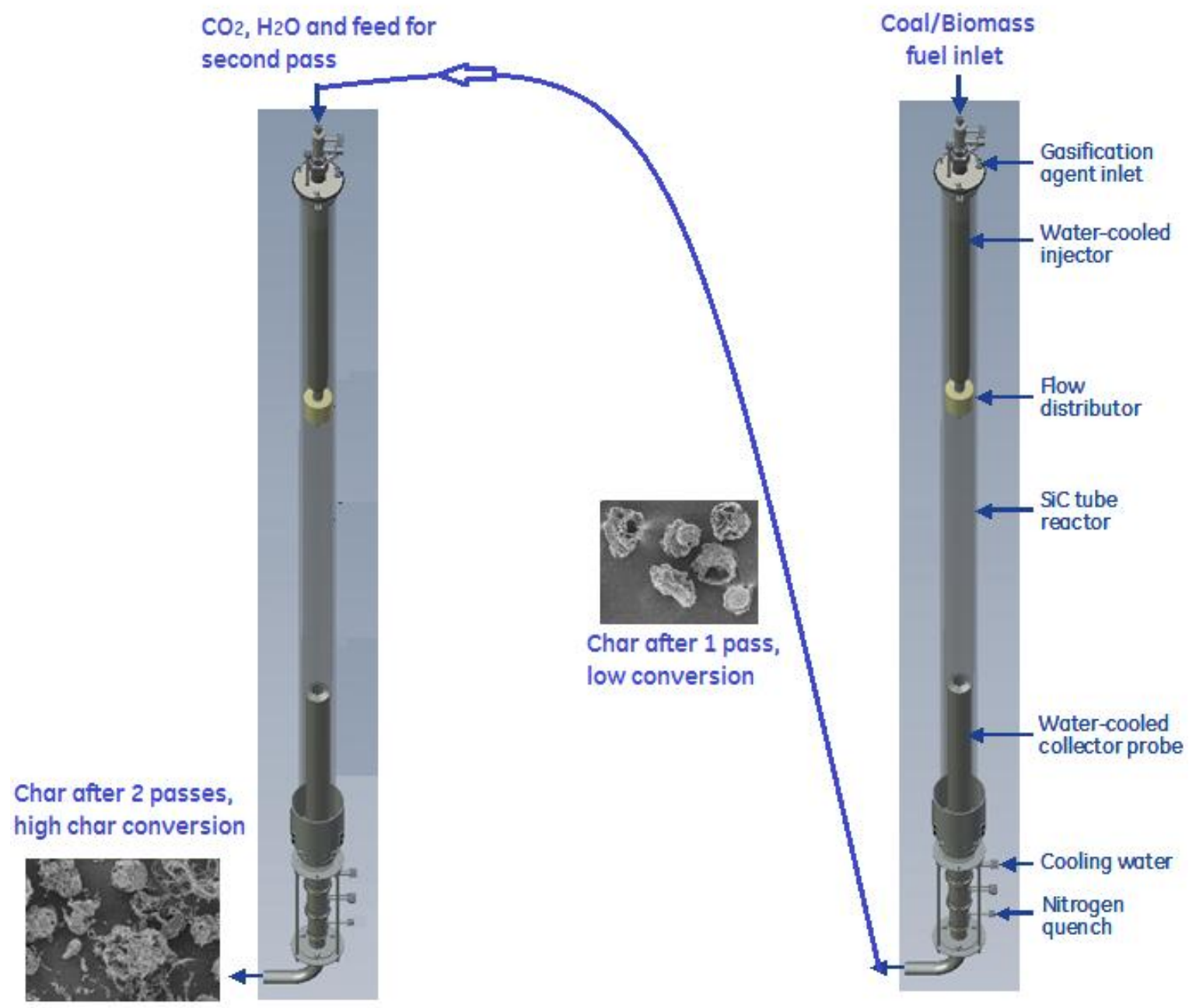

Figure 18: Diagram illustrating the $1^{\text {st }}$ and $2^{\text {nd }}$ pass in the BSG 
In order to study the transformations of the organic and inorganic char components during the later stages of char gasification, char reinjection experiments can be performed. The initial tests performed in the BSG have provided data on the early and medium stages of the coal/biomass mixture gasification as char conversions are limited by the BSG residence times at atmospheric pressure. The char re-injection experiments are performed using two passes of solid material through the BSG reactor. In the first pass, the coal/biomass mixture is injected with oxygen diluted in nitrogen as a gasifying agent. The coal and biomass particles are completely devolatilized, and the resulting char undergoes initial gasification resulting in moderate char conversions. This partially gasified char is collected in the cyclone and subsequently re-injected in the second pass through the $\mathrm{BSG}$ using pure $\mathrm{CO}_{2}, \mathrm{H}_{2} \mathrm{O}$, or their mixtures with or without nitrogen to study the later stages of the gasification. Since the later stages of char gasification in a full-scale entrained flow gasifier take place in the absence of oxygen, the two most important char gasification reactions include heterogeneous reactions of char with steam $\left(\mathrm{H}_{2} \mathrm{O}\right)$ and carbon dioxide $\left(\mathrm{CO}_{2}\right)$. Preliminary char re-injection experiments conducted in the BSG using bituminous coal char indicated that high degrees of char conversion (above 95\%) could be achieved using re-injection method.

The re-injection approach offers several benefits. First, intermediate product compositions after the first pass in the BSG are measured using this approach, in addition to final compositions after char re-injection, providing additional information on chemical transformations taking place during gasification. These two sets of data can be used for calibration and validation of the kinetic models describing coal and biomass gasification under entrained flow conditions. Second, there is an enhanced flexibility in choosing the gasification environment for the char reinjection experiments. For instance, $\mathrm{H}_{2}, \mathrm{CO}$, or their mixtures with or without $\mathrm{NH}_{3}$ and $\mathrm{H}_{2} \mathrm{~S}$ can be co-fed along with $\mathrm{CO}_{2}$ and $\mathrm{H}_{2} \mathrm{O}$ in the second pass through the BSG. These tailored experiments will improve our understanding of the specific transformations of organic and inorganic char components during the later stages of char gasification. Finally, the proposed reinjection approach appears less risky, as many of the critical risks associated with this approach have already been mitigated. While this approach can provide critical insights into the gasification of coal and biomass mixtures under entrained flow conditions, the representativeness of the product characterization data obtained using this approach will be limited due to its lack of realistic pressure configuration. 


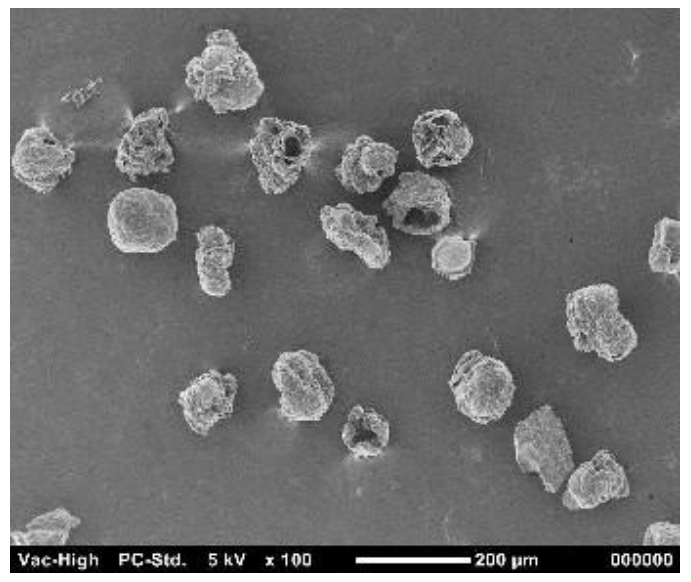

Figure 19. SEM photograph of char particles formed in the first pass through the BSG.

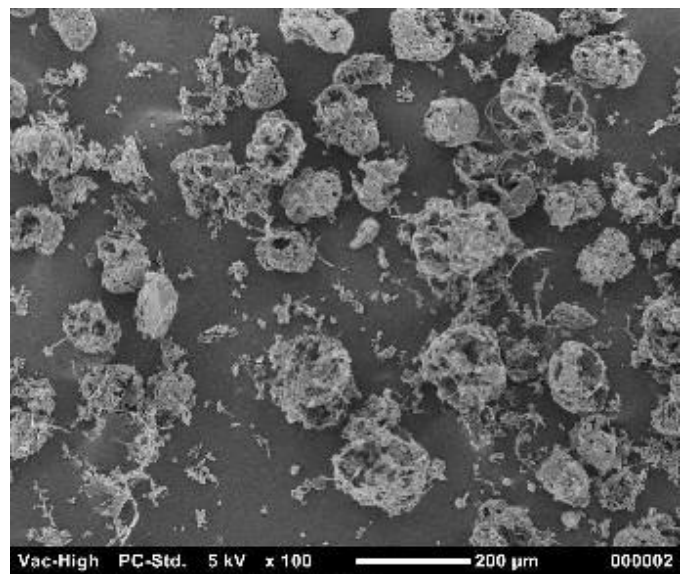

Figure 20. SEM photograph of char particles formed in the second pass through the BSG.

\section{Minor and Trace Element Analysis of Cyclone and Filter Catch Samples}

Prior to ICP analyses, cyclone catch (char) samples were ground in an agate mortar and pestle. Filter catch samples were not ground. Samples were prepared using either microwave digestion or fusion methods described below.

\section{Microwave digestion}

Approximately $0.25 \mathrm{~g}$ (char) or $0.1 \mathrm{~g}$ (filter catch) samples were weighted by difference (weigh paper) and transferred into pre-cleaned Teflon microwave vessels. An antistatic gun was used to prevent particles from adhering to the top and walls of the vessels. $10 \mathrm{~mL} \mathrm{HNO}_{3}$ (Ultrex ${ }^{\mathrm{TM}}$ ) and $5 \mathrm{~mL} \mathrm{H}_{2} \mathrm{SO}_{4}$ (Ultrex ${ }^{\mathrm{TM}}$ ) was added to each vessel. The vessels were sealed according to the manufacturer's instructions and were digested in a MARS5 ${ }^{\mathrm{TM}}$ microwave oven. After cooling, 2 $\mathrm{mL}$ of $\mathrm{H}_{2} \mathrm{O}_{2}$ (trace metal grade) was added in $0.5 \mathrm{~mL}$ increments to each vessel. The vessels then DOE Contract: DE-NT0006305 
were re-sealed and digested in a microwave oven. After cooling, $1 \mathrm{~mL} \mathrm{HCl}\left(\right.$ Ultrex $^{\mathrm{TM}}$ ) and $3 \mathrm{~mL}$ HF (Ultrex ${ }^{\mathrm{TM}}$ ) were added to each vessel and digested in a microwave oven. After cooling, samples solutions were quantitatively transferred to pre-weighed $50 \mathrm{~mL}$ natural cap centrifuge tubes, diluted to $50 \mathrm{~mL}$ with $18 \mathrm{M} \Omega$ de-ionized water, capped, shaken, and weighed. A 10x dilution for minor element analysis of char samples was prepared by weighing $1.0 \mathrm{~g}$ sample solution into a $13 \mathrm{~mL}$ tube, adding $1 \mathrm{~mL} 10 \mathrm{ppm} \mathrm{Sc} / 400 \mathrm{ppb}$ Y internal standard solution, and diluting to $10 \mathrm{~mL}$ with de-ionized water. A 2x dilution for minor element analysis of filter catch samples was prepared in the same way, except $5.0 \mathrm{~g}$ sample solution was used. A second 10x dilution for $\mathrm{Si}$ analysis was prepared by weighing $1.0 \mathrm{~g}$ sample solution into a $13 \mathrm{~mL}$ tube, adding $1 \mathrm{~mL}+10$ drops CFA-C amines (to bring $\mathrm{pH}$ above 8) and $1 \mathrm{~mL}$ of $10 \mathrm{ppm} \mathrm{Sc/400} \mathrm{ppb}$ $\mathrm{Y}$ internal standard solution, and diluting to $10 \mathrm{~mL}$ with de-ionized water. A third 10x dilution was prepared by weighing $1.0 \mathrm{~g}$ sample solution into a $13 \mathrm{~mL}$ tube, adding $1 \mathrm{~mL} 200 \mathrm{ppb} \mathrm{Sc}, \mathrm{Y}$, In, Bi internal standard solution, and diluting to $10 \mathrm{~mL}$ with de ionized water.

\section{Fusion}

Prior to all analyses, char samples were ground in an agate mortar and pestle. $0.1 \mathrm{~g}$ sample, in duplicate, was weighed directly into a Pt crucible. Samples were ashed in Thermolyne Furnace using program \#2 - without lids. $0.2-0.5 \mathrm{~g} \mathrm{Na}_{2} \mathrm{O}_{2}$ was added to each crucible and mixed with plastic spatula. Samples were fused in Thermolyne Furnace using program \#4 - with lids. After cooling, crucibles were placed in $100 \mathrm{~mL}$ Teflon beakers and $40 \mathrm{~mL}$ of $10 \% \mathrm{HNO}_{3}$ was added to each. A stir bar was added to each crucible and samples were heated to approximately $150^{\circ} \mathrm{C}$ for about 2 hours (until only white filmy precipitate remained). Solutions were transferred to preweighed $50 \mathrm{~mL}$ orange cap vials, rinsing lids and crucibles into total solution. 10 drops of HF were added to each vial, capped, and heat sonicated for several hours, until white precipitate dissolved completely. Vials were diluted up to $50 \mathrm{~mL}$ and weighed again. 2x and 10x dilutions were made from digested solutions, with 3 sample spikes made in the 10x step. 10x dilutions also had $0.3 \mathrm{~mL} \mathrm{HNO}_{3}$ added so all solutions had $4 \% \mathrm{HNO}_{3}$ as final concentration. $10 \mathrm{ppm} \mathrm{Sc} \mathrm{/} 400$ ppb Y was used as internal standard.

\section{Results and Comments}

Results are expressed as weight percent or $\mathrm{mg} / \mathrm{kg} \pm$ the $95 \%$ confidence intervals (CI). The confidence intervals reported reflect the variability in the calibration regression line only and not in the sample preparation method. Variability in the sample preparation method can be seen if replicates of each sample are analyzed (assuming the sample is homogeneous). It might be possible to minimize the confidence intervals with further work.

The limits of detection (LOD) and quantification (LOQ) for the method were calculated from the calibration uncertainty and sample dilution factors, using the following equations.

$L O D($ method $)=\left[\frac{3 \times \text { calibration standarderror }- \text { intercept }}{\text { calibration slope }}\right] \times$ dilution factors 
$L O Q($ method $)=\left[\frac{10 \times \text { calibration standarderror }- \text { intercept }}{\text { calibration slope }}\right] \times$ dilution factors

where calibration standard error, intercept, and calibration slope refer to the calibration curve. Please note that method detection limit is always greater than or equal to instrument detection limit.

It is possible that the LOD and LOQ for the method might be minimized with additional work. When the sample result falls below the LOD, the results are expressed as <LOD where the LOD is expressed as wt or $\mathrm{mg} / \mathrm{kg}$. When the sample result falls between the LOD and LOQ, the results are reported as follows: LOD $<\mathrm{X}<\mathrm{LOQ}$, where $\mathrm{X}$ represents the sample value and LOD and LOQ are expressed as wt \% or $\mathrm{mg} / \mathrm{kg}$.

\section{Standards, QC, and spikes}

ICP-AES: The calibration standards in natural cap tubes included: $0.05,0.1,0.2,0.5,1,2,5,10$, 20, 40, 60, 80, 100 ppm of $\mathrm{Al}, \mathrm{Ca}, \mathrm{Fe}, \mathrm{K}, \mathrm{Mg}, \mathrm{Na}$, Ti in $2 \% \mathrm{HNO}_{3}, 1 \% \mathrm{H}_{2} \mathrm{SO}_{4}, 0.4 \% \mathrm{HCl}$, $0.4 \% \mathrm{HF}$ with $1 \mathrm{ppm} \mathrm{Sc}$ and $40 \mathrm{ppb} \mathrm{Y}$. Quality check solution included $1 \mathrm{ppm}$ Spex $2 \mathrm{~A}$ and 4 in $2 \% \mathrm{HNO}_{3}, 1 \% \mathrm{H}_{2} \mathrm{SO}_{4}, 0.4 \% \mathrm{HCl}, 0.4 \% \mathrm{HF}$ with $1 \mathrm{ppm} \mathrm{Sc}$ and $40 \mathrm{ppb}$ Y. High sample spike was performed with $0.1 \mathrm{~mL} 1000 \mathrm{ppm} \mathrm{Al}$ and Fe (10 ppm in solution). Low sample spike was performed with $0.5 \mathrm{~mL}$ Spex $2 \mathrm{~A}$ and 4 (0.5 ppm in solution).

ICP-AES (Si only): The calibration standards in natural cap tubes included: $0.1,0.2,0.5,1,2,5$, 10, 20, 40, 60, 80, $100 \mathrm{ppm} \mathrm{Si}$ in 10\% CFA-C amines with $1 \mathrm{ppm}$ Sc and $40 \mathrm{ppb}$ Y. Quality check solution included 1 ppm Spex 4 in 10\% CFA-C amines with 1 ppm Sc and 40 ppb Y. Sample spike was performed with $2 \mathrm{~mL} 50 \mathrm{ppm}$ Si intermediate standard (10 ppm in solution).

NIST SRM 1632b ("Trace elements in coal") was carried through the digestion and analysis process as an independent measure of accuracy and precision. 
Table 6. SRM and sample spike recoveries using microwave based sample preparation method. All values in wt\%. Non-certified SRM elements in italics.

\begin{tabular}{|c|cccccccc|}
\hline & Al & $\mathbf{C a}$ & $\mathbf{F e}$ & $\mathbf{K}$ & $\mathbf{M g}$ & $\mathbf{N a}$ & $\mathbf{T i}$ & $\mathbf{S i}$ \\
\hline NIST 1632b & $102 \%$ & $99 \%$ & $96 \%$ & $70 \%$ & $97 \%$ & $100 \%$ & $98 \%$ & $87 \%$ \\
NIST 1632b & $105 \%$ & $99 \%$ & $102 \%$ & $66 \%$ & $101 \%$ & $111 \%$ & $100 \%$ & $87 \%$ \\
& & & & & & & & \\
12426A spk low & $102 \%$ & $100 \%$ & $99 \%$ & $92 \%$ & $98 \%$ & $96 \%$ & $100 \%$ & \\
12426A spk hi & $103 \%$ & $102 \%$ & $102 \%$ & $99 \%$ & $102 \%$ & $103 \%$ & $102 \%$ & $92 \%$ \\
12431A spk hi & $112 \%$ & $103 \%$ & $102 \%$ & $104 \%$ & $103 \%$ & $104 \%$ & $102 \%$ & $95 \%$ \\
& & & & & & & & \\
\hline
\end{tabular}

Table 7. SRM and sample spike recoveries using fusion based sample preparation method. All values in $\mathrm{wt} \%$. Non-certified SRM elements in italics.

\begin{tabular}{|c|ccccccc|}
\hline & Al & $\mathbf{C a}$ & $\mathbf{F e}$ & $\mathbf{K}$ & $\mathbf{M g}$ & $\mathbf{T i}$ & $\mathbf{S i}$ \\
\hline SRM NIST 1632b & 96 & 99 & 94 & 118 & 85 & 91 & 89 \\
Sample Spike recovery & 95 & 104 & 102 & 95 & 105 & 101 & 85 \\
\hline
\end{tabular}




\section{Results}

Each of the gasification tests were performed with a 70\% coal, 30\% biomass by dry coal and dry biomass weight mixture. Three coals and three biomasses were chosen representing all major types of feedstocks. The ultimate and proximate analysis is shown for each fuel in Table 8 below. The first mixture is a bituminous coal mixed with an energy crop, Indiana \#5 coal and switchgrass. The second mixture is a sub-bituminous coal mixed with a wood product, Powder river basin coal (PRB) and pine wood. The third mixture is a lignite coal mixed with agricultural residue, Mississippi lignite and corn stover. For the results presented below an O/C of 1.0, and three temperatures ranging from $1000^{\circ} \mathrm{C}$ to $1400^{\circ} \mathrm{C}$ were chosen. The experimental temperatures reported here refer to the $\mathrm{BSG}$ reactor wall temperature that is controlled by the furnace temperature controllers. The feed rate of coal/biomass mixture was maintained constant at approximately $30 \mathrm{~g} / \mathrm{hr}$ in all experiments. The overall feed rate of the secondary gas was also kept constant during these tests at 5.0 SLPM. The rest of experimental parameters, including quench and sampling gas flows, were kept constant throughout these experiments.

Table 8: Fuel ultimate and proximate analysis

\begin{tabular}{|c|c|c|c|c|c|c|}
\hline & \multicolumn{2}{|c|}{ Mixture 1 } & \multicolumn{2}{c|}{ Mixture 2 } & \multicolumn{2}{c|}{ Mixture 3 } \\
\hline Proximate analysis & Indiana\#5 & Switchgrass & PRB & Pine & $\begin{array}{c}\text { Mississippi } \\
\text { Lignite }\end{array}$ & Cornstover \\
\hline Moisture wt\% & $6.31 \%$ & $9.65 \%$ & $15.07 \%$ & $7.46 \%$ & $31.34 \%$ & $8.57 \%$ \\
Volatiles wt\% (dry) & $41.51 \%$ & $74.60 \%$ & $46.84 \%$ & $80.85 \%$ & $65.44 \%$ & $79.00 \%$ \\
\hline Fixed Carbon wt\% (dry) & $50.16 \%$ & $17.75 \%$ & $46.53 \%$ & $18.78 \%$ & $25.22 \%$ & $16.32 \%$ \\
Ash wt\% (dry) & $8.33 \%$ & $7.65 \%$ & $6.63 \%$ & $0.37 \%$ & $9.34 \%$ & $4.68 \%$ \\
& & & & & & \\
Ultimate analysis & & & & & & \\
C wt\% (daf) & $83.06 \%$ & $50.31 \%$ & $73.85 \%$ & $51.35 \%$ & $65.28 \%$ & $49.33 \%$ \\
H wt\% (daf) & $5.61 \%$ & $5.32 \%$ & $5.10 \%$ & $5.87 \%$ & $4.85 \%$ & $5.53 \%$ \\
N wt\% (daf) & $1.73 \%$ & $0.52 \%$ & $1.08 \%$ & $0.05 \%$ & $1.19 \%$ & $0.88 \%$ \\
S wt\% (daf) & $4.44 \%$ & $0.14 \%$ & $0.42 \%$ & $0.00 \%$ & $0.71 \%$ & $0.08 \%$ \\
O wt\% (daf) & $5.16 \%$ & $43.71 \%$ & $19.56 \%$ & $42.73 \%$ & $26.61 \%$ & $44.18 \%$ \\
\hline
\end{tabular}

The char samples collected from these experiments were then re-injected into the BSG in a second pass using a mixture of $40 \% \mathrm{CO}_{2}, 40 \% \mathrm{H}_{2} \mathrm{O}$, and $20 \% \mathrm{~N}_{2}$ as the gasification agent. The char feed rate in the second pass was chosen to match the char generation rate in the first pass through the BSG. Reactor temperature for char re-injection during the second pass was identical to that used in the first pass for char generation. The secondary gas flow rate during the re- 
injection experiments was kept constant at 1 SLPM. The results below show the gas concentrations from the sum of two passes.

Gaseous product data collected during both passes through the BSG was analyzed by assuming that $\mathrm{H}_{2}, \mathrm{CO}, \mathrm{H}_{2} \mathrm{~S}, \mathrm{NH}_{3}$, and $\mathrm{HCN}$ formed during the first pass do not interact with species in the second pass through the BSG. Further, the gas flow rates measured during the second pass were scaled to the same char-feeding rate in the second pass as the char generation rate in the first pass. Uncertainties in gas concentrations measured during both passes were established using the Design for Six Sigma (DFSS) statistical tools

\section{Gas concentration results for three mixtures of coal and biomass}

Concentrations of the major gaseous species calculated using the 'two-pass' approach are illustrated in Figure 21 through Figure 22. The error bars correspond to one standard deviation of the measured gas concentrations. The shown concentrations are low since they are reported as measured in the quenched sample gas, under substantial nitrogen dilution. As can be seen from Figure 21 and Figure 22, the concentrations of $\mathrm{H}_{2}$ and $\mathrm{CO}$ increase with temperature for the subbituminous/pine mixture and the bituminous/switchgrass mixture. The concentrations of $\mathrm{CO}$ and $\mathrm{H}_{2}$ do not increase with temperature for the more reactive lignite/corn stover mixture.

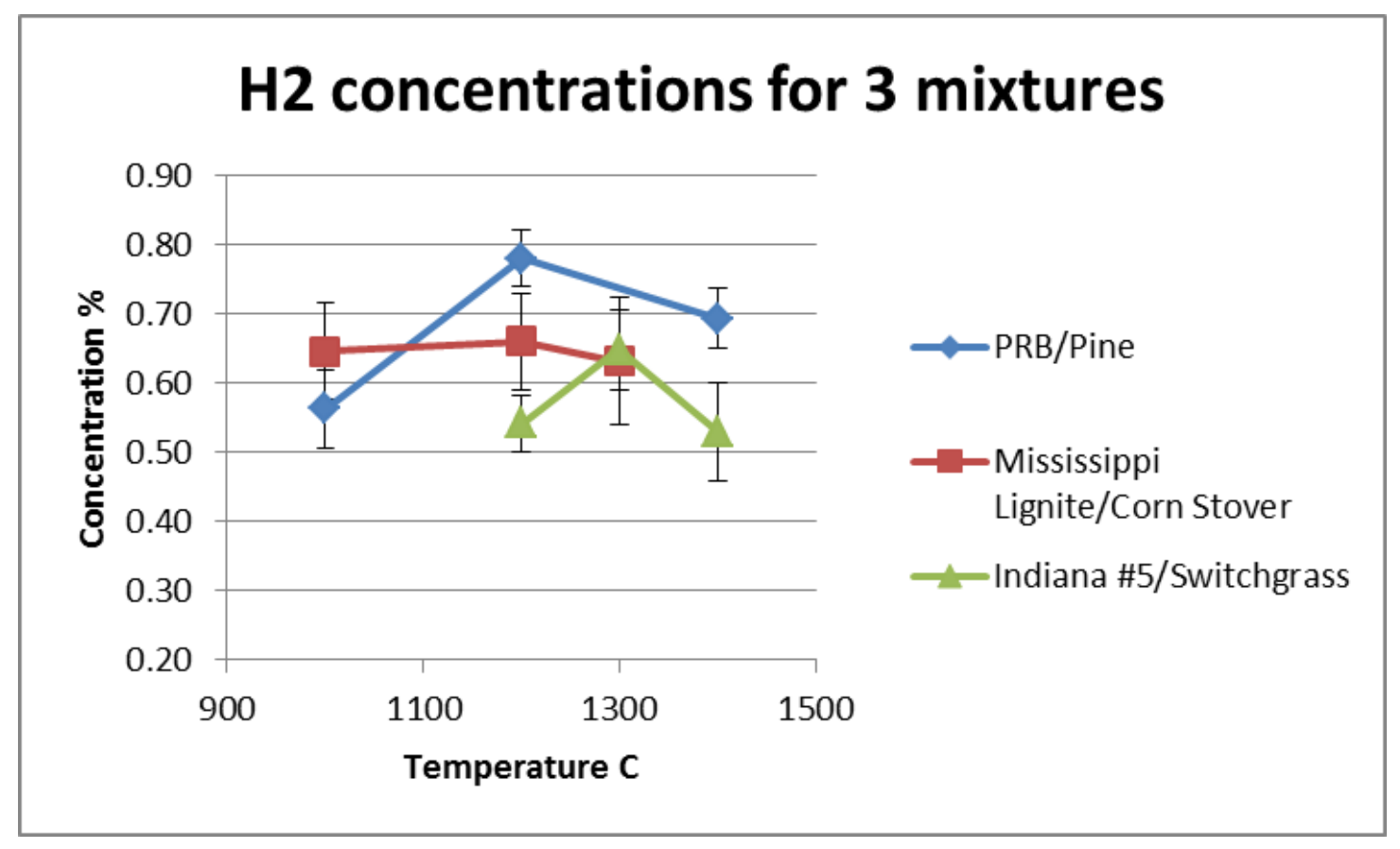

Figure 21: Hydrogen concentration for three different coal/biomass mixtures 


\section{CO concentrations for 3 mixtures}

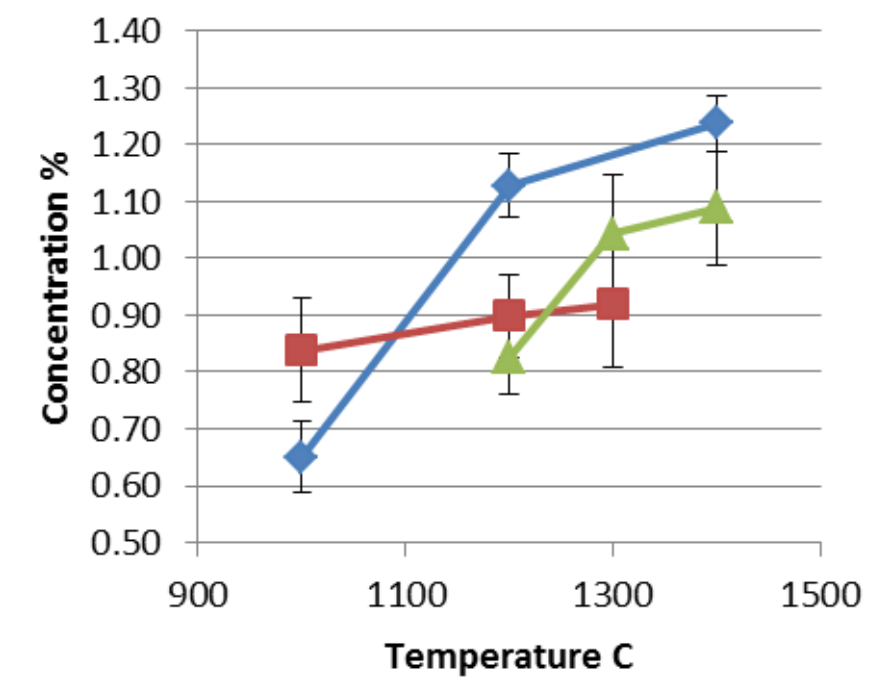

$\simeq$ PRB/Pine

- Mississippi

Lignite/Corn Stover

—-Indiana \#5/Switchgrass

Figure 22: Carbon Monoxide concentration for three different coal/biomass mixtures

The trace gas measurements shown below in Figure 23 through Figure 26 are measured using the previously described ChemCassette trace gas measurement system. Sulfur dioxide was measured using a California analytical continuous emission monitor previously described. Figure 23 shows ammonia concentrations for the three mixtures in the legend. Ammonia decreases with increased temperature for the three feed stocks. There is also a strong correlation between fuel nitrogen and ammonia concentration. There is an initial increase and then decrease with increasing temperatures for ammonia and hydrogen cyanide. The initial increase can be explained by enhanced fuel nitrogen (fuel-N) release from the solid particles with increasing char conversion. The subsequent drop of measured $\mathrm{NH}_{3}$ and $\mathrm{HCN}$ concentrations is probably due to the conversion of part of fuel-N to $\mathrm{NO}$ and $\mathrm{N}_{2}$ species, and possible reaction of $\mathrm{NH}_{3}$ with $\mathrm{NO}$, resulting in additional production of $\mathrm{N}_{2}$. 


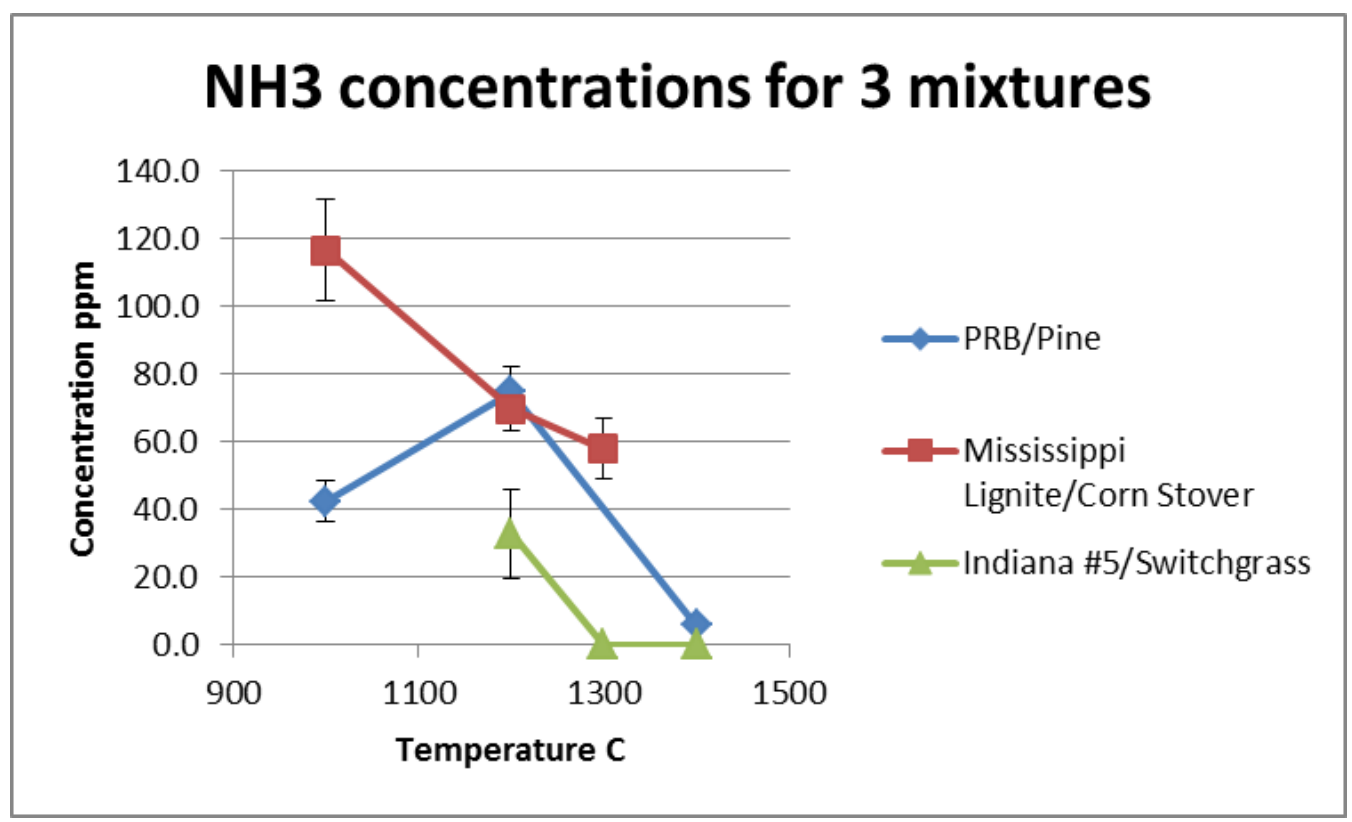

Figure 23: Ammonia concentration for three different coal/biomass mixtures

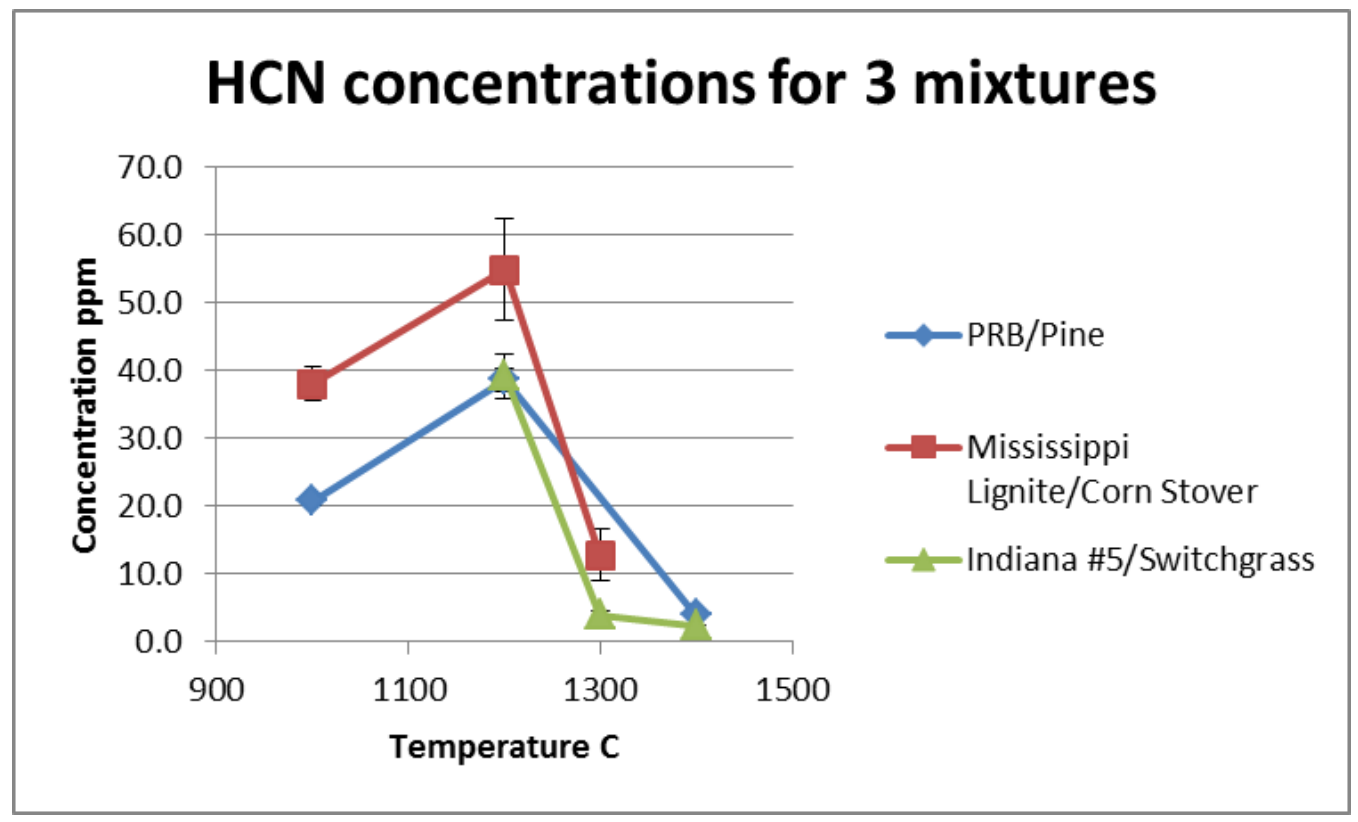

Figure 24: Hydrogen cyanide concentration for three different coal/biomass mixtures 
The trace sulfur species shown in Figure 25and Figure 26 show a similar dependence on the amount of sulfur present in the feed. A decrease in sulfur dioxide with increase in temperature is due to lower availability of oxygen.

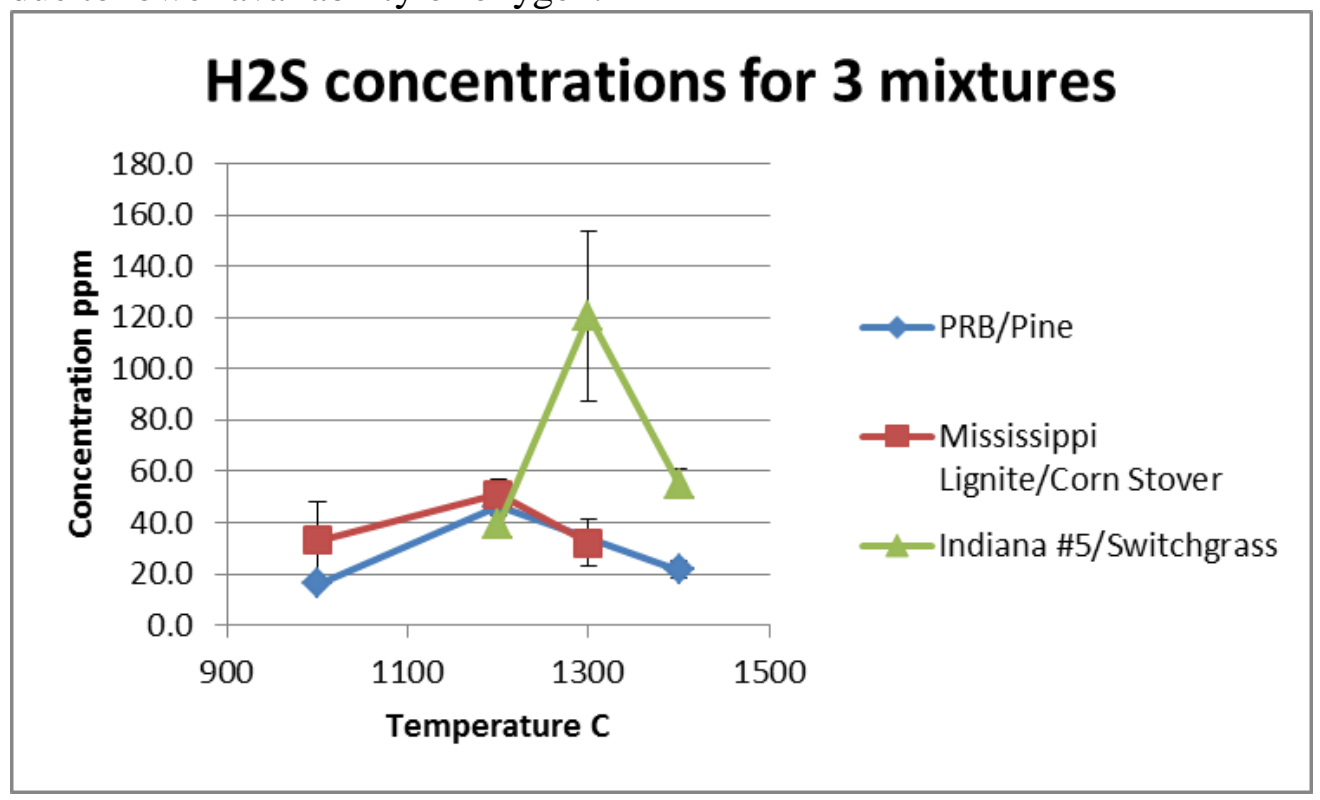

Figure 25: Hydrogen Sulfide concentration for three different coal/biomass mixtures

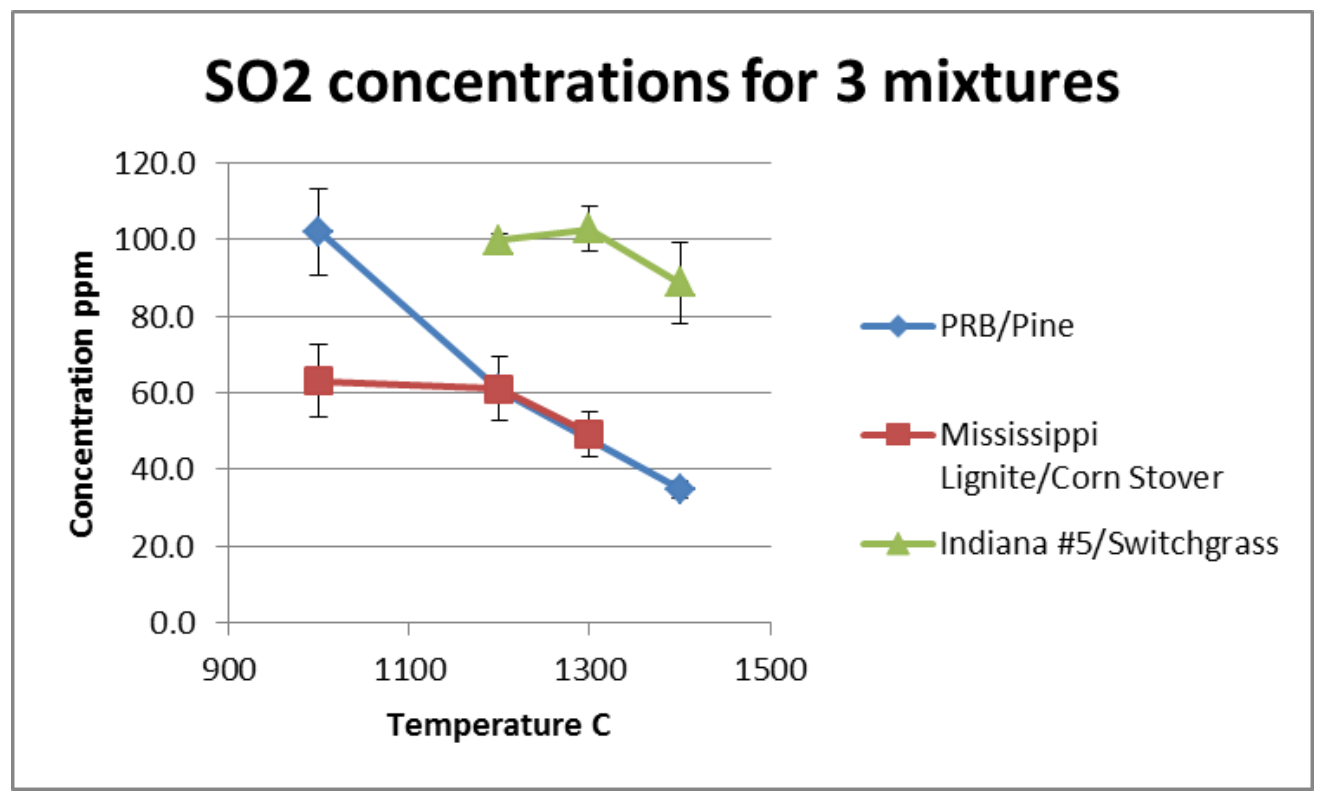

Figure 26: Sulfur dioxide concentration for three different coal/biomass mixtures 
It should be noted here that the key parameters of the BSG are very different from the full-scale EF gasifier. While the flow is essentially one-dimensional in the BSG, with minimal recirculation, the flow inside a full-scale EF gasifier is three-dimensional and leads to the formation of one or more high-speed recirculation zones. Flow recirculation can substantially increase effective residence times in the gasifier. Due to these differences in operation between the BSG and a full-scale EF gasifier, the $\mathrm{NH}_{3}, \mathrm{HCN}, \mathrm{H}_{2} \mathrm{~S}$ and $\mathrm{HCN}$ concentrations, as displayed in Figure 23 through Figure 26, do not imply that these gas species will be released in the syngas in the same amounts or even in the same proportion under full-scale gasifier configurations. Also, $\mathrm{H}_{2}$ and $\mathrm{CO}$ concentrations from $\mathrm{BSG}$ for PRB mixture with two different biomass types are shown in Figure 27and Figure 28.

\section{Gas concentration results for PRB coal with two biomass types}

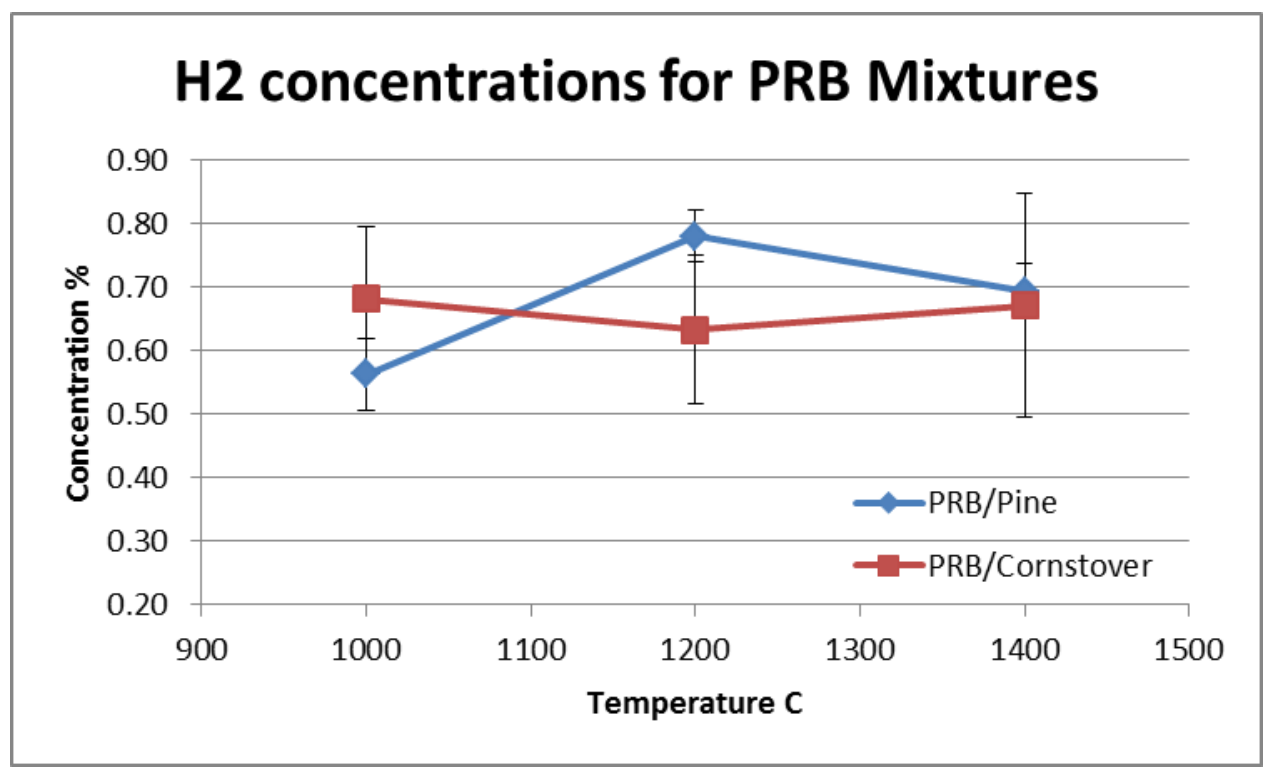

Figure 27: Hydrogen concentration for two different PRB/biomass mixtures 


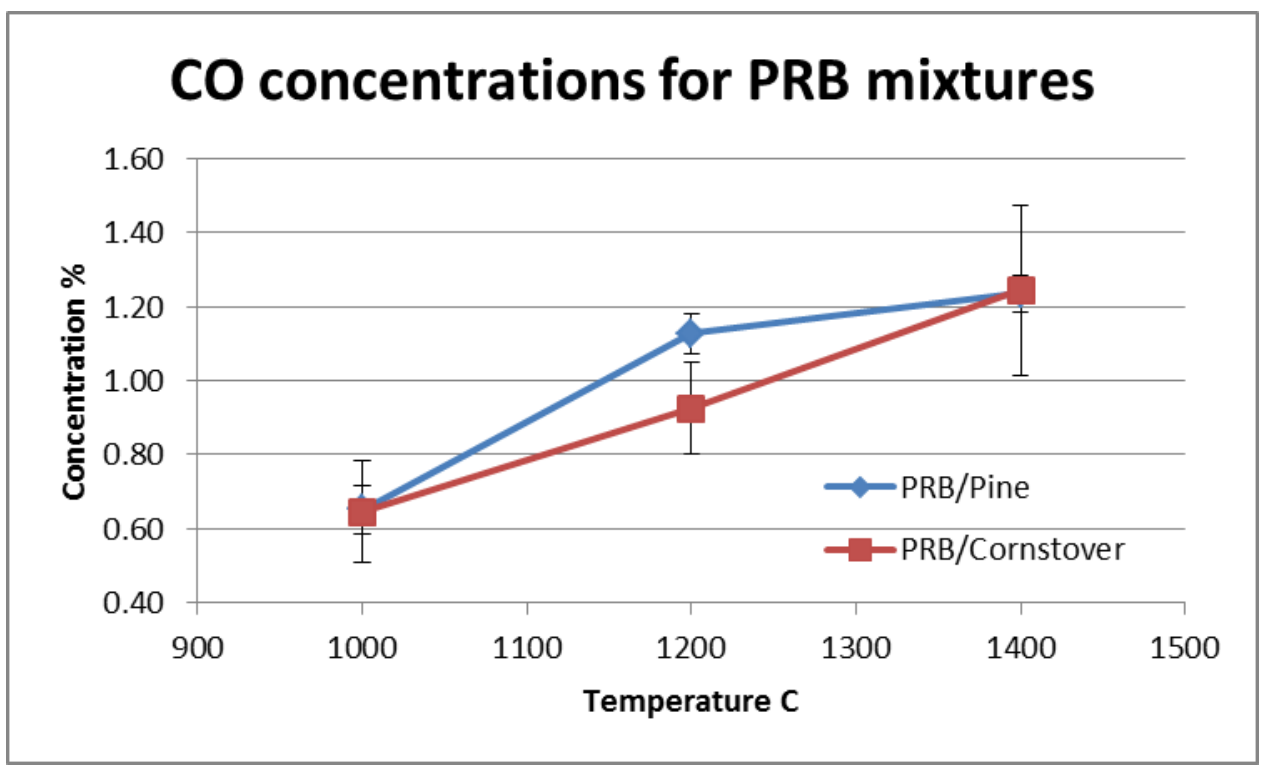

Figure 28: Carbon Monoxide concentration for two different PRB/biomass mixtures

Trace gas concentration plots below in Figure 29- Figure 32 are similar for both sub-bituminous mixtures. The nitrogen content of corn stover is higher than that for pine. The higher fuel nitrogen mixture, PRB/corn stover, has higher trace gas measurement of nitrogen containing species (ammonia and hydrogen cyanide).

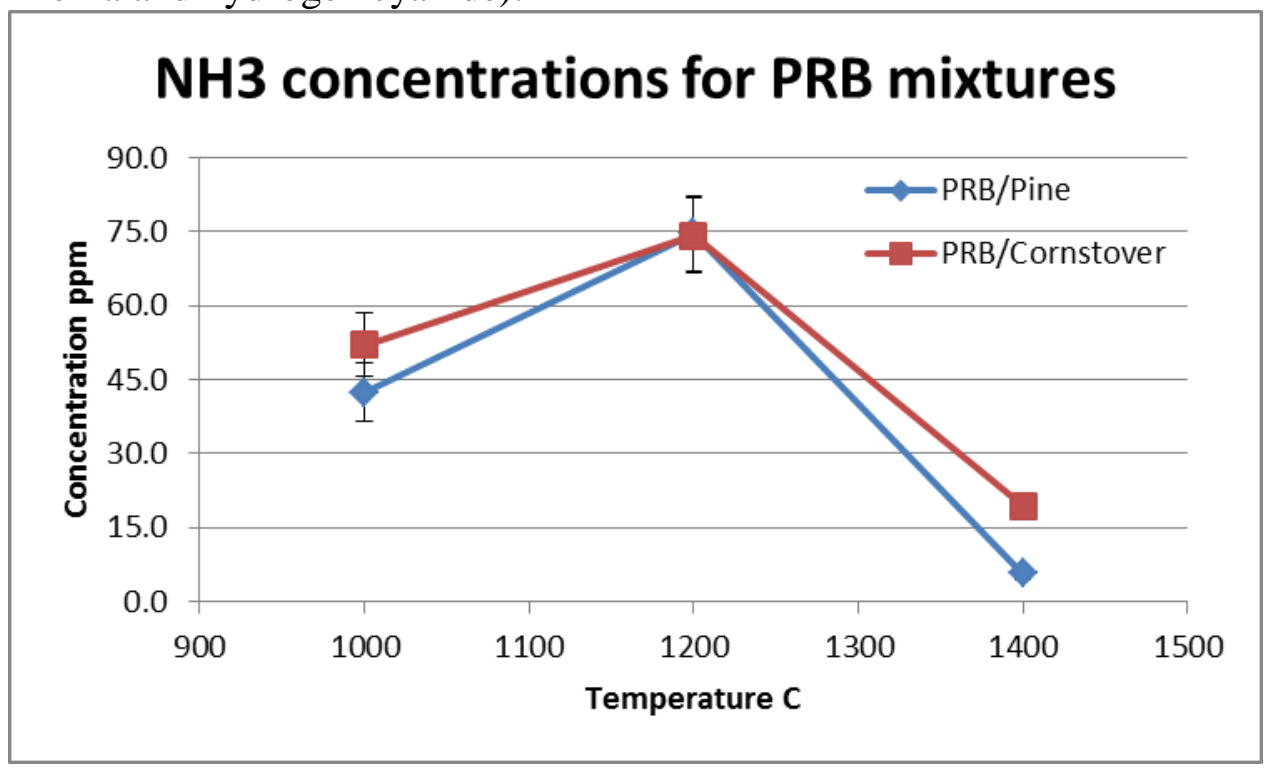

Figure 29: Ammonia concentration for two different PRB/biomass mixtures 


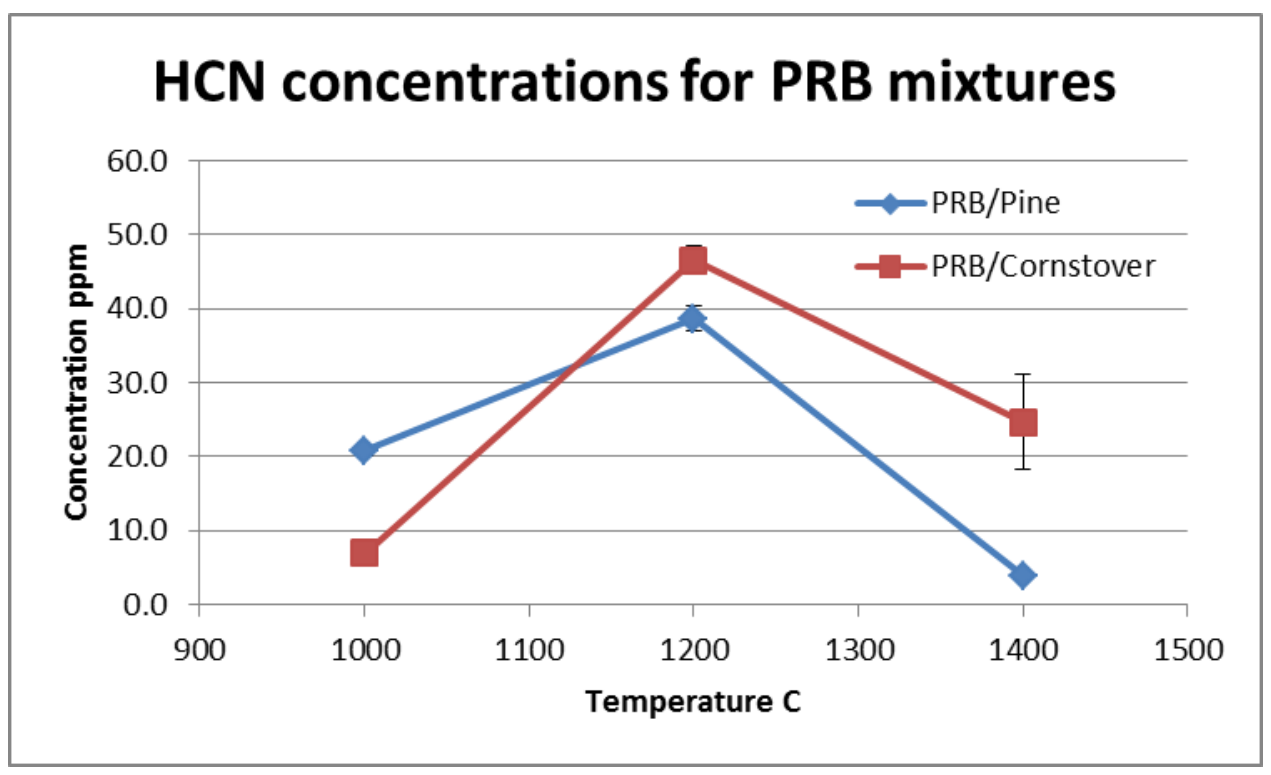

Figure 30: Hydrogen Cyanide concentration for two different PRB/biomass mixtures

There is a trace quantity of sulfur in cornstover while there is none in pine. The increased sulfur in corn stover in not likely the reason for a difference in trace sulfur species shown in Figure 31 and Figure 32. The differences are more likely due to the higher reactivity of pine when compared to cornstover. 


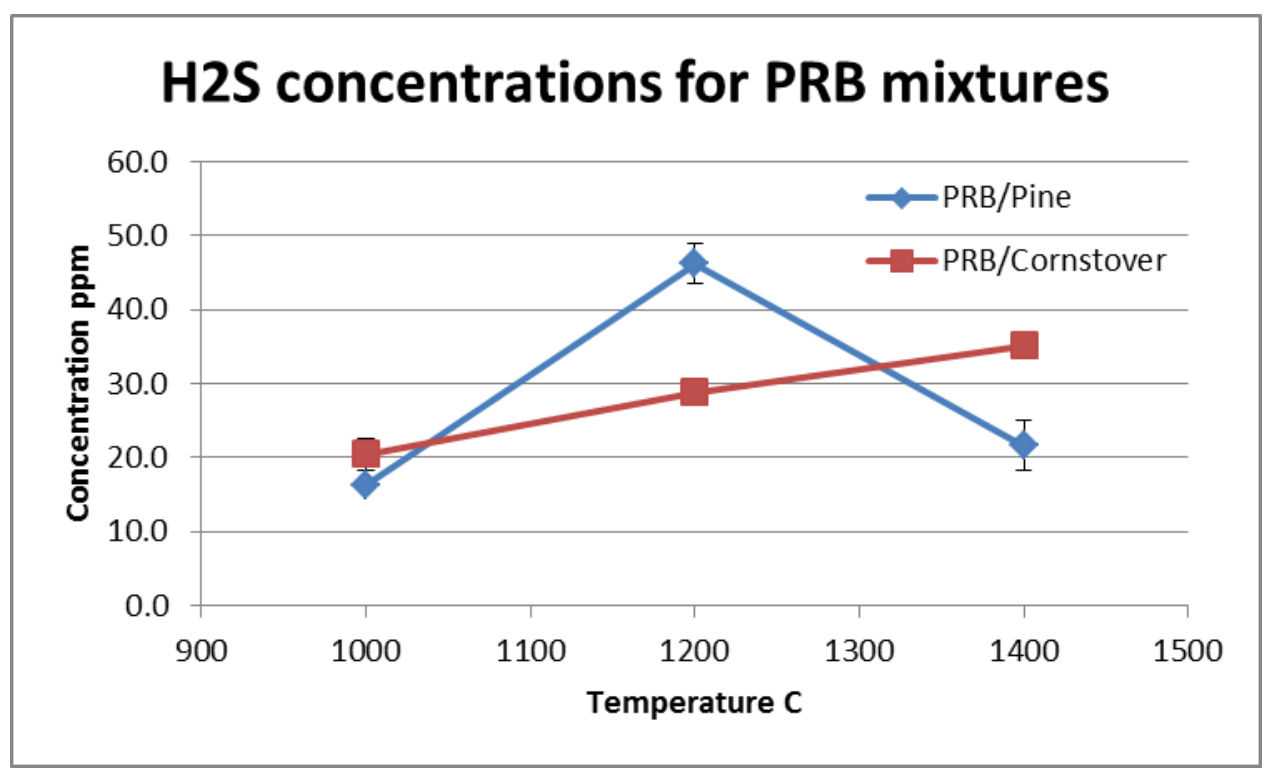

Figure 31: Hydrogen Sulfide concentration for two different PRB/biomass mixtures

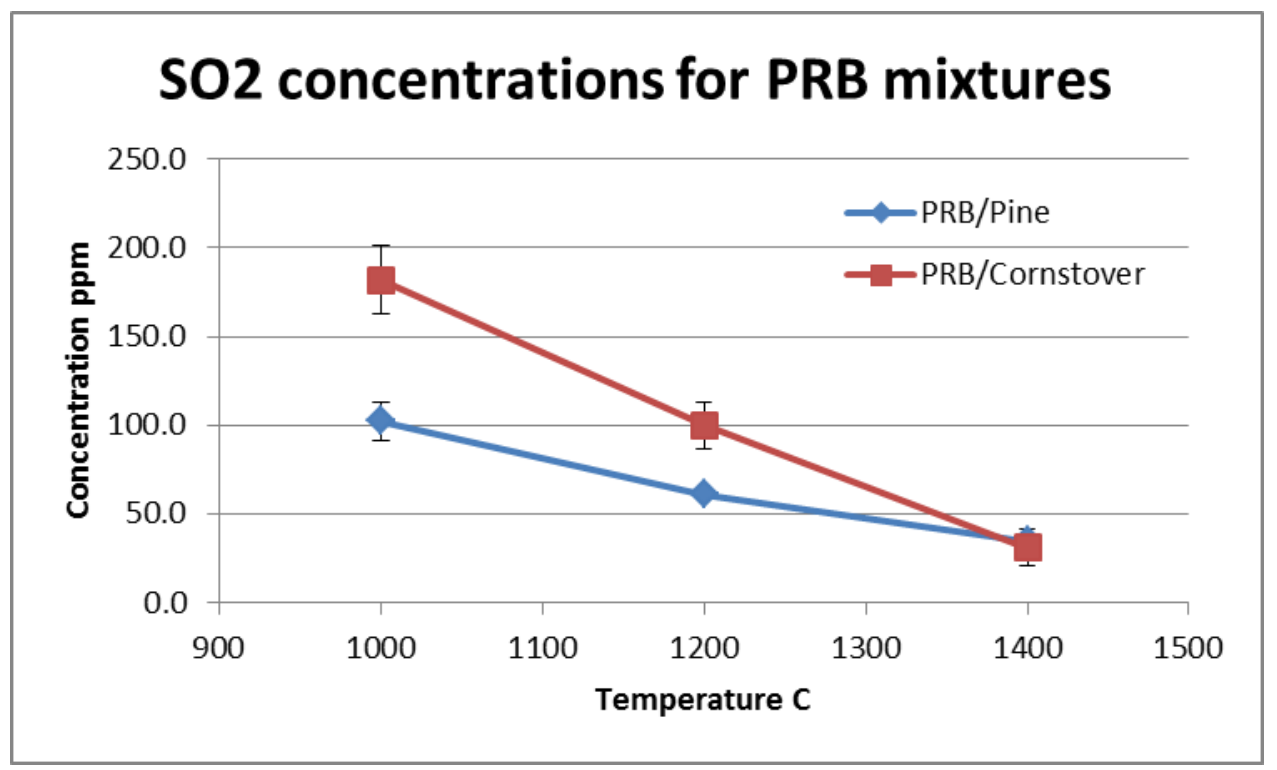

Figure 32: Sulfur Dioxide concentration for two different PRB/biomass mixtures 


\section{Metal volatility for Indiana \#5/Switchgrass}

Figure 33 and Figure 34 show metal volatility verses BSG wall temperature. The method for determining metal volatility is described previously. Figure 33 shows volatility for Arsenic and Selenium, two high volatility metals with high human health risk. Figure 34 shows volatility for potassium and sodium, two metals known to plug and damage downstream equipment.

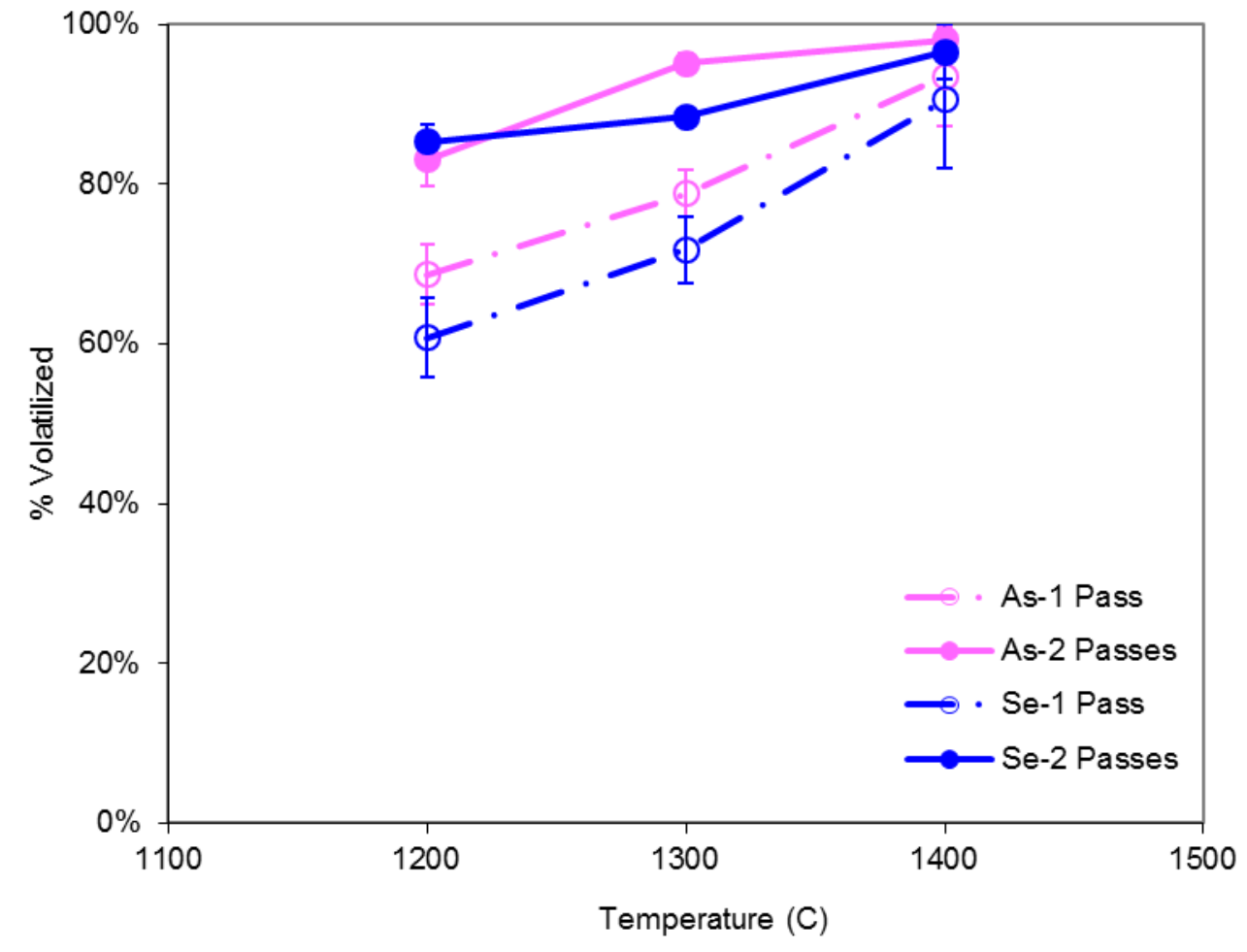

Figure 33: Metal volatility of Arsenic and Selenium for Indiana \#5/Switchgrass mixture 


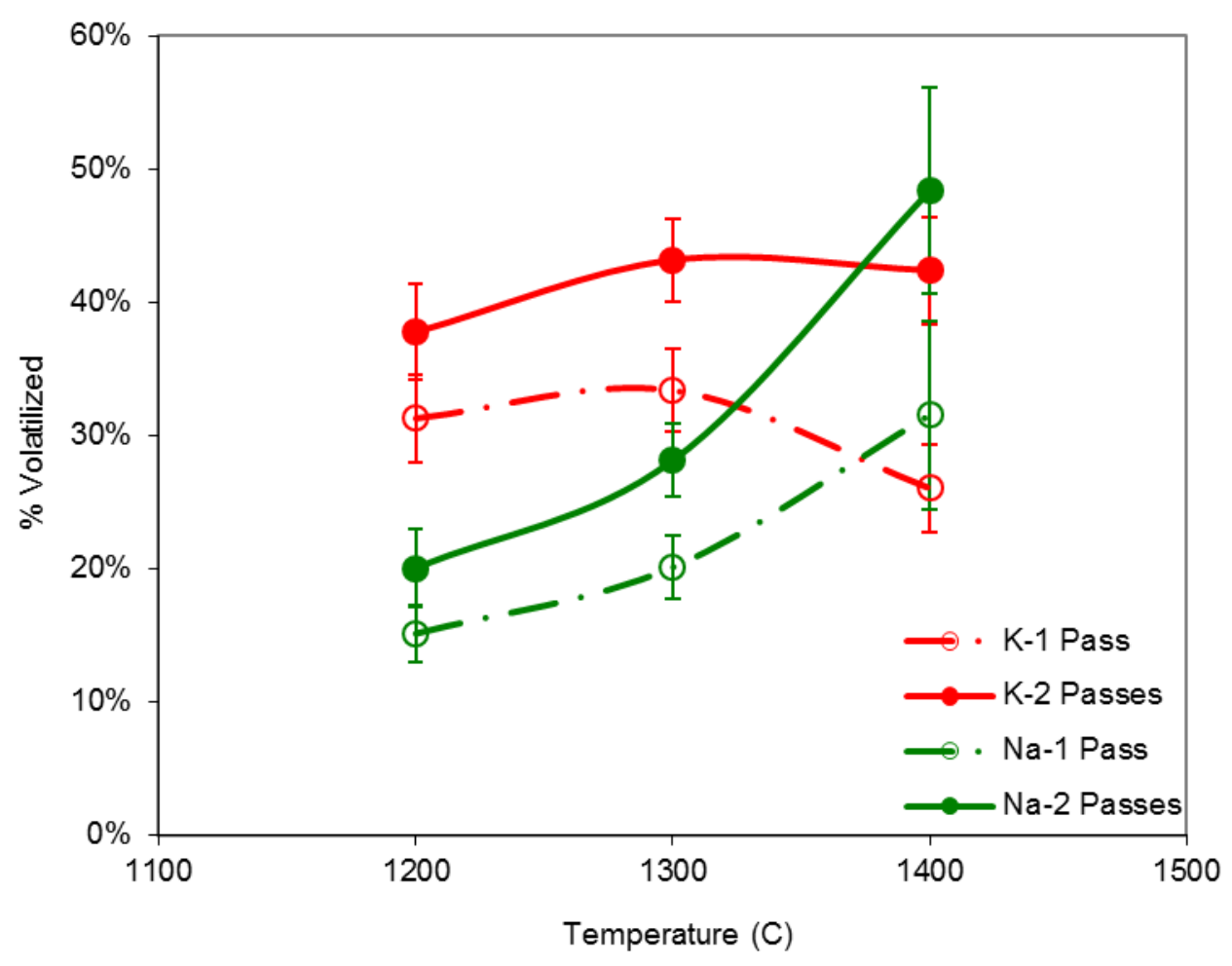

Figure 34: Potassium and Sodium volatility for Indiana \#5/Switchgrass mixture

Minor and trace elements can be divided into two groups: those that displayed very low volatility (non-volatile elements, including $\mathrm{Al}, \mathrm{Ca}, \mathrm{Fe}, \mathrm{Ti}, \mathrm{Si}, \mathrm{V}, \mathrm{Ba}, \mathrm{Th}, \mathrm{U}$ ) and those that showed substantial volatility (volatile elements, including $\mathrm{K}, \mathrm{Na}, \mathrm{Co}, \mathrm{Cu}, \mathrm{As}, \mathrm{Se}, \mathrm{Rb}, \mathrm{Mo}, \mathrm{Sb}, \mathrm{Pb}$ ). The volatilities of some non-volatile elements at $1400^{\circ} \mathrm{C}$ and $\mathrm{O} / \mathrm{C}$ ratio of 1.0 are shown in Figure 35. While the volatilities of these non-volatile elements, calculated using the 'two-pass' approach are also higher than those calculated for the first pass through the BSG, this effect is probably not due to enhanced volatilization of these elements during the second pass, but rather due to the formation of fine liberated inorganic particles with sizes smaller than the cyclone cut point. The volatilities of several volatile elements calculated using the 'two-pass' approach at reactor temperature of $1400^{\circ} \mathrm{C}$ and $\mathrm{O} / \mathrm{C}$ ratio of 1.0 are shown in Figure 36. The error bars correspond to one standard deviation of volatility, calculated as described above. The volatilities of these elements in the first pass through the BSG are shown for comparison. It can be seen that the volatilities of these elements calculated using the 'two-pass' approach are consistently higher than those calculated for the first pass through the BSG. This can be explained by enhanced release of these elements during the char conversion in the second pass. 


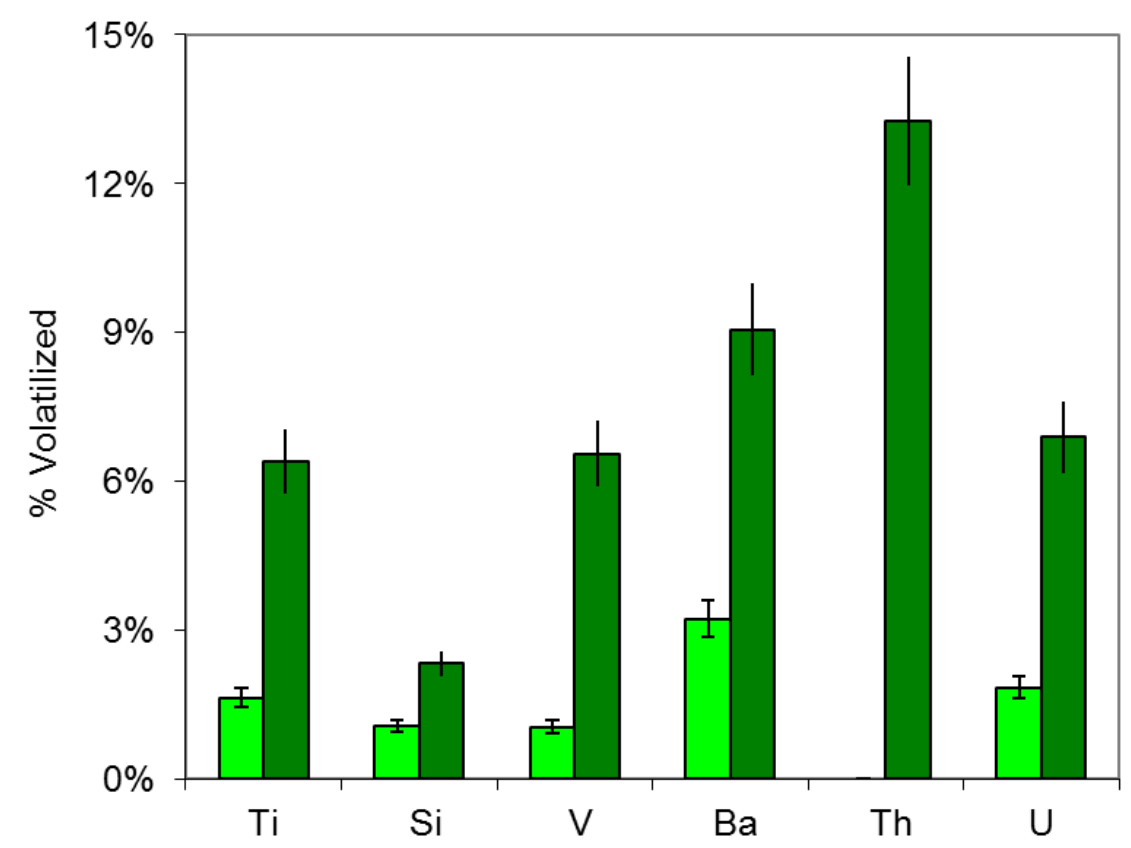

Figure 35: Non-volatile metal volatility for Indiana \#5/Switchgrass mixture 


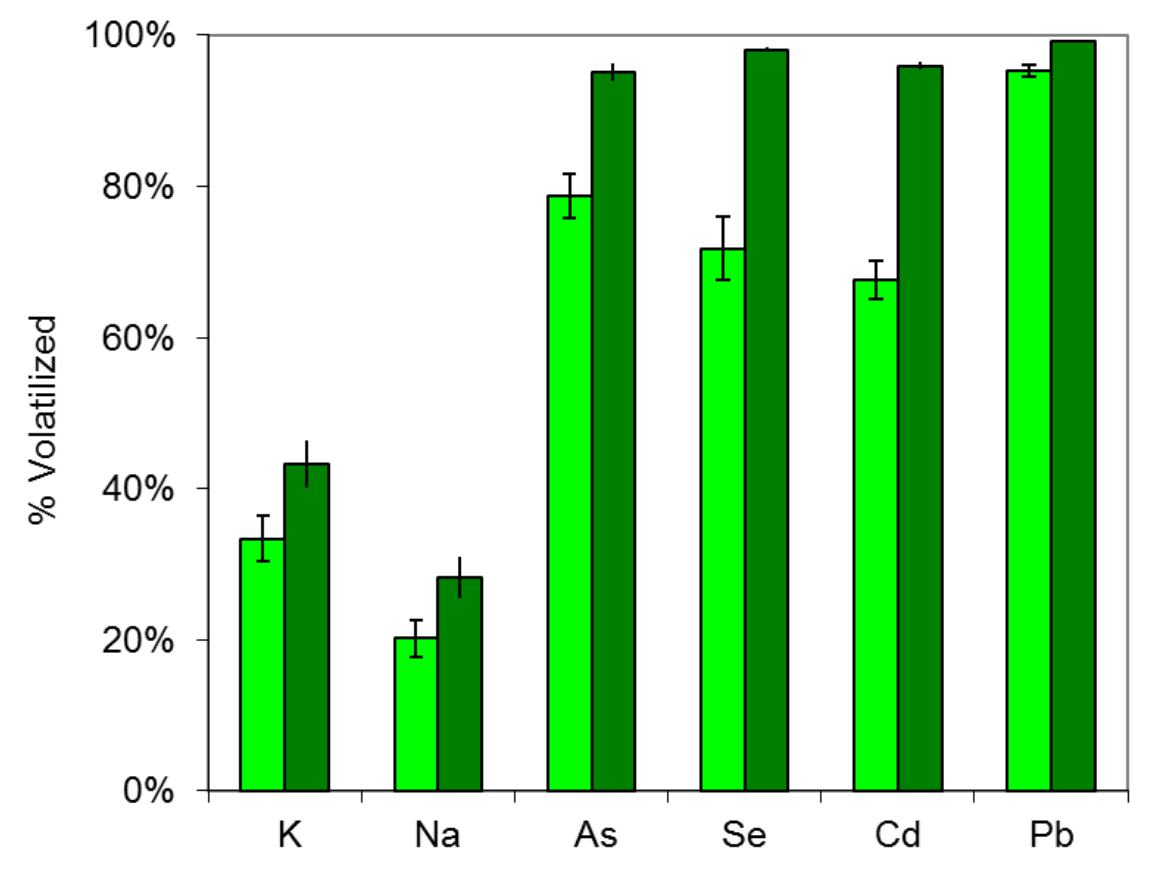

Figure 36: Volatile metal volatility for Indiana \#5/Switchgrass mixture

\section{Metal volatility for Mississippi lignite/Corn stover}

A set of plots is shown below similar to those shown for Indiana \#5/Switchgrass (Figure 37Figure 40). A maximum temperature of $1300{ }^{\circ} \mathrm{C}$ was chosen for this feedstock due to higher reactivity of lignite coal. The minor and trace metal plots show one and two pass results for the $1300{ }^{\circ} \mathrm{C}$ and oxygen to carbon ratio of 1 . 


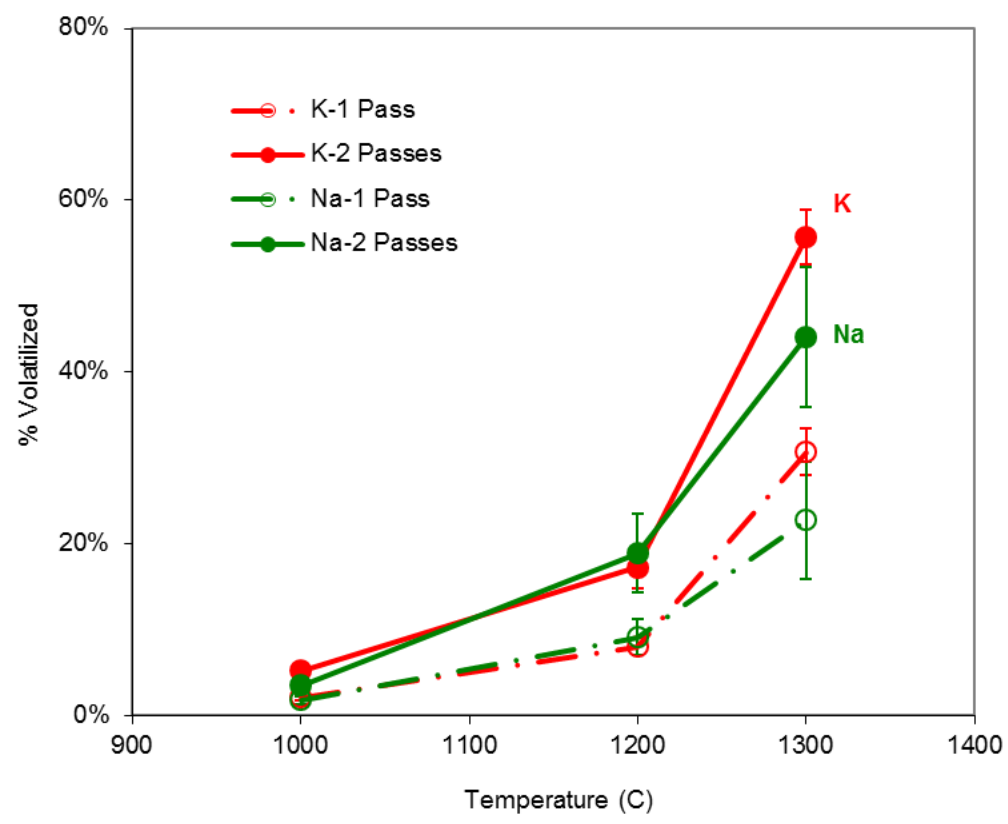

Figure 37: Potassium and Sodium volatility for Mississippi Lignite/Corn stover mixture

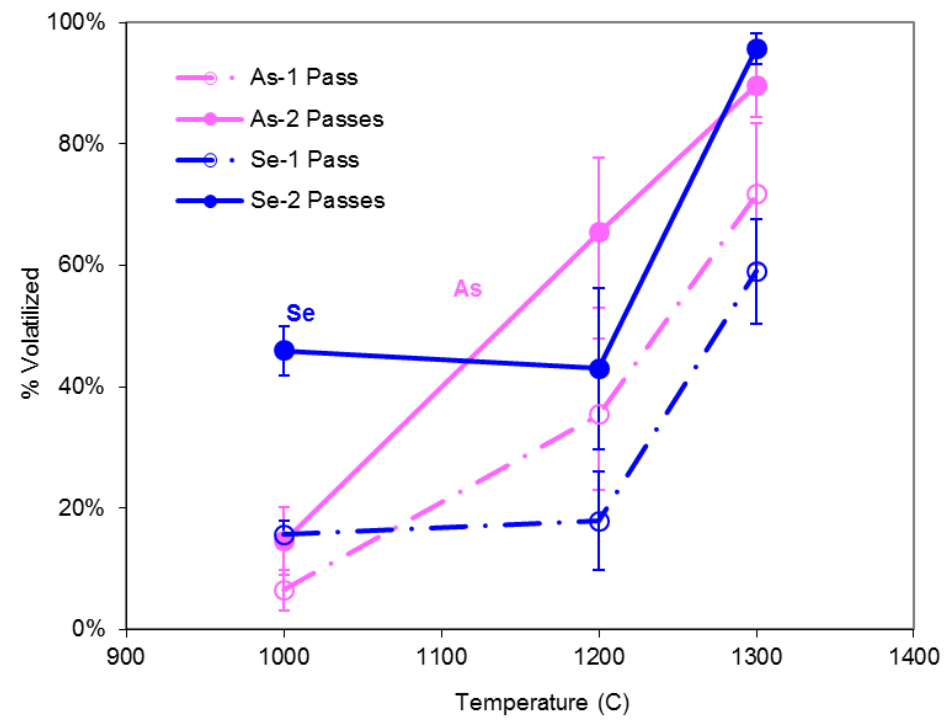

Figure 38: Arsenic and Selenium volatility for Mississippi Lignite/Corn stover mixture 


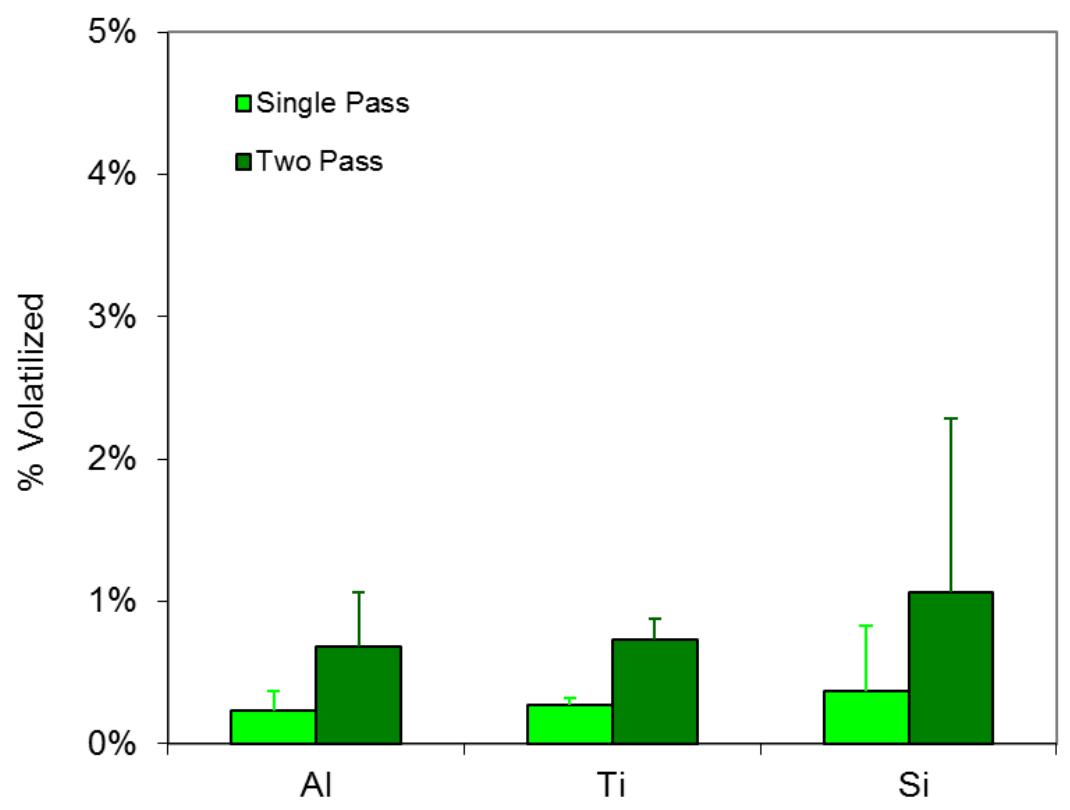

Figure 39: Non-volatile metal volatility for Mississippi Lignite/Corn stover mixture

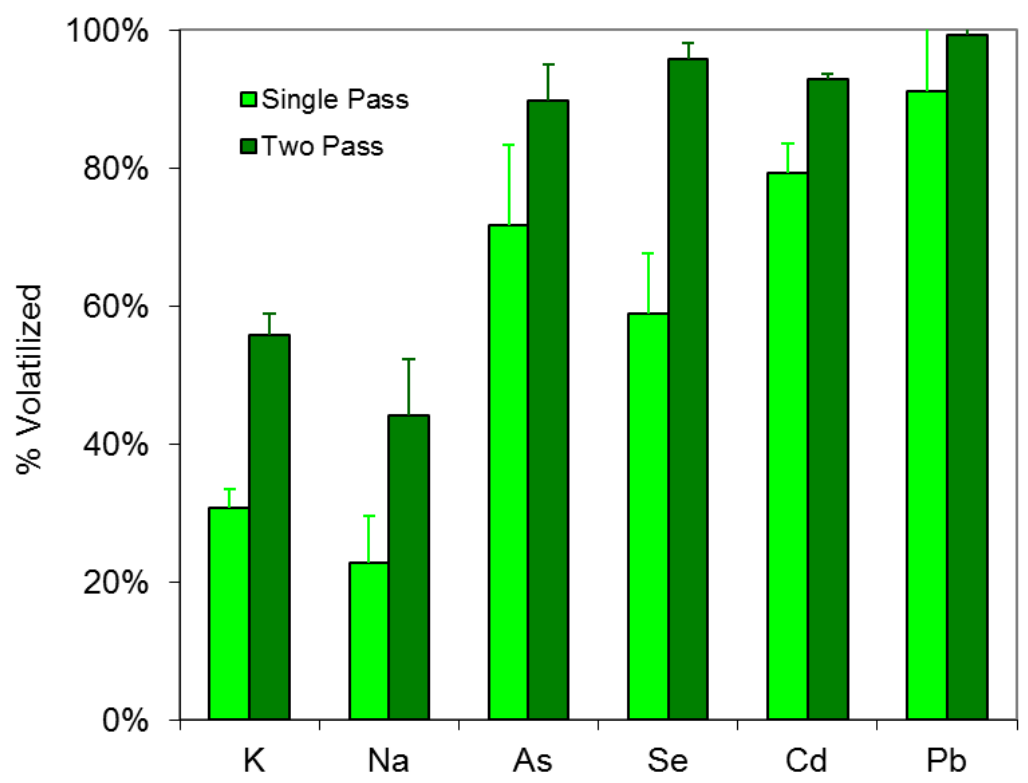

Figure 40: Volatile metal volatility for Mississippi Lignite/Corn stover mixture 


\section{Metal volatility for PRB/ Pine}

The metal volatility figures are similar to those previously shown. The plots for volatile and non-volatile metals are shown in Figure 41 -Figure 44 are for the $1400{ }^{\circ} \mathrm{C}$ at oxygen to carbon ratio of 1 .

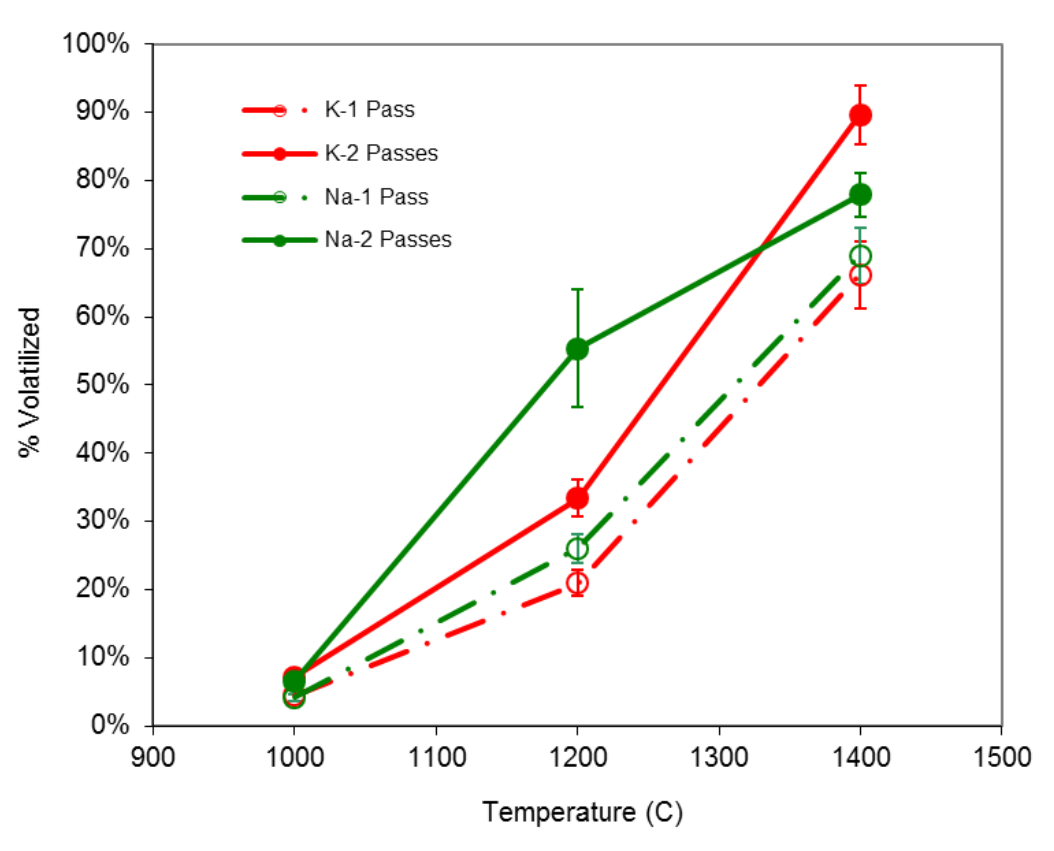

Figure 41: Potassium and Sodium volatility for PRB/Pine mixture 


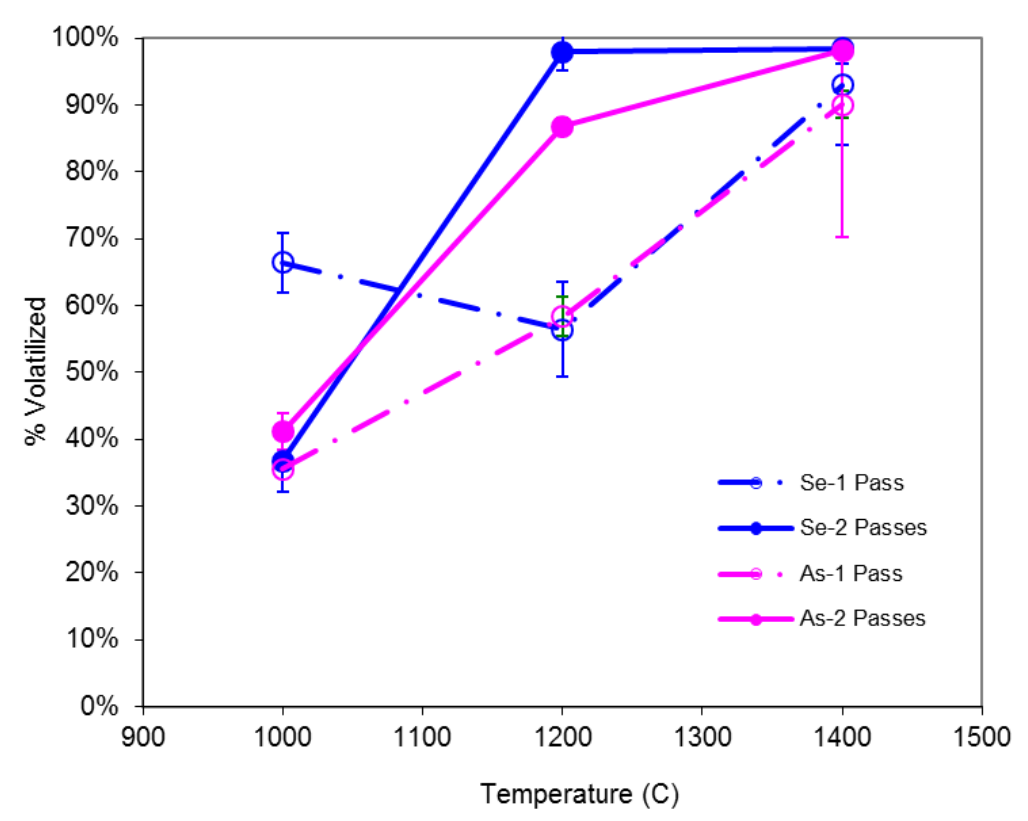

Figure 42: Arsenic and Selenium volatility for PRB/Pine mixture

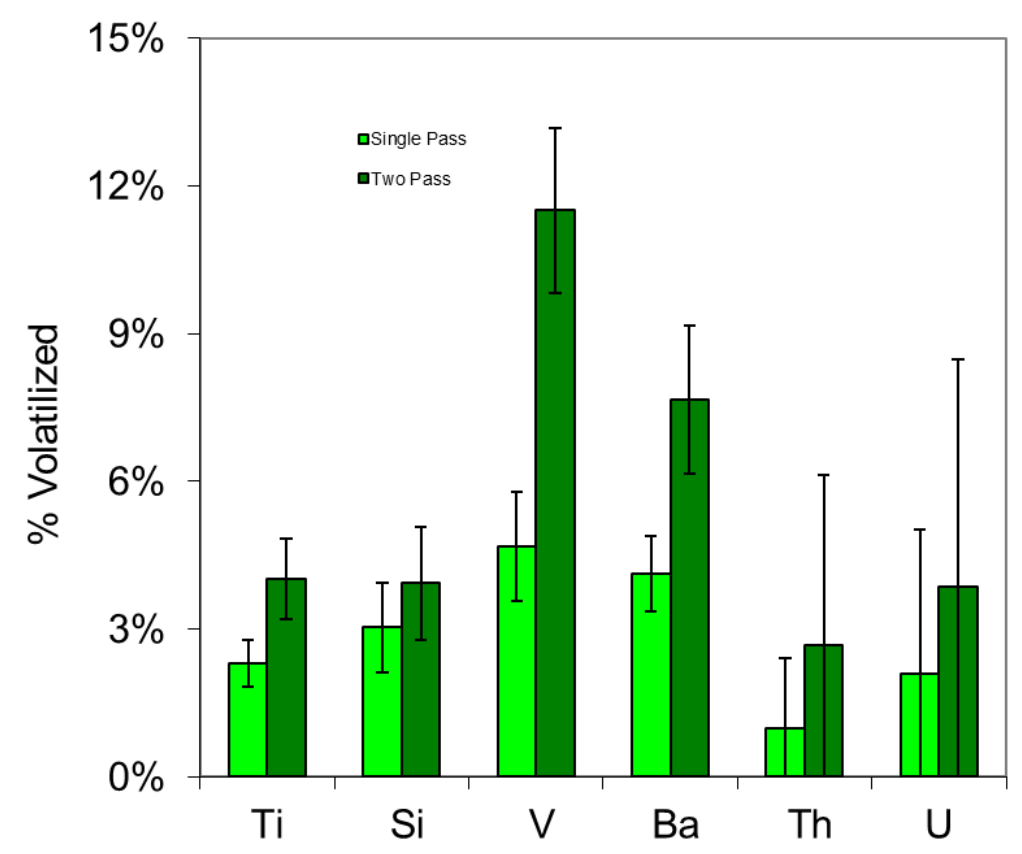

Figure 43: Volatile metal volatility for PRB/Pine mixture 


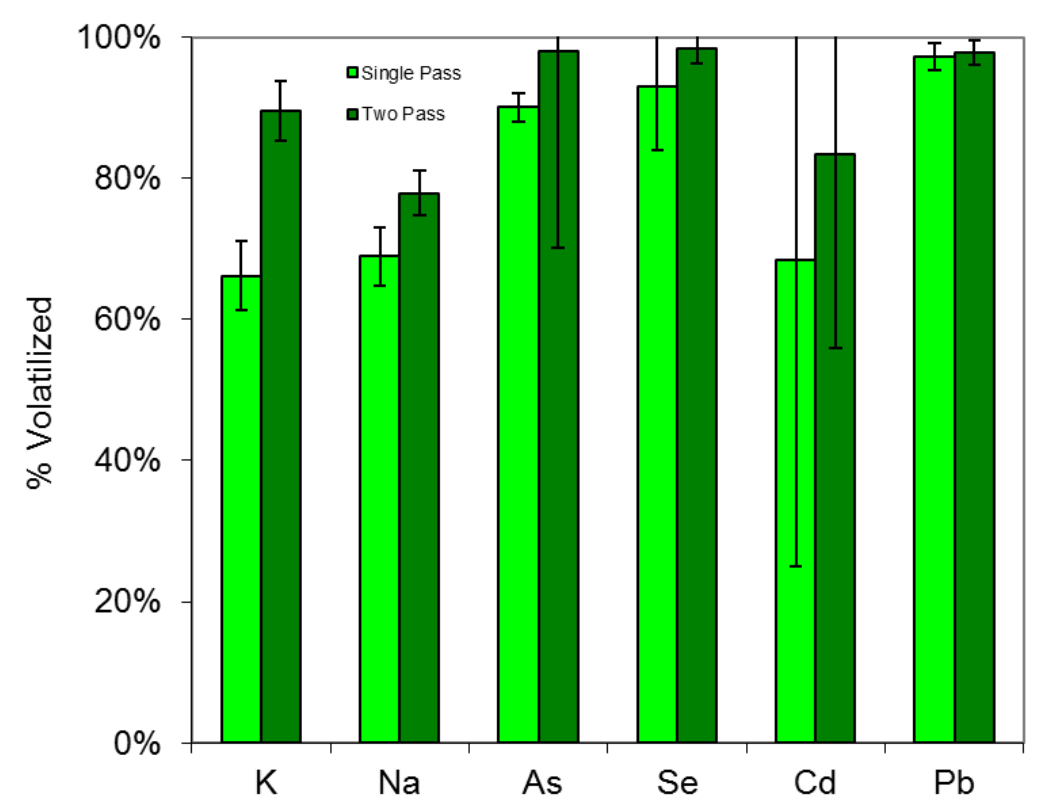

Figure 44: Non-volatile metal volatility for PRB/Pine mixture

\section{Metal volatility for PRB/Corn stover}

The metal volatility figures are similar to those previously shown. The plots for volatile and non-volatile metals are shown in Figure 45 - Figure 48 are for the 1400 centigrade at oxygen to carbon ratio of one test point. 


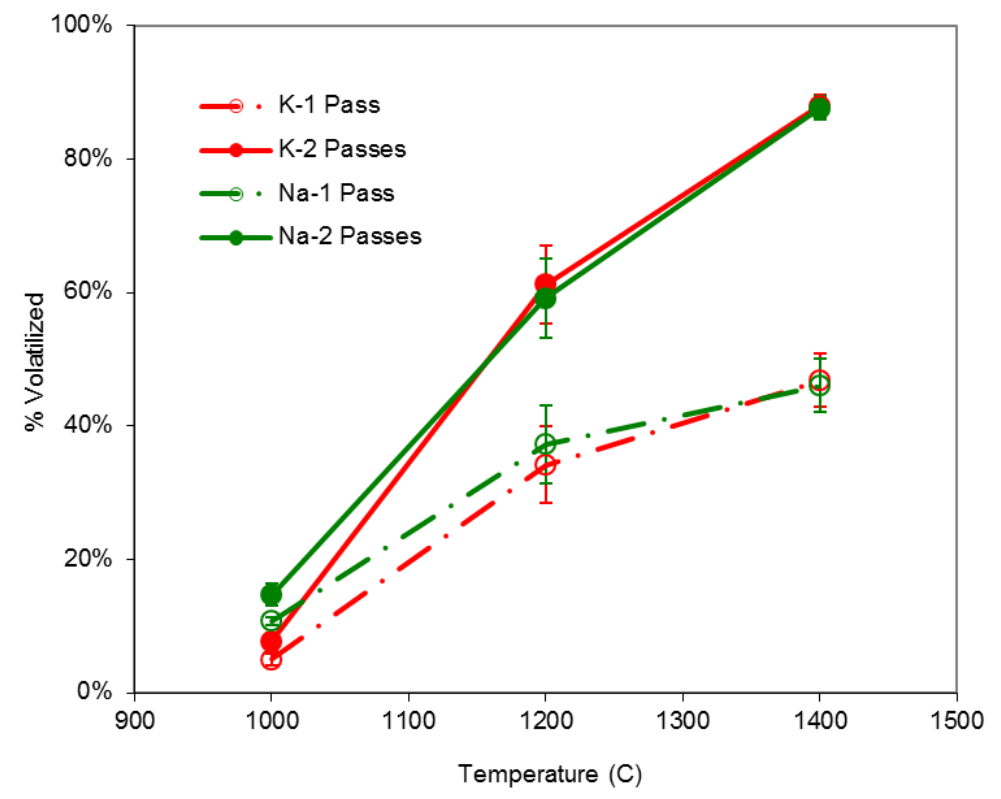

Figure 45: Potassium and Sodium volatility for PRB/Corn stover mixture

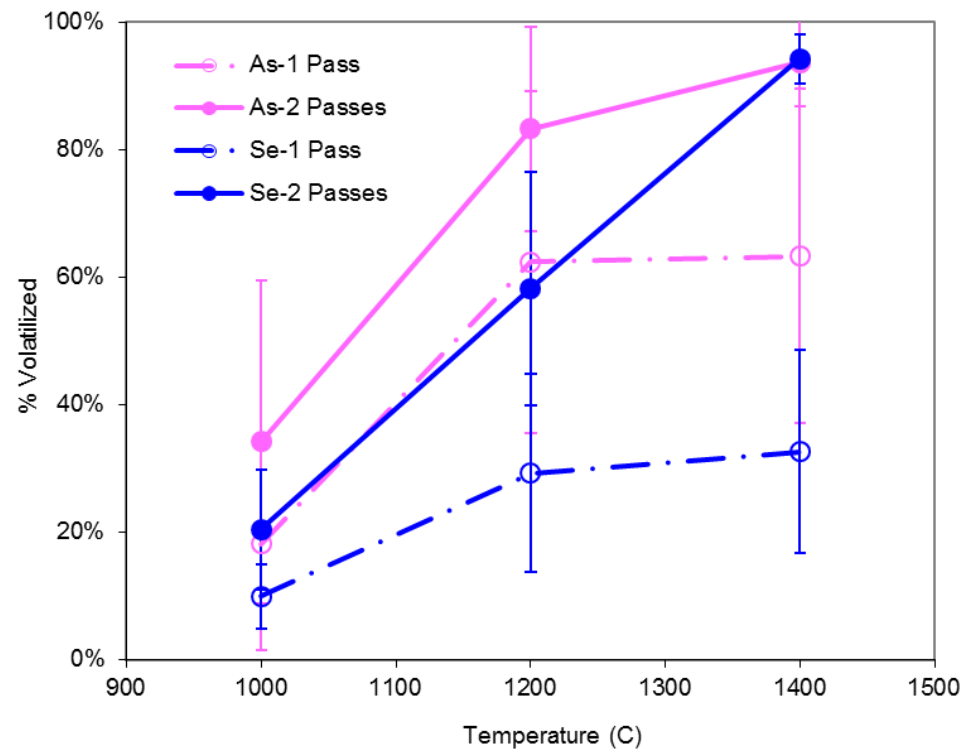

Figure 46: Arsenic and Selenium volatility for PRB/Corn Stover mixture 


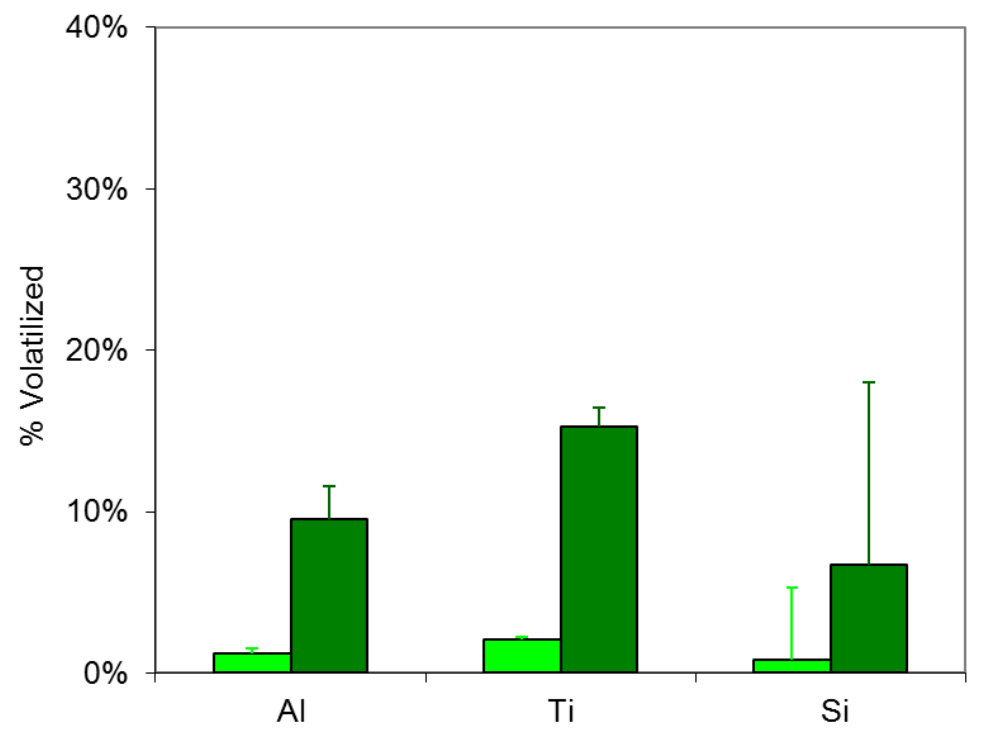

Figure 47: Non-volatile metal volatility for PRB/Corn stover mixture

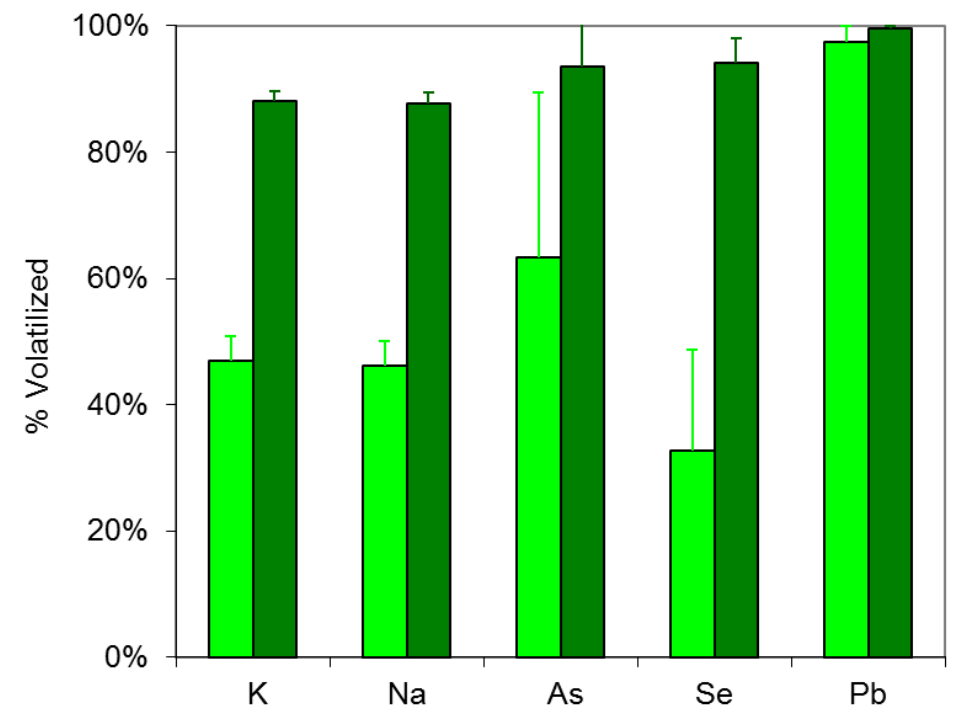

Figure 48: Volatile metal volatility for PRB/Corn stover mixture 


\section{Baseline comparison of pure coal to coal/biomass mixture}

A bituminous coal was used as a baseline to compare to a mixture of $30 \%$ switchgrass and the same coal. Both tests were conducted at a BSG wall temperature of 1400 degrees Celsius and $\mathrm{O} / \mathrm{C}$ equal to 1 . Results shown are those from the sum of the first and second pass. All fuel feed and gas feeds match those of the previously presented tests. Figure 49-Figure 51 display gas and metals data of the mixture verses the pure coal case. In each plot the dotted line marks the pure coal baseline level. The mixture has higher gas concentrations hydrogen sulfide and lower for sulfur dioxide than the pure coal baseline. The higher reactivity of the mixture lowering oxygen availability is likely the cause for this difference. The differences in metal volatility are due primarily to changes in the quantity of minor or trace metal in the feed as shown in Table 8 .

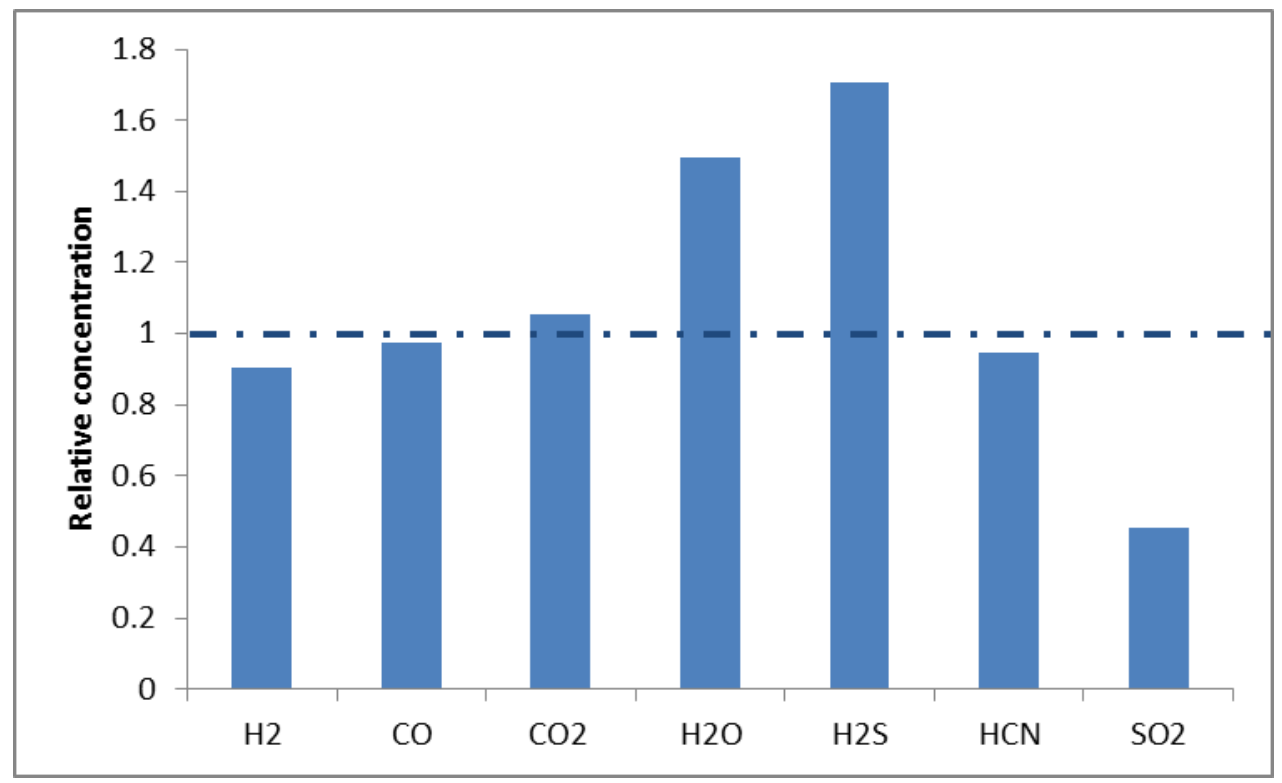

Figure 49: Relative concentration of coal/biomass mixture gas concentrations with coal baseline

Table 9: Minor and trace metal concentration of coal and biomass feedstocks 


\begin{tabular}{|c|c|c|c|c|c|c|c|c|c|c|c|c|c|c|c|c|}
\hline & \multicolumn{8}{|c|}{ Minor metals } & & & & & & & & \\
\hline & $M g(w t \%)$ & $\mathrm{K}(\mathrm{wt} \%)$ & Ca (wt \%) & Na (wt \%) & Al (wt \%) & Ti (wt \%) & Fe (wt \%) & Si (wt \%) & & & & & & & & \\
\hline Indiana\#5 & $0.0379 \%$ & $0.1363 \%$ & $0.1658 \%$ & $0.0379 \%$ & $0.6886 \%$ & $0.0417 \%$ & $0.9837 \%$ & $1.4194 \%$ & & & & & & & & \\
\hline \multirow[t]{3}{*}{ Switch Grass } & $0.1021 \%$ & $0.4269 \%$ & $0.3912 \%$ & $0.0032 \%$ & $0.0334 \%$ & $0.0009 \%$ & $0.0461 \%$ & $1.7754 \%$ & & & & & & & & \\
\hline & \multicolumn{16}{|c|}{ Trace metals } \\
\hline & $\mathrm{V}$ & $\mathrm{Cr}$ & $\mathrm{Mn}$ & $\mathrm{Co}$ & $\mathrm{Ni}$ & $\mathrm{Cu}$ & As & $\mathrm{Se}$ & $\mathrm{Rb}$ & Mo & $\mathrm{Cd}$ & $\mathrm{Sb}$ & $\mathrm{Ba}$ & $\mathrm{Pb}$ & Th & $\mathrm{U}$ \\
\hline Indiana\#5 & $0.0029 \%$ & $0.0012 \%$ & $0.0016 \%$ & $0.0002 \%$ & $0.0008 \%$ & $0.0010 \%$ & $0.0003 \%$ & $0.0002 \%$ & $0.0010 \%$ & $0.0006 \%$ & $0.0000 \%$ & $0.0002 \%$ & $0.0019 \%$ & $0.0002 \%$ & $0.0001 \%$ & $0.0003 \%$ \\
\hline Switch Grass & $0.0001 \%$ & $0.0041 \%$ & $0.0065 \%$ & $0.0001 \%$ & $0.0022 \%$ & $0.0009 \%$ & $0.0000 \%$ & $0.0000 \%$ & $0.0006 \%$ & $0.0003 \%$ & $0.0000 \%$ & $0.0000 \%$ & $0.0020 \%$ & $0.0000 \%$ & $0.0000 \%$ & $0.0000 \%$ \\
\hline
\end{tabular}

Minor metals relative volatility

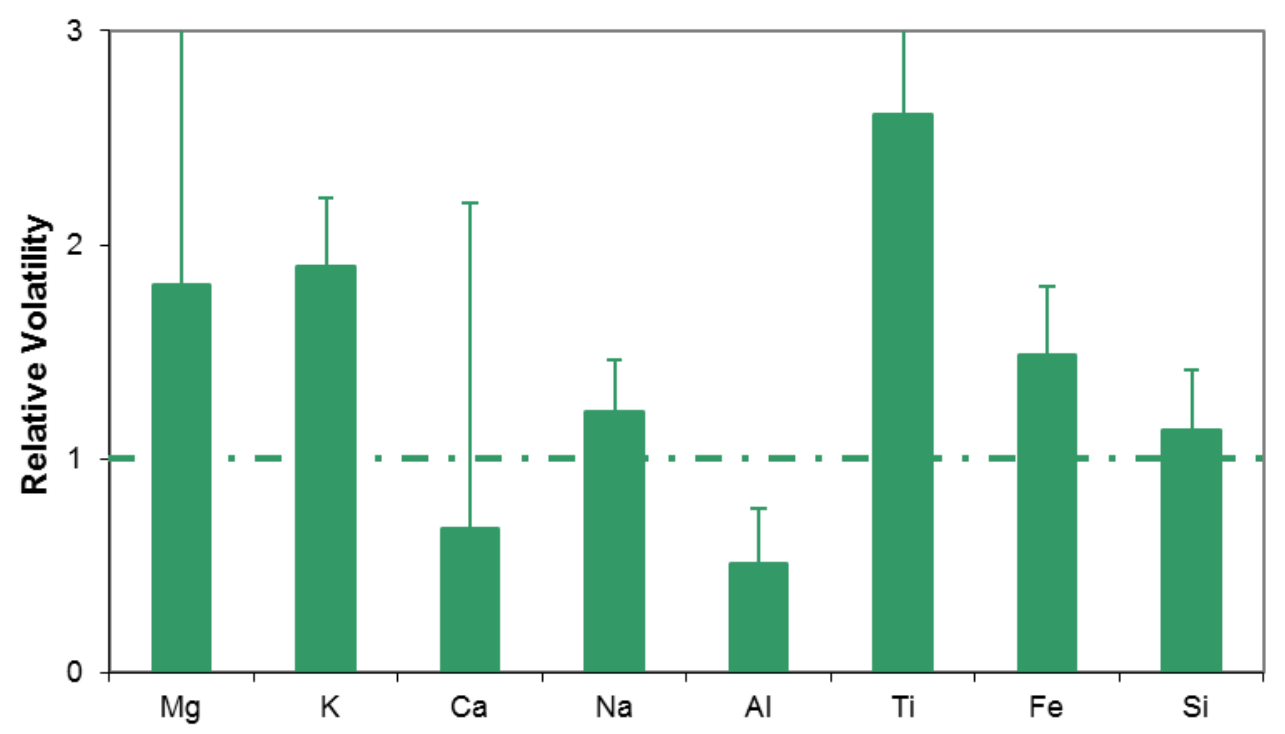

Figure 50: Relative minor metal volatility of coal/biomass mixture with coal baseline 
Trace metals relative volatility

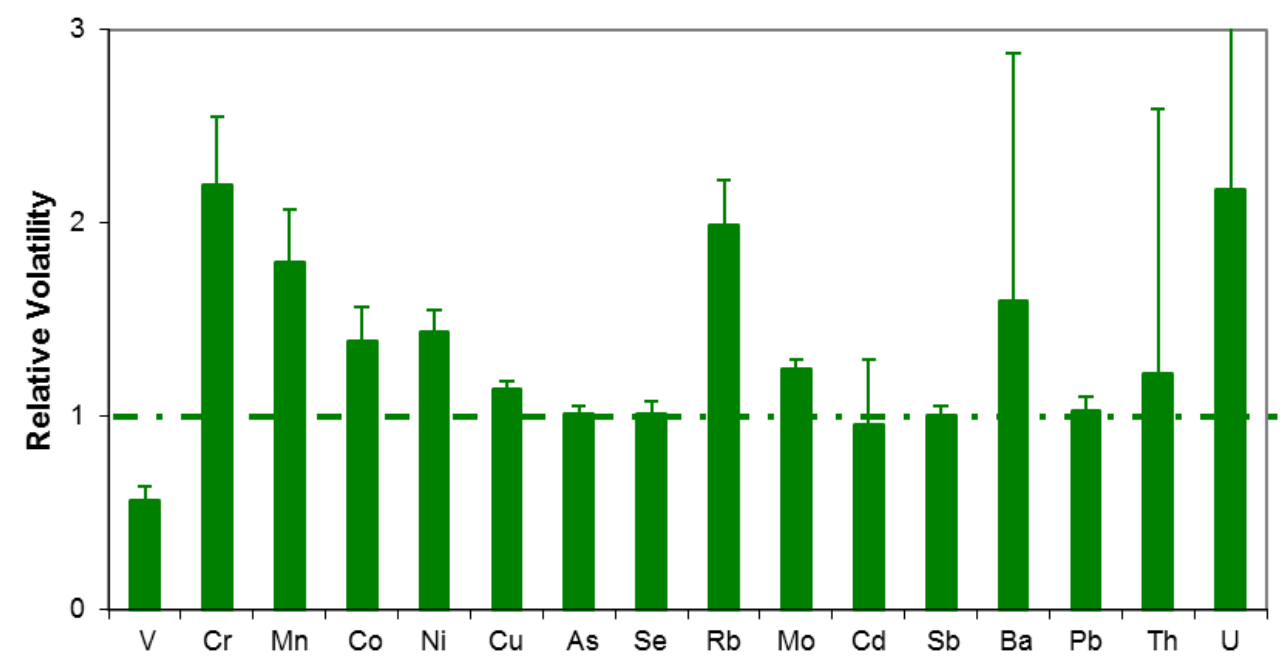

Figure 51: Relative minor metal volatility of coal/biomass mixture with coal baseline

EERC EFG REPORT: GASIFICATION OF INDIANA NO. 5 COAL BLENDED WITH SWITCHGRASS IN THE EERC'S SMALL PILOTSCALE ENTRAINED-FLOW GASIFIER

A report from EERC was submitted to GE Global research. The report is shown in the next section (Page 71- 87 and EFG Conclusions on Page 91) and adapted for this final report. 


\section{GASIFICATION OF INDIANA NO. 5 COAL BLENDED WITH SWITCHGRASS IN THE EERC'S SMALL PILOT-SCALE ENTRAINED-FLOW GASIFIER}

Final Report

(for the period June 1, 2011, through December 31, 2011)

Prepared for:

George Rizeq

GE Global Research Center

18A Mason

Irvine, CA 92618

Prepared by:

Joshua J. Stanislowski

Energy \& Environmental Research Center University of North Dakota 15 North 23rd Street, Stop 9018

Grand Forks, ND 58202-9018 


\section{EERC DISCLAIMER}

LEGAL NOTICE This research report was prepared by the Energy \& Environmental Research Center (EERC), an agency of the University of North Dakota, as an account of work sponsored by GE Global Research Center. Because of the research nature of the work performed, neither the EERC nor any of its employees makes any warranty, express or implied, or assumes any legal liability or responsibility for the accuracy, completeness, or usefulness of any information, apparatus, product, or process disclosed or represents that its use would not infringe privately owned rights. Reference herein to any specific commercial product, process, or service by trade name, trademark, manufacturer, or otherwise does not necessarily constitute or imply its endorsement or recommendation by the EERC. 


\section{GASIFICATION OF INDIANA NO. 5 COAL BLENDED WITH SWITCHGRASS IN THE EERC'S SMALL PILOT-SCALE ENTRAINED-FLOW GASIFIER}

\section{Introduction}

The Energy \& Environmental Research Center (EERC) has completed an evaluation of Indiana No. 5 coal blended with switchgrass in the EERC's small pilot-scale entrained-flow gasifier (EFG). The project was sponsored by GE Global Research Center and the U.S. Department of Energy (DOE) through the EERC's Center for Biomass Utilization ${ }^{\circledR}$. The major goal of the project was to evaluate the performance of the coal blended with switchgrass in the EFG based on generated syngas compositions and ash and slag properties at given operating conditions. Specifically, the ash and slag behavior under different operating conditions of temperature and pressure was evaluated. This report details the gasifier setup, operating conditions, and results of the testing.

\section{Test Plan and Methods}

The goal of the proposed testing was to gasify coal-biomass blends in the EERC's EFG and evaluate the resulting syngas composition and the fate of trace metals in the solids. A 70-30 wt\% mixture of Indiana No. 5 coal and switchgrass was used for the test. The test plan as provided by GE Global Research Center is shown in Table 10. Three test runs were planned, each 10-12 hours in duration. The plan also called for depressurizing the system and emptying the slag pot between each run, which takes about 12 hours. Pressure was varied between 150 and 275 psi for the tests, and temperature was varied between $1300^{\circ}$ and $1500^{\circ} \mathrm{C}$.

\section{EFG}

Figure 52 shows a cross-sectional view of the EFG. The EFG is a dry-feed, downfired system. The reactor tube is vertically housed in a pressure vessel approximately 24 in. in diameter and $7 \mathrm{ft}$ in length. The EFG fires nominally $8 \mathrm{lb} / \mathrm{hr}$ of coal and produces up to $20 \mathrm{scfm}$ of fuel gas. The maximum allowable working pressure is $300 \mathrm{psig}$. The reactor has the capability to run in oxygen- or air-blown mode. The supplemental electrical heating system is capable of reaching a nominal temperature of $1500^{\circ} \mathrm{C}\left(2732^{\circ} \mathrm{F}\right)$ and is separated into four independent zones so that a consistent temperature can be maintained throughout the length of the furnace. The radially spaced heating elements provide the initial heat for the centrally located alumina reactor tube, and refractory walls outside the heating elements provide insulation. Type $S$ thermocouples are used to monitor and control the temperatures of the heating zones and reactor tube. All of the gasification reactions occur inside the reactor tube, and slag is able to flow on the tube walls. 
Pressure inside the alumina reactor tube is balanced with a slight positive nitrogen pressure outside of the alumina reactor tube. 
Table 10. Test Plan for Coal-Biomass Blend Testing at the EERC

\begin{tabular}{|c|c|c|c|c|c|c|c|c|c|c|}
\hline Test & $\begin{array}{l}\text { Temp., } \\
{ }^{\circ} \mathrm{C}\end{array}$ & Feedstock & Reactant & $\begin{array}{l}\text { Pressure, } \\
\text { psi }\end{array}$ & $\begin{array}{l}\mathrm{O} / \mathrm{C} \\
\text { Ratio }\end{array}$ & $\begin{array}{c}\text { Start with a } \\
\text { Clean Slag Pot }\end{array}$ & $\begin{array}{c}\text { Run Time, } \\
\mathrm{hr}\end{array}$ & $\begin{array}{l}\text { Gases to } \mathrm{Be} \\
\text { Measured }\end{array}$ & $\begin{array}{l}\text { Gas-Phase } \\
\text { Trace Metal } \\
\text { Measurement }\end{array}$ & $\begin{array}{c}\text { Solid } \\
\text { Samples }\end{array}$ \\
\hline 1 & 1500 & $\begin{array}{c}70-30 \\
\text { Indiana }\end{array}$ & Oxygen & 275 & 1 & Yes & $10-12$ & \multirow{3}{*}{$\begin{array}{c}\mathrm{H}_{2}, \mathrm{CO}, \mathrm{CO}_{2} \\
\mathrm{H}_{2} \mathrm{O}, \mathrm{NH}_{3} \\
\mathrm{H}_{2} \mathrm{~S}, \mathrm{HCN}\end{array}$} & No & \multirow{3}{*}{$\begin{array}{c}\text { Trace } \\
\text { metals } \\
\text { analysis at } \\
\text { the EERC }\end{array}$} \\
\hline 2 & 1500 & $\begin{array}{c}\text { No.5- } \\
\text { switchgrass }\end{array}$ & Oxygen & 150 & 1 & Yes & $10-12$ & & No & \\
\hline 3 & 1300 & mixture & Oxygen & 275 & 1 & Yes & $10-12$ & & No & \\
\hline
\end{tabular}



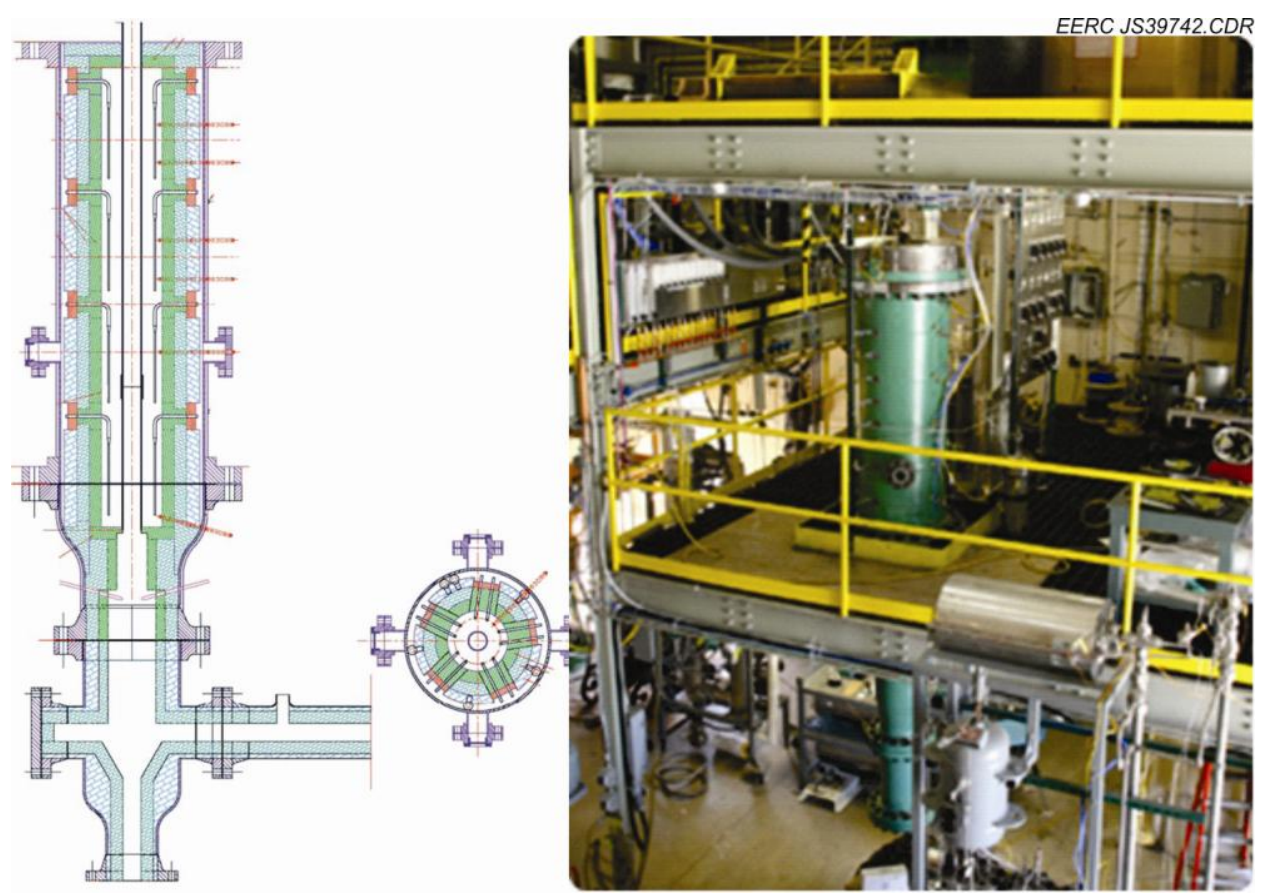

Figure 52. EFG.

Pulverized coal is fed into the top of the furnace via a twin screw feeder and scale contained in a pressurized vessel. A lock hopper is in place that allows the system to be refilled while running, thereby facilitating continuous-mode operation. Feed rates are calculated in real time. The feed system can be run in either volumetric mode or gravimetric mode. Nitrogen or syngas is used to convey the solid pulverized coal into the combustion zone.

Product gas exits at the bottom of the furnace tube and enters a reducing section that houses a quench system capable of injecting water, syngas, or nitrogen as the quench fluid. The product gas then enters a cross, making a $90^{\circ}$ turn, then exits the main unit on its way to the back-end control devices. Slag, ash, and char drop through the cross and are collected in a refractory-lined slag trap. Fine particulate is able to flow with the gas through the $90^{\circ}$ turn and is collected in a downstream filter.

\section{System Layout}

The overall system layout and sample points for the test runs are shown in Figure 53. Slag was collected below the gasifier in a refractory-lined slag trap. The system had to be depressurized and cooled for slag samples to be collected. Fly ash was captured in the hot-gas filter vessel (HGFV) that uses an iron aluminide candle filter, providing near absolute filtration. Fly ash samples were collected from this vessel while the system was operated by back-pulsing the candle and then collecting the ash through lock hoppers. Dräger tube samples were taken in 
the $\mathrm{HGFV}$, measuring for ammonia, $\mathrm{HCN}, \mathrm{HCl}$, and $\mathrm{H}_{2} \mathrm{~S}$. Quench pots are used to remove moisture and any tars formed in the system. A gas sample is taken after the back-pressure control valve and sent to a dedicated analyzer bank.

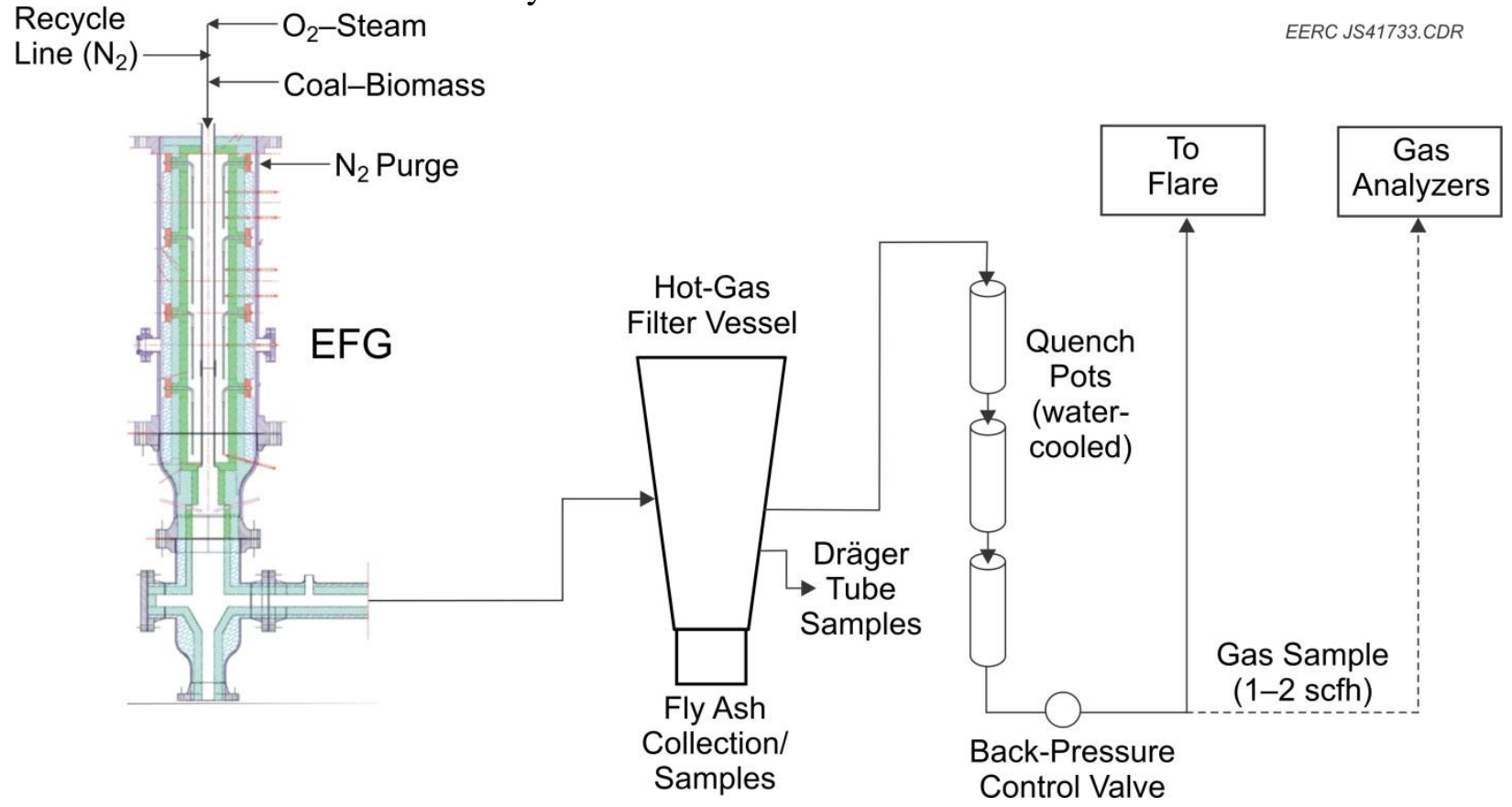

Figure 53. EFG, back-end cleanup, and sample points.

\section{Gas Analysis}

Syngas compositions were monitored with two gas analyzers. Sample gas tubing from sample ports to the analyzers is polyethylene, with no line longer than $50 \mathrm{ft}$. Sample gas transit times to the analyzers are estimated to be less than 1 minute, depending on the individual sample gas flow rate. The first analyzer is a laser gas analyzer (LGA) that is capable of detecting and measuring the concentration of eight gases at once: $\mathrm{H}_{2}, \mathrm{CO}, \mathrm{CO}_{2}, \mathrm{~N}_{2}, \mathrm{O}_{2}, \mathrm{H}_{2} \mathrm{~S}, \mathrm{CH}_{4}$, and total hydrocarbons. The LGA provides real-time feedback of the gas composition and is typically used to aid in the control of the system. The second analyzer used is a Varian gas chromatograph (GC) equipped with two thermal conductivity (TC) detectors and a pulsed flame photometric detector for ultralow sulfur detection. The first TC detector is dedicated solely to analyzing hydrogen and provides three hydrogen measurements for each 15-minute analysis cycle. The second detector analyzes the gas stream for $\mathrm{CO}, \mathrm{CO}_{2}, \mathrm{~N}_{2}, \mathrm{O}_{2}, \mathrm{H}_{2} \mathrm{~S}, \mathrm{COS}, \mathrm{CH}_{4}$, ethane, ethene, propane, and propene. One measurement is provided every 15 minutes for each of those gases. The third detector is capable of ultralow sulfur detection, down to $50 \mathrm{ppb}$. It provides three $\mathrm{H}_{2} \mathrm{~S}$ and COS measurements per 15-minute cycle. 


\section{Results}

\section{Fuels Analysis}

The coal and the switchgrass were submitted to the EERC coal laboratory for proximate, ultimate, and heating value analysis. The results of the analyses are shown in Table 11 for the coal and Table 12 for the switchgrass. The Indiana No. 5 fuel has a high heating value with similar amounts of volatile matter and fixed carbon. Moisture and ash are very low, and sulfur is high. The switchgrass has a lower heating value and is very high in volatile matter. It has low moisture, ash, and sulfur content and is also very high in oxygen.

The Indiana No. 5 fuel was also submitted for elemental ash analysis using x-ray fluorescence. The results of the analysis are shown in Table 13. The fuel is relatively high in iron content and has some potassium, which helps to lower the melting point of the slag.

Table 11. Proximate-Ultimate and Heating Value Analysis of Indiana No. 5 Coal

\begin{tabular}{lccc}
\hline & As-Received,wt\% & Dry, wt\% & Dry, Ash-Free ,wt\% \\
\hline Proximate Analysis & & & \\
Moisture & 6.72 & N/A* & N/A \\
Volatile Matter & 40.44 & 43.35 & 46.67 \\
Fixed Carbon, ind. & 46.20 & 49.53 & 53.33 \\
Ash & 6.64 & 7.12 & N/A \\
Ultimate Analysis & & & \\
Hydrogen & 5.68 & 5.28 & 5.68 \\
Carbon & 68.05 & 72.96 & 78.55 \\
Nitrogen & 1.32 & 1.42 & 1.53 \\
Sulfur & 3.95 & 4.24 & 4.56 \\
Oxygen, ind. & 14.35 & 8.98 & 9.67 \\
Ash & 6.64 & 7.12 & N/A \\
Heating Value, Btu/lb & 12,111 & 12,984 & 13,979 \\
\hline
\end{tabular}

* Not applicable.

Table 12.Proximate-Ultimate and Heating Value Analysis of Switchgrass

\begin{tabular}{lccc}
\hline & As-Received,wt\% & Dry, wt\% & Dry, Ash-Free, wt $\%$ \\
\hline Proximate Analysis & & & \\
Moisture & 8.13 & N/A & N/A \\
Volatile Matter & 66.78 & 72.69 & 75.57 \\
Fixed Carbon, ind. & 21.59 & 23.50 & 24.43 \\
\hline
\end{tabular}




\begin{tabular}{lrrr}
\hline Ash & 3.50 & 3.81 & N/A \\
Ultimate Analysis & & & \\
Hydrogen & 5.72 & 5.24 & 5.44 \\
Carbon & 44.81 & 48.78 & 50.71 \\
Nitrogen & 0.26 & 0.28 & 0.29 \\
Sulfur & 0.06 & 0.07 & 0.07 \\
Oxygen, ind. & 45.65 & 41.83 & 43.49 \\
Ash & 3.50 & 3.81 & N/A \\
Heating Value, Btu/lb & 7382 & 8035 & 8354 \\
\hline
\end{tabular}

Table 13.Elemental Ash Analysis of the Indiana No. 5 Fuel, wt $\%$

\begin{tabular}{lr}
\hline Oxides & \\
\hline $\mathrm{SiO}_{2}$ & 45.45 \\
$\mathrm{Al}_{2} \mathrm{O}_{3}$ & 24.23 \\
$\mathrm{Fe}_{2} \mathrm{O}_{3}$ & 20.93 \\
$\mathrm{TiO}_{2}$ & 1.67 \\
$\mathrm{P}_{2} \mathrm{O}_{5}$ & 0.08 \\
$\mathrm{CaO}$ & 1.45 \\
$\mathrm{MgO}$ & 1.45 \\
$\mathrm{Na} 2$ & 0.67 \\
$\mathrm{~K}_{2} \mathrm{O}$ & 2.95 \\
$\mathrm{SO}_{3}$ & 1.11 \\
\hline
\end{tabular}

\section{Operating Conditions}

The biggest challenge encountered during the gasification of the 70-30 coal-biomass blend was the feeding of the fuel. The fuel was shown to have very high caking tendencies and proved very difficult to even load through the lock hoppers. By the end of the test, the coal was fed in 5-pound batches through the lock hoppers to prevent plugging. Feeding through the feed line was also challenging, and the feed line was purged frequently during the first two tests. The optimum conditions were found for the third test, and very little feed line plugging occurred. However, a feed line plug did occur at the end of that test.

Table 14 summarizes the gasifier operating conditions for the three test runs. Steady state was reached on the first test just before noon on September 19, 2011. The system was shut down for just over 2 hours during the listed run because of a plug in the coal feed line. Occasional short-term plugging occurred during the test run as well, but in those cases, the feed line was able to be cleared without shutting down the system. The average data reported exclude the shutdown time period. Zones 1-4 represent the temperature of the outside of the EFG furnace tube. Zone 1 averaged $2576^{\circ} \mathrm{F}$ during the test period, and Zones $2-4$ averaged very close to the target temperature of $2732^{\circ} \mathrm{F}$. The postquench temperature represents the first syngas 
temperature measurement and is in a location just above the slag pot. The syngas remained above the condensation point until it reached the quench pots. The moisture and tars were removed in the quench pots before the syngas was sent to the gas analyzers and thermal oxidizer.

For Test 2, the average temperature was very close to the values in Test 1 . Zone 1 was slightly cooler and was most likely a result of the faster residence time. The temperatures were dropped for Test 3 according to the test plan, and all zones were very close to the set point of $2372^{\circ} \mathrm{F}$. 
Table 14.Average Steady-State Operating Conditions

\begin{tabular}{|c|c|c|c|}
\hline & Test 1 & Test 2 & Test 3 \\
\hline Start Date & 9/19/2011 & $9 / 20 / 2011$ & $10 / 17 / 2011$ \\
\hline Data Averages Start Time & $11: 52$ & $14: 30$ & 23:00 \\
\hline End Date & 9/19/2011 & $9 / 20 / 2011$ & $10 / 18 / 2011$ \\
\hline Data Averages End Time & $22: 55$ & $23: 59$ & 10:07 \\
\hline \multicolumn{4}{|l|}{ EFG Temp., ${ }^{\circ} \mathrm{F}$} \\
\hline Coal Feeder & 86 & 81 & 82 \\
\hline $\mathrm{O}_{2} / \mathrm{N}_{2} /$ Steam Inlet & 545 & 590 & 545 \\
\hline Nitrogen (in recycle line) Inlet & 311 & 269 & 300 \\
\hline Zone 1 & 2576 & 2508 & 2365 \\
\hline Zone 2 & 2732 & 2732 & 2363 \\
\hline Zone 3 & 2730 & 2732 & 2362 \\
\hline Zone 4 & 2724 & 2729 & 2349 \\
\hline EFG Outlet (post quench zone) & 1470 & 1472 & 1204 \\
\hline EFG Outlet (final) & 460 & 420 & 499 \\
\hline Slag Pot Temp. & 78 & 70 & 64 \\
\hline \multicolumn{4}{|l|}{ Filter Vessel Temp., ${ }^{\circ} \mathrm{F}$} \\
\hline Filter Vessel Inlet & 489 & 471 & 481 \\
\hline Filter Vessel Outlet & 411 & 428 & 444 \\
\hline \multicolumn{4}{|l|}{ Quench Pot Temp., ${ }^{\circ} \mathrm{F}$} \\
\hline West Pot 1 Inlet & 482 & 428 & 481 \\
\hline West Pot 2 Inlet & 235 & 206 & 234 \\
\hline West Pot 3 Inlet & 147 & 128 & 138 \\
\hline West Pot 3 Outlet & 93 & 83 & 86 \\
\hline \multicolumn{4}{|l|}{ Stream Flows and Closure } \\
\hline Coal Feed Rate, lb/hr & 4.6 & 3.9 & 4.0 \\
\hline Oxygen Flow, scfh & 60 & 50 & 50 \\
\hline $\mathrm{O} / \mathrm{C}$ (mole basis) & 1.31 & 1.28 & 1.25 \\
\hline Nitrogen Flow, scfh & 0 & 43 & 43 \\
\hline Steam Flow, lb/hr & 6.7 & 6.8 & 6.7 \\
\hline Nitrogen Flow (in recycle line), lb/hr & 8.5 & 7.6 & 7.8 \\
\hline Total Purge Flow, scfh & 217 & 136 & 138 \\
\hline Product Gas Flow, scfh & 525 & 458 & 443 \\
\hline Closure, $\%$ & 129 & 172 & 130 \\
\hline Gas Residence Time(s) & 9.8 & 5.8 & 11.9 \\
\hline \multicolumn{4}{|l|}{ Pressure, psi } \\
\hline EFG Top Pressure & 275 & 150 & 275 \\
\hline EFG Bottom Pressure & 275 & 150 & 275 \\
\hline Filter Vessel Pressure & 273 & 148 & 273 \\
\hline Quench Pot Pressure & 270 & 142 & 270 \\
\hline
\end{tabular}


Coal feed rate was lower than the test plan set point of $8 \mathrm{lb} / \mathrm{hr}$ for all three tests, which was based on the feeder calibrations before the run. Running in a pressurized state appeared to significantly change the feed rate through the screws from the atmospheric calibration. The losson-weight feed system indicated feed rate was low, and since there were feed line-plugging problems occurring, the oxygen levels were dropped as opposed to increasing the coal feed rate. Despite this adjustment, the resulting $\mathrm{O} / \mathrm{C}$ ratios still came out a little high, ranging from 1.25 to 1.31. The primary nitrogen was set at zero for the first test, but the coal feed seemed to be more problematic with this shut off. Therefore, the nitrogen was set at about 43 scfh for Tests 2 and 3 . Nitrogen was also used in the recycle line to prevent nozzle plugging. The nitrogen flow averaged near $8 \mathrm{lb} / \mathrm{hr}$ in this line which is equivalent to about $110 \mathrm{scfh}$. Gas residence time was calculated based on the product gas flow and a measured/calculated value indicating that $31.3 \%$ of the total purged gas was flowing in the reactor tube. This value assumes that all of the nitrogen entering the feeder also enters the furnace tube and that the electrical purges bypass the furnace tube. Residence times were slightly longer than originally calculated because of the lower coal and oxygen rates. Closure refers to the amount of gas entering the system versus the amount leaving the system. Closures were greater than $100 \%$ for all three runs because of the syngas generated.

The system was operated at 275 psi for Tests 1 and 3. For Test 2, a pressure set point of 150 psi was used. System pressure drops in the system as the gas travels to the back end and is usually 5-10 psi below the gasifier pressure just below the system exit.

\section{Syngas Compositions}

An LGA-35 and the Varian GC were used to monitor the syngas produced during Tests 1 and 2. An LGA-39 was used with the Varian GC for Test 3 based on availability during the test runs. Figures 54-56 show the process syngas output from the LGAs during each of the three test periods. Tables 15 and 16 display the average gas compositions that were attained during testing for the LGAs and Varian GC, respectively.

As shown in Figure 54, there was a significant shutdown period during Test 1 which was caused by a plug in the coal feed line. The inconsistency in the lines is also an indication of some of the coal feed problems that were occurring. There was a significant difference in the syngas composition during the second half of the test, which was caused by an increase in the coal feed rate. The coal feed rate presented in Table 14 represents the average over the two steady-state times during the test. Table 16 shows that the average concentrations of hydrogen, $\mathrm{CO}$, and $\mathrm{CO}_{2}$ were similar during Test $1 . \mathrm{H}_{2} \mathrm{~S}$ was about $2300 \mathrm{ppm}$, and the balance of the gas was nitrogen. $\mathrm{CH}_{4}$ and hydrocarbons were below detection limits for the analyzers for all of the tests, which is typical for the EFG. It should be noted that the average data presented in Table 16 for Test 1 only cover the last couple of hours of the test because of an analyzer problem.

Figure 55 shows that Test 2 went more smoothly than Test 1, but there were still three very brief periods of coal feed plugging. The plugs were able to be cleared during operation without having to shut down the system. Hydrogen and $\mathrm{CO}_{2}$ were at similar levels for the test, and $\mathrm{CO}$ was considerably lower. $\mathrm{H}_{2} \mathrm{~S}$ was similar to Test 1 at about $2300 \mathrm{ppm}$. The measurements between the two analyzers were very similar. 


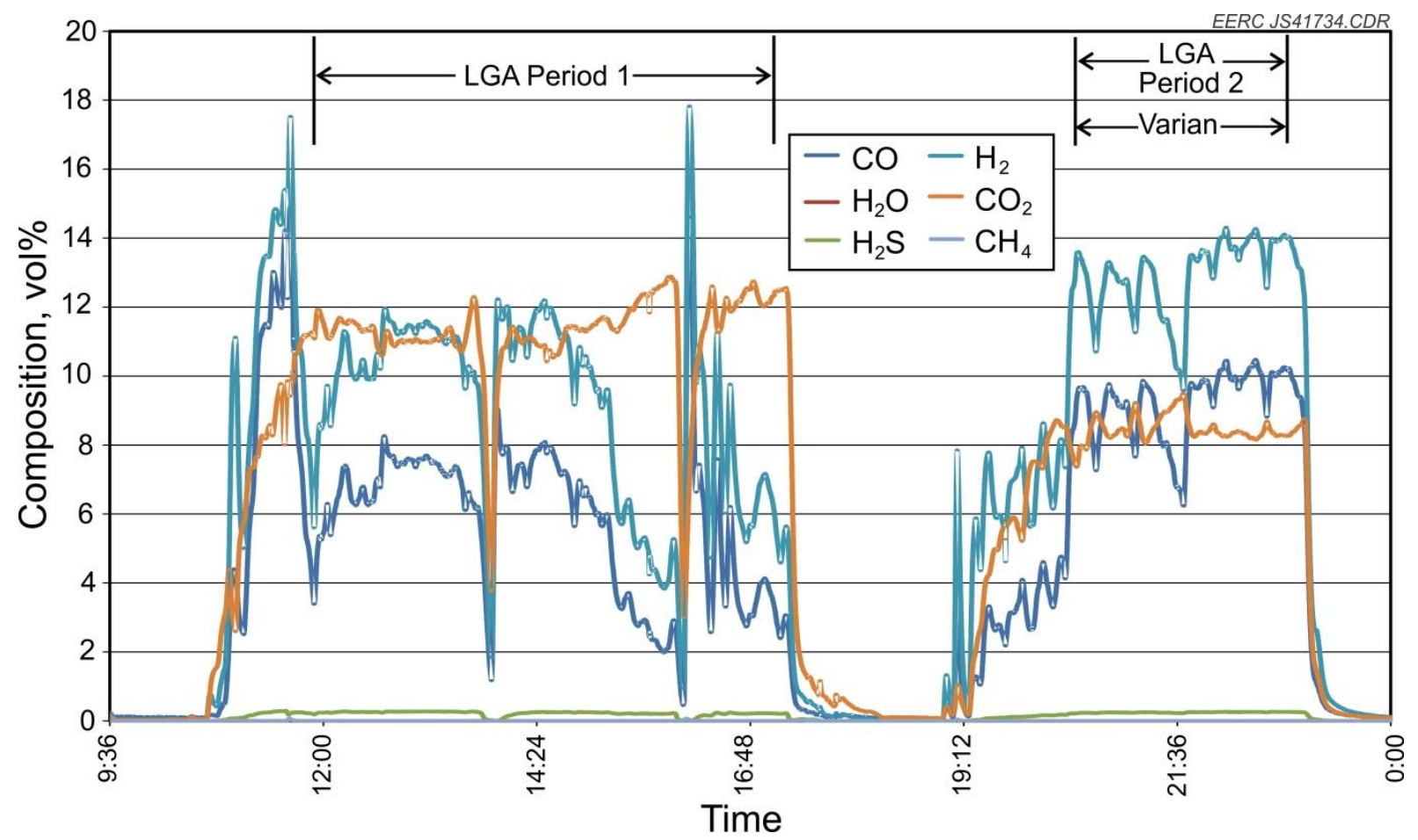

Figure 54. Syngas composition as measured by the LGA-35 for Test 1 (September 19, 2011).

Figure 56 shows that much more consistent feeding was achieved during Test 3 . The syngas composition was very similar to that achieved in Test 2 . The $\mathrm{H}_{2} \mathrm{~S}$ value from the LGA-39 was significantly higher than the previous tests, but the Varian measurement was similar to previous runs. Two Dräger $\mathrm{H}_{2} \mathrm{~S}$ samples were taken to verify the measurement, and the average value measured was $2300 \mathrm{ppm}$, validating the Varian measurement. Periods of oxygen also showed up during the steady-state period, but this was caused by a low-flow condition to the LGA, which caused it to draw in small amounts of air. The concentration of oxygen was typically below $0.3 \%$, so this issue did not have a significant impact on the overall syngas measurement. A coal feed plug occurred at the end of the test (hence the oxygen peak), but since 11.5 hours of steady state had already been achieved, the system was shut down rather than making any attempt to free the plug.

The Dräger tube measurements for other gases not measured by the gas analyzers are shown in Table 17. Measurements were taken for Tests 2 and 3. Ammonia levels were significantly different for these tests, and it is unclear if this is a measurement error or a result of the operating conditions. $\mathrm{HCN}$ and $\mathrm{HCl}$ levels were similar for the two tests. 


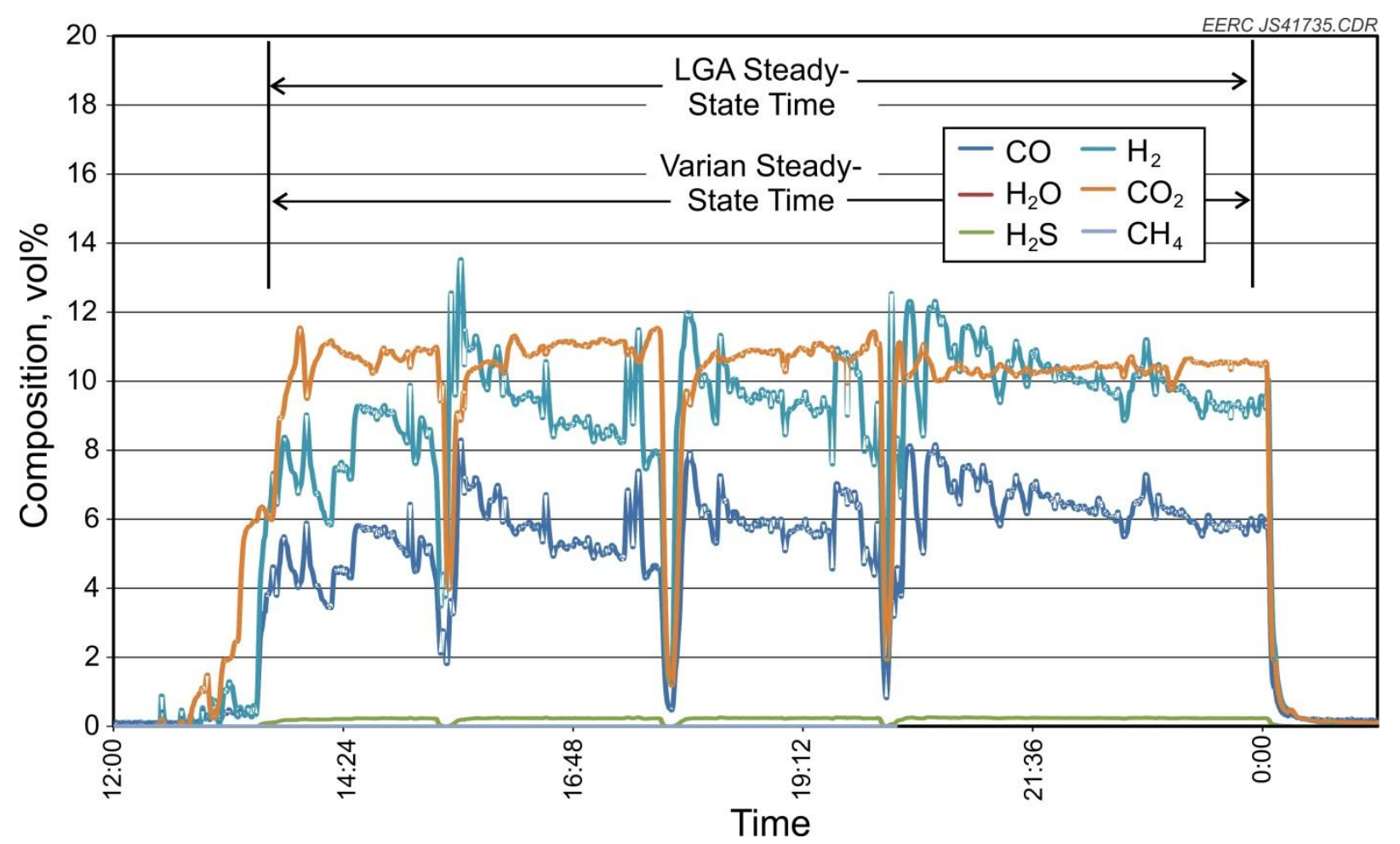

Figure 55. Syngas composition as measured by the LGA-35 for Test 2 (September 20, 2011).

\section{Solids Samples Analysis}

Solid samples were taken from the slag pot at the end of the run and from the FV during the run. These samples were weighed and then sent to the lab for analysis. For all of the runs, there were significant amounts of black char found in the slag pot, along with pieces of "tear drop"-shaped glassy slag. Some of the char was assumed to have been created under non-steadystate conditions and when there were feed problems. The glassy slag was assumed to be created under steady state and, therefore, was submitted to the lab for analysis. No slag deposits or plugs were found in the tube for the runs, with the exception of a very thin slag layer on the tube walls after Test 3 at low temperature. Table 18 shows the weights of the samples collected during the runs. Piping/tubing refers to solids that were found to be deposited in the piping and tubing runs between the slag pot and FV.

It is difficult to determine carbon conversion during the run because of the feed difficulties. However, assuming that the glassy slag pellets were produced during steady state and contain no carbon, the steady-state carbon conversion appeared to be very high. The FV amounts collected were very low; therefore, the carbon conversion under steady state is indicated to be greater than $99 \%$. 


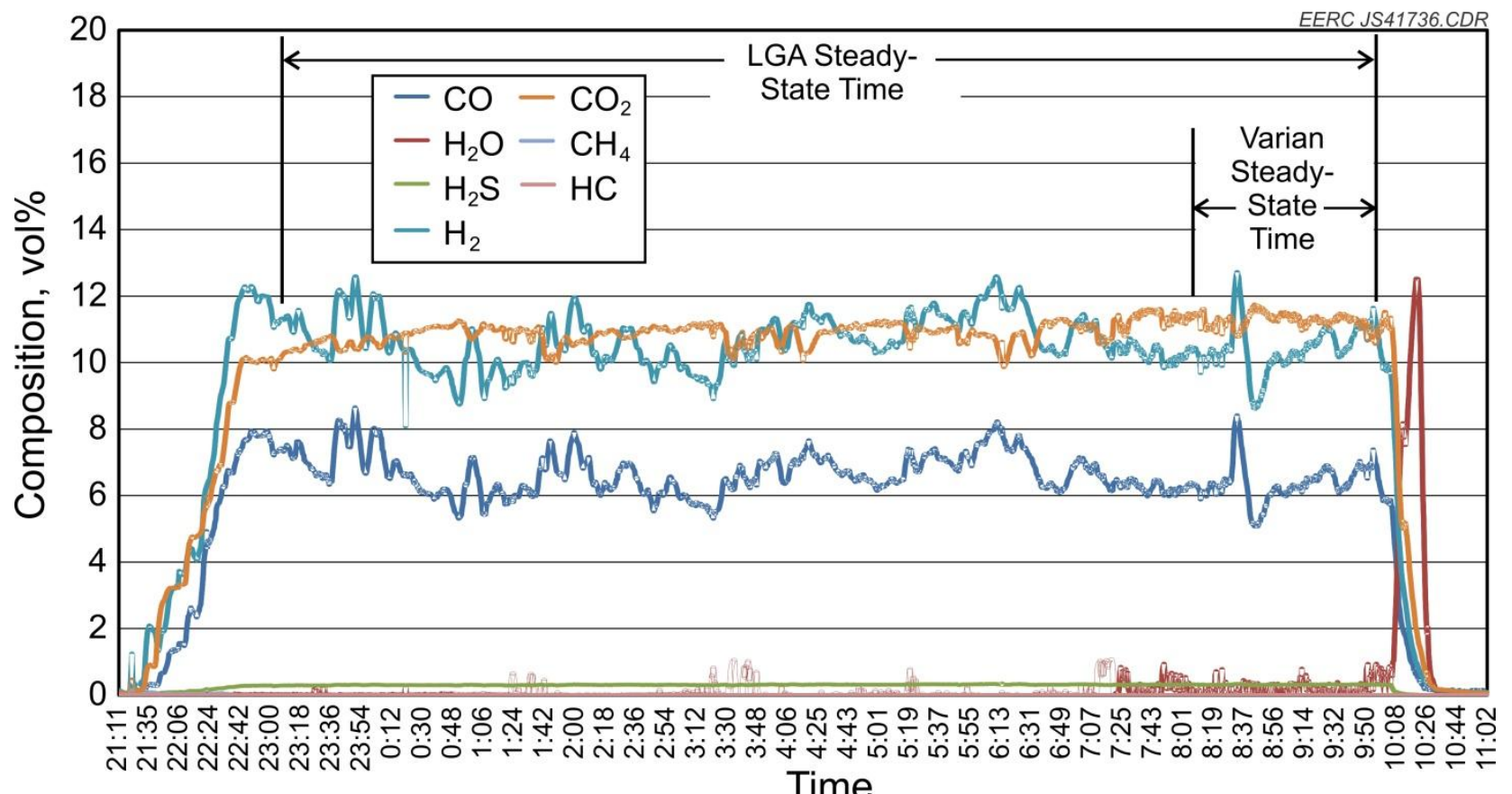

Figure 56. Syngas composition as measured by the LGA-39 for Test 3 (October 17 and 18, 2011).

Table 15.Average Syngas Compositions Attained During Two Test Periods Using the LGA-35

\begin{tabular}{lccc}
\hline & Test 1 & Test 2 & Test $3^{*}$ \\
\hline Start Date & $9 / 19 / 2011$ & $9 / 20 / 2011$ & $10 / 17 / 2011$ \\
Start Time & $11: 52$ & $14: 30$ & $23: 00$ \\
End Date & $9 / 19 / 2011$ & $9 / 20 / 2011$ & $10 / 18 / 2011$ \\
End Time & $22: 55$ & $23: 59$ & $10: 07$ \\
Composition, $\%$ & & & \\
$\mathrm{H}_{2}$ & 10.4 & 9.7 & 10.6 \\
$\mathrm{CO}$ & 7.0 & 6.0 & 6.6 \\
$\mathrm{CO}_{2}$ & 10.2 & 10.4 & 10.9 \\
$\mathrm{H}_{2} \mathrm{~S}$ & 2276 & 2320 & 3083 \\
$\mathrm{~N}_{2}$ & 70.0 & 72.2 & 66.2 \\
$\mathrm{CH}_{4}$ & $\mathrm{ND} * *$ & $\mathrm{ND}$ & $\mathrm{ND}$ \\
$\mathrm{Hydrocarbons}$ & $\mathrm{ND}$ & $\mathrm{ND}$ & $\mathrm{ND}$ \\
\hline$*$ LGA-39 was used for this test. & & \\
** Not detected. & & &
\end{tabular}


Table 16.Average Syngas Composition Attained During Two Test Periods Using the Varian Analyzer

\begin{tabular}{lccc}
\hline & Test 1 & Test 2 & Test 3 \\
\hline Start Date & $9 / 19 / 2011$ & $9 / 20 / 2011$ & $10 / 18 / 2011$ \\
Start Time & $20: 35$ & $14: 30$ & $8: 10$ \\
End Date & $9 / 19 / 2011$ & $9 / 20 / 2011$ & $10 / 18 / 2011$ \\
End Time & $22: 55$ & $23: 59$ & $10: 31$ \\
Composition, \% & & & \\
$\mathrm{H}_{2}$ & 13.4 & 10.1 & 11.2 \\
$\mathrm{CO}$ & 9.4 & 6.2 & 7.0 \\
$\mathrm{CO}_{2}$ & 8.6 & 10.9 & 11.8 \\
$\mathrm{~N}_{2}$ & 67.2 & 70.9 & 69.0 \\
$\mathrm{H}_{2} \mathrm{~S}$, ppm & 2470 & 2302 & 2502 \\
$\mathrm{CH}_{4}$ & $\mathrm{ND}$ & $\mathrm{ND}$ & $\mathrm{ND}$ \\
$\mathrm{Hydrocarbons} \mathrm{C}_{2}-\mathrm{C}_{3}$ & $\mathrm{ND}$ & $\mathrm{ND}$ & $\mathrm{ND}$ \\
\hline
\end{tabular}

Table 17.Dräger Tube Measurements

\begin{tabular}{lrcccc}
\hline & \multicolumn{5}{c}{ Gas Concentration } \\
Test & Time & $\mathrm{NH}_{3}$ & $\mathrm{HCN}, \mathrm{ppm}$ & $\mathrm{HCl}, \mathrm{ppm}$ & $\mathrm{H}_{2} \mathrm{~S}, \mathrm{ppm}$ \\
\hline 2 & $14: 39$ & $17 \mathrm{ppm}$ & 150 & 6 & $\mathrm{NS}$ \\
2 & $18: 30$ & $5 \mathrm{ppm}$ & 150 & $\mathrm{MF}^{* *}$ & $\mathrm{NS}$ \\
3 & $8: 17$ & $0.30 \%$ & $\mathrm{MF}$ & 12 & 2200 \\
3 & $10: 00$ & $0.10 \%$ & 125 & 6 & 2400 \\
\hline * Not sampled. & & &
\end{tabular}

Table 18.Weight of Solid Samples Collected

\begin{tabular}{lcccc}
\hline & \multicolumn{4}{c}{ Sample Weights, g } \\
Test & Coal Fed & Slag Pot & Piping/Tubing & FV \\
\hline 1 & 23,866 & 1382 & 84 & 40 \\
2 & 19,966 & 558 & 109 & 52 \\
3 & 25,358 & 1275 & 306 & 267 \\
\hline
\end{tabular}


Trace metal analysis of the solid samples is shown in Table 190. As expected, volatile elements such as arsenic, selenium, and potassium were enriched in the FV ash, and elements such as aluminum and silicon were depleted in the FV ash.

Table 19.Analysis of Solid Samples Collected, $\mu \mathrm{g} / \mathrm{g}$

\begin{tabular}{lcccrcc}
\hline & \multicolumn{3}{c}{ Slag Pot } & & \multicolumn{3}{c}{ FV } \\
\hline & Test 1 & Test 2 & Test 3 & Test 1 & Test 2 & Test 3 \\
\hline Aluminum & 112,000 & 105,000 & 102,000 & 41,100 & 80,700 & 33,600 \\
Arsenic & 3 & 2.2 & 5.5 & 301 & 142 & 47.8 \\
Lead & 3.5 & 2.0 & 1.6 & 1380 & 438 & 98.8 \\
Magnesium & 11,000 & 14,400 & 13,200 & 5960 & 18,900 & 7600 \\
Manganese & 514 & 569 & 707 & 475 & 665 & 250 \\
Molybdenum & 100 & 20.2 & 17.7 & 977 & 616 & 118 \\
Nickel & 182 & 190 & 247 & 476 & 350 & 122 \\
Potassium & 27,900 & 29,500 & 34,000 & 44,600 & 34,800 & 27,100 \\
Rubidium & $<500$ & $<500$ & $<500$ & $<500$ & $<500$ & $<500$ \\
Selenium & 0.94 & 1.3 & 0.38 & 33 & 3.5 & 5.5 \\
Silicon & 217,000 & 216,000 & 215,000 & 97,000 & 186,000 & 78,200 \\
Sodium & 6500 & 4400 & 7300 & 3000 & 3500 & 3200 \\
Titanium & 5640 & 4840 & 4840 & 3300 & 6380 & 2500 \\
\hline
\end{tabular}




\section{Syngas Cleanup}

Equilibrium modeling was done to evaluate the behavior of metals during gasification. The equilibrium calculations only predict stable species at the given temperature and pressure. The models do not predict how quickly the equilibrium is achieved.

The equilibrium calculations require thermodynamic properties of the species that are being evaluated. The starting conditions are also given as an input to the model. The species representation in the thermodynamic library is critical and determines the accuracy of the predictions made by the model. A number of codes were considered for the equilibrium analysis. Aspen model treats ash as an inert substance that passes through the gasification process without any changes in the state or composition. If desired there is an option to specify the components in the ash. A second code, CET, was also evaluated for the equilibrium modeling. CET or Chemical Equilibrium and Transport Properties code had wider representation of metals as compared to Aspen. A decision was made to use CET for this study. The syngas composition used for the study is shown in Table $20^{28}$.

Table 20: Syngas composition from a coal gasification plant. $^{28}$

\begin{tabular}{|l|r|}
\hline Component & \multicolumn{1}{|c|}{$\%$} \\
\hline $\mathrm{Ar}$ & 0.86 \\
\hline $\mathrm{CH}_{4}$ & 0.12 \\
\hline $\mathrm{CO}$ & 35.79 \\
\hline $\mathrm{CO}_{2}$ & 13.66 \\
\hline $\mathrm{COS}$ & 0.02 \\
\hline $\mathrm{H}_{2}$ & 34.16 \\
\hline $\mathrm{H}_{2} \mathrm{O}$ & 13.58 \\
\hline $\mathrm{N}_{2}$ & 0.8 \\
\hline $\mathrm{NH}_{3}$ & 0.21 \\
\hline $\mathrm{H}_{2} \mathrm{~S}$ & 0.73 \\
\hline
\end{tabular}

Equilibrium modeling was performed at pressure of $1 \mathrm{~atm}$ and $65 \mathrm{~atm}$ and temperatures in the range of $1900 \mathrm{~K}$ and $300 \mathrm{~K}$. Figure 57 shows partition of some metals in syngas as function of temperature. For all practical purposes only As remains in syngas as it cools to temperature less than $300{ }^{\circ} \mathrm{C}$. Remaining metals condense as syngas cools on particular matter or form fine mist. 

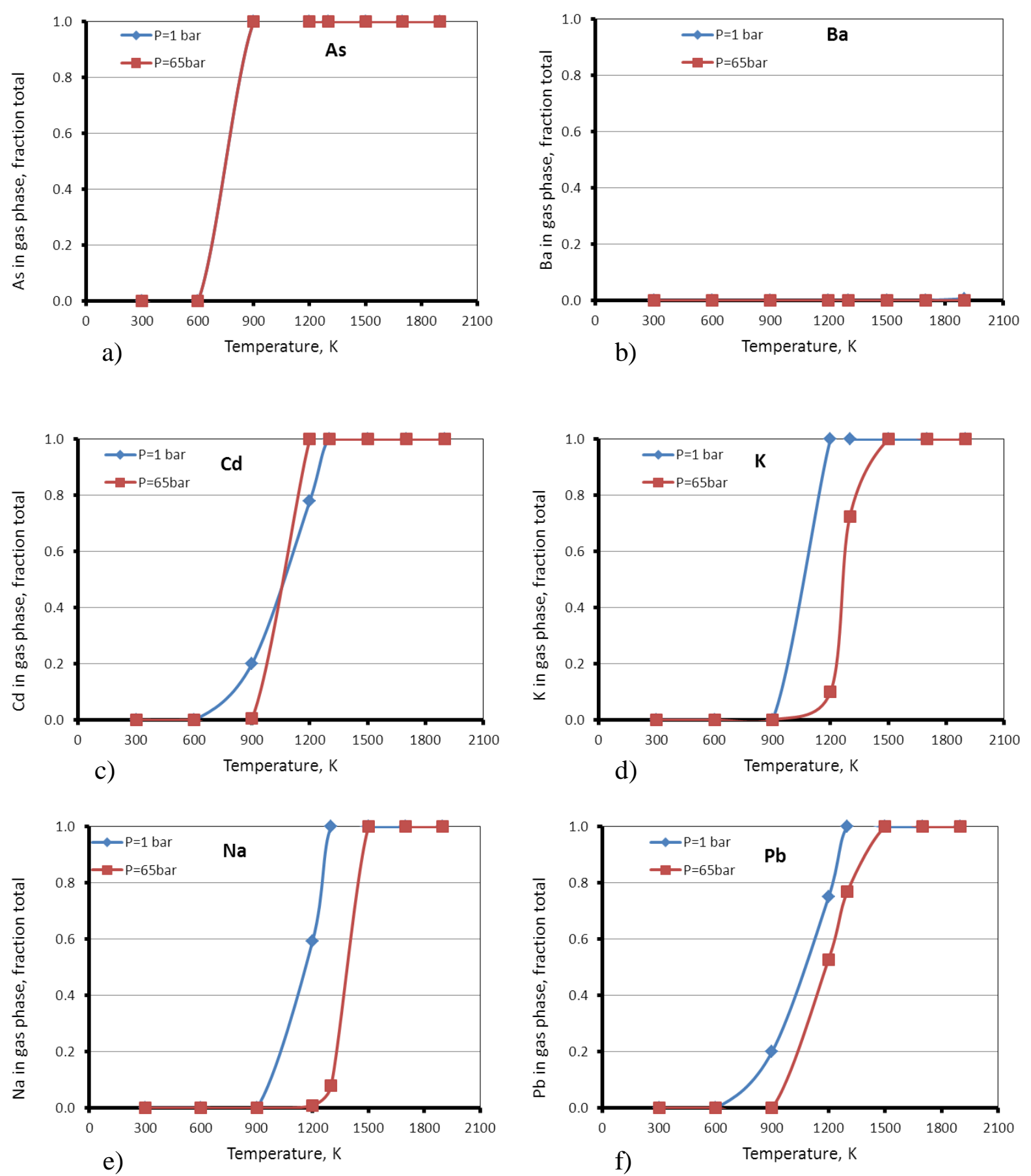


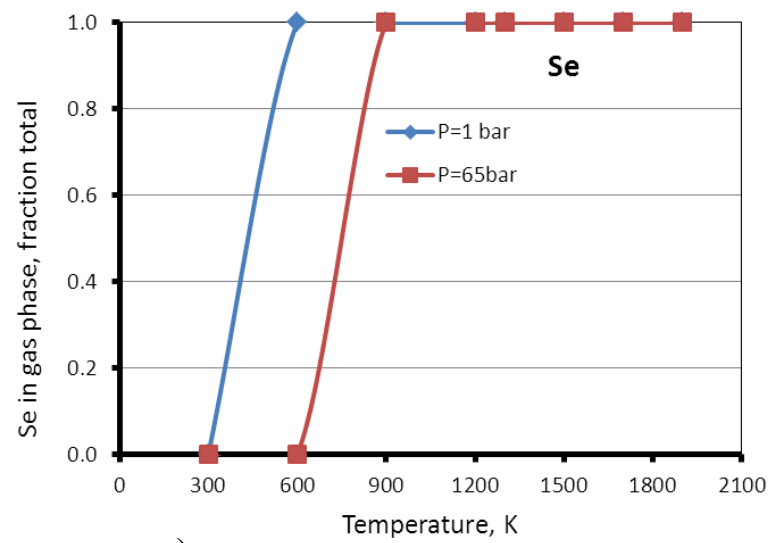

g)
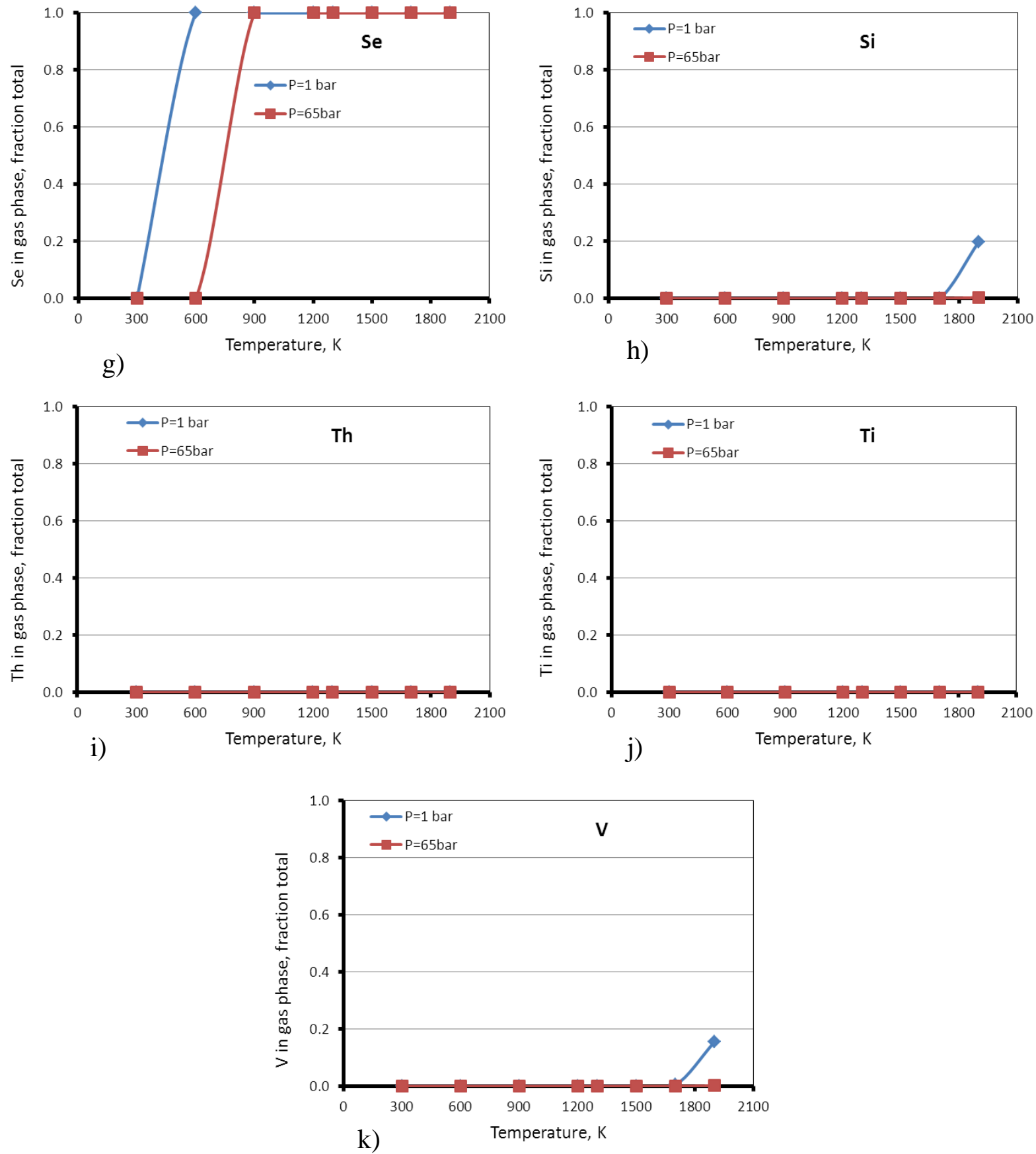

Figure 57. Effect of syngas temperature on partition of metals a) As, b) Ba, c) Cd, d) K, e) Na, f) $\mathrm{Pb}, \mathrm{g}) \mathrm{Se}, \mathrm{h}) \mathrm{Si}$, i) $\mathrm{Th}, \mathrm{j}$ ) $\mathrm{Ti}, \mathrm{k}) \mathrm{V}$.

Other metals such as $\mathrm{Cd}, \mathrm{K}, \mathrm{Na}, \mathrm{Pb}$ and $\mathrm{Se}$ are in the gas phase at temperatures greater than 300 ${ }^{\circ} \mathrm{C}$, hence dry clean up technologies may need further deveopment and analysis to remove the alkali metals. Pressure also plays a role in the state of the metals at different temperatures as is seen in Figure 57. It is known in the literature that the temperature of the syngas after water scrubbing of the syngas that is produced from a gasification proces is $250-300{ }^{\circ} \mathrm{C}^{28,29}$. At these temperatures all of the metal species considered will be in the condensed phase and hence will 
not leave with the syngas under equilibrium conditions. Hence a regular syngas cleanup that is being used in the gasification processes should be able to remove the metals leaving the gasifier. Also, during the experimental phase of the program it was observed the relative volatility for As and Se, which are the two most volatile metals, for coal and biomass mixture was similar to when coal was used (Figure 51). Hence, the cleanup system required should not be different from the cleanup systems currently employed for coal gasification. In regular coal gasification process the cooled syngas is then further processed to remove $\mathrm{COS}, \mathrm{Hg}$ and $\mathrm{H}_{2} \mathrm{~S}$ by using COS hydrolysis, an activated carbon bed and acid gas removal respectively. It was observed that the relative concentration of $\mathrm{H}_{2} \mathrm{~S}$ was higher (Figure 49) for the coal/biomass mixtures and hence it is expected that a more stringent AGR process will be required to remove the sulfur from the syngas stream.

\section{Conclusions}

\section{a. BSG conclusions}

As mentioned earlier in the report, a bituminous coal was used as a baseline to compare to a mixture of $30 \%$ switchgrass and the same coal. Tests were conducted at a BSG wall temperature of 1400 degrees Celsius and O/C equal to 1. Results shown are those from the sum of the first and second pass. All fuel feed and gas feeds match those of the previously presented tests. Figure 49-Figure 51 display gas and metals data of the mixture verses the pure coal case. In each plot the dotted line marks the pure coal baseline level. The mixture has higher gas concentrations hydrogen sulfide and lower for sulfur dioxide than the pure coal baseline. The higher reactivity of the mixture lowering oxygen availability is likely the cause for this difference. The differences in metal volatility are due primarily to changes in the quantity of minor or trace metal in the feed as shown in Table 8.

\section{b. EFG Conclusions}

The biggest challenge encountered with the 70-30 coal-switchgrass blend was fuel feeding. The material had high caking properties which led to significant challenges with the feed line and even with refilling the coal hopper. Once inside the gasifier, the fuel converted to syngas very easily, even at the lower temperature setting. The slag produced flowed easily out of the furnace tube, and no furnace tube plugging occurred. Syngas compositions were reasonable for the run conditions and could be improved upon if some of the feed issues were resolved.

Carbon conversion appeared to be very high for the test run, even at the lowest temperatures. Very little material reached the FV. The trace metals behaved as expected, with the high-volatile metals getting enriched in the fly ash. 


\section{LIST OF ACRONYMS AND ABBREVIATIONS}

\begin{tabular}{ll} 
BSG & bench scale gasifier \\
ccm & cubic centimeters per minute \\
CEM & continuous emissions monitor \\
CFD & computational fluid dynamics \\
COV & coefficient of variation \\
DFSS & Design for Six Sigma \\
DOE & US Department of Energy \\
EFG & entrained flow gasifier \\
GE & General Electric Company \\
ICP-AES & inductively coupled plasma-atomic emission spectroscopy \\
ICP-MS & inductively coupled plasma-mass spectrometry \\
NETL & National Energy Technology Laboratory \\
ppm & parts per million \\
PSD & particle size distribution \\
R\&D & research and development \\
SEM & scanning electron microscope \\
SLPM & standard liters per minute \\
SNCR & selective non-catalytic reduction \\
SPM & single point monitor \\
TGA & thermogravimetric analyzer \\
UPA & ultimate and proximate analysis \\
EFG & Entrained Flow Gasifier \\
EERC & Energy and Environmental Research Center \\
NDIC & North Dakota Industrial Commission \\
CBU & DOE/EERC Center for Biomass Utilization \\
& \\
\hline
\end{tabular}




\section{Bibliography \& References}

1. Obernberger, I., et al. (2006). "Chemical properties of solid biofuels-significance and impact." Biomass and Bioenergy 30: 973-982.

2. Brown, R. C., et al. (2000). "Catalytic effects observed during the co-gasification of coal and switchgrass." Biomass and Bioenergy 18: 499-506.

3. Fahmi, R., et al. (2007). "The effect of alkali metals on combustion and pyrolysis of Lolium and Festuca grasses, switchgrass and willow." Fuel 86: 1560-1569.

4. Raveendran, K,. et al. (1995). "Influence of mineral matter on biomass pyrolysis characteristics." Fuel 74: 1812-1822.

5. Miles, T. R., et al. (1996) "Boiler deposits from firing biomass fuels" Biomass and Bioenergy 10: $125-138$.

6. Baxter, L. L., et al. (1998) "The behavior of inorganic material in biomass-fired power boilers: field and laboratory experiences" Fuel Processing Technology 54: 47-78.

7. Demirbas, A. (2005) "Potential applications of renewable energy sources, biomass combustion problems in boiler power systems and combustion related environmental issues" Progress in Energy and Combustion Science 31: 171-192 and references therein.

8. Baxter, L. L. (2005) "Biomass-coal co-combustion: opportunity for affordable renewable energy" Fuel 84: 1295-1302 and references therein.

9. Thompson, D., and Argent, B. B. (1999). "The mobilization of sodium and potassium during coal combustion and gasification." Fuel 78: 1679-1689.

10. Dayton, D. C., et al. (1999). "Release of Inorganic Constituents from Leached Biomass during Thermal Conversion.” Energy \& Fuels 13: 860-870.

11. Tijmensen, M. J. A., et al. (2002). "Exploration of the possibilities for production of Fischer Tropsch liquids and power via biomass gasification." Biomass and Bioenergy 23: 129-152.

12. Smith, K. L., and Smoot, L. D. (1990). "Characteristics of commonly-used U.S. coals: Towards a set of standard research coals." Progress in Energy and Combustion Science 16: 1-53.

13. Miller, B. B., et al. (2006). "The Fate of Trace Elements during the Co-Combustion of Wood-Bark with Waste" Energy \& Fuels 20: 520-531.

14. Miller, B. B., et al. (2002). "Trace Element Emissions from Co-combustion of Secondary Fuels with Coal: A Comparison of Bench-Scale Experimental Data with Predictions of a Thermodynamic Equilibrium Model.” Energy \& Fuels 16: 956-963.

15. Boman, C., et al. (2006). "Trace Element Enrichment and Behavior in Wood Pellet Production and Combustion Processes" Energy \& Fuels 20: 993-1000.

16. Senior, C. L., et al. (2000) "Pilot scale study of trace element vaporization and condensation during combustion of a pulverized sub-bituminous coal." Fuel Processing Technology 63: 149165.

17. Seames, W. S., and Wendt, J. O. L. (2000) "Partitioning of arsenic, selenium, and cadmium during the combustion of Pittsburgh and Illinois \#6 coals in a self-sustained combustor" Fuel Processing Technology 63: 179-196.

18. Linak, W. P., and Went, J. O. L. (1993) "Toxic metal emissions from incineration: mechanisms and control" Progress in Energy and Combustion Science 19: 145-185 and references therein.

19. Lighty, J. S., et al. (2000). "Combustion Aerosols: Factors Governing Their Size and Composition and Implications to Human Health" Journal of the Air \& Waste Management Association 50: 1565-1618 and references therein. 
20. Baernthaler, G., et al. (2006) "Determination of major and minor ash-forming elements in solid biofuels" Biomass and Bioenergy 30: 983-997.

21. Richaud, R., et al. (2004). "Comparison of trace element contents in low-temperature and hightemperature ash from coals and biomass." Fuel 83: 2001-2012.

22. Richaud, R., et al. (2000a). "Identification of organically associated trace elements in wood and coal by inductively coupled plasma mass spectrometry." Rapid Commun. Mass Spectrom. 14: $317-328$.

23. Richaud, R., et al. (2000b). "Trace element analysis of gasification plant samples by ICPMS: validation by comparison of results from two laboratories." Fuel 79: 1077-1087.

24. Fletcher, T. H., (1989) "Time-Resolved Particle Temperature and Mass Loss Measurements of a Bituminous Coal During Devolatilization", Combustion and Flame, 78, 223-236. 25. Ma, J. (1996) "Soot formation during coal pyrolysis", Ph.D. Thesis, Department of Chemical Engineering. Provo, Brigham Young University.

26. Bailey, J.G. et al. (1990) "A char morphology system with applications to coal combustion", Fuel, 69, 225-239.

27. Wall, T.F., et al. (2002) "The effects of pressure on coal reactions during pulverized coal combustion and gasification", Progress in Energy and Combustion Science, 28, 405-433.

28. Cost and Performance Baseline for Fossil Energy Plants Volume 1: Bituminous Coal and Natural Gas to Electricity. Revision 2, November 2010. DOE/NETL-2010/1397

29. An Overview of Coal based Integrated Gasification Combined Cycle (IGCC) Technology. September 2005. MIT, LFEE 2005-002 WP, Ola Maurstad, Massachusetts Institute of Technology, Laboratory for Energy and the Environment 